\title{
Visualização e exploração de dados multidimensionais na web
}

\author{
Lucas de Carvalho Pagliosa
}



Assinatura:

\section{Lucas de Carvalho Pagliosa}

\section{Visualização e exploração de dados multidimensionais na web}

\footnotetext{
Dissertação apresentada ao Instituto de Ciências Matemáticas e de Computação - ICMC-USP, como parte dos requisitos para obtenção do título de Mestre em Ciências - Ciências de Computação e Matemática Computacional. VERSÃO REVISADA

Área de Concentração: Ciências de Computação e Matemática Computacional

Orientador: Prof. Dr. Luis Gustavo Nonato
}

\section{USP - São Carlos \\ Novembro de 2015}


Ficha catalográfica elaborada pela Biblioteca Prof. Achille Bassi e Seção Técnica de Informática, ICMC/USP, com os dados fornecidos pelo(a) autor(a)

Pagliosa, Lucas de Carvalho
Visualização e exploração de dados
multidimensionais na web / Lucas de
Carvalho Pagliosa; orientador Luis Gustavo Nonato.
- São Carlos - SP, 2015.
105 p.
Dissertação (Mestrado - Programa de Pós-Graduação
em Ciências de Computação e Matemática Computacional)
- Instituto de Ciências Matemáticas e de Computação,
Universidade de São Paulo, 2015.
1. Visualização. 2. Projeção Multidimensional.
3. Análise de Atributos. 4. Exploração de Dados.
5. Interatividade. I. Nonato, Luis Gustavo, orient.
II. Título.




\title{
Lucas de Carvalho Pagliosa
}

\section{Exploratory multidimensional data visualization on the web}

\author{
Master dissertation submitted to the Instituto de \\ Ciências Matemáticas e de Computação - ICMC- \\ USP, in partial fulfillment of the requirements for the \\ degree of the Master Program in Computer Science \\ and Computational Mathematics. FINAL VERSION \\ Concentration Area: Computer Science and \\ Computational Mathematics \\ Advisor: Prof. Dr. Luis Gustavo Nonato
}



À minha avó, Guiga. 

Quero agradecer ao professor doutor Luis Gustavo Nonato, pelos dois anos de ensino, apoio e orientação.

Ao Instituto de Ciências Matemáticas e de Computação (ICMC), aos seus professores e funcionários pela formação acadêmica, apoio e colaboração. Aos professores doutores Afonso Paiva Neto e Rodrigo Mello, e ao colega Tiago Etiene pelo incentivo e contribuição no desenvolvimento desta pesquisa e de outros trabalhos, além dos bons momentos fora campus.

Em especial aos meus queridos pais, Claudia e Paulo, com os quais sempre pude contar; a minha namorada Nidia; e aos meus queridos familiares por todo apoio e carinho.

À Fundação de Amparo à Pesquisa do Estado de São Paulo (FAPESP), vinculado ao processo 20013/15928-9, e à Coordenação de Aperfeiçoamento de Pessoal de Nível Superior (CAPES) pela concessão de bolsa de mestrado e pelo apoio financeiro que possibilitou a realização deste trabalho. 



\section{RESUMO}

LUCAS PAGLIOSA. Visualização e exploração de dados multidimensionais na web. 2015. 105 f. Dissertação (Mestrado em Ciências - Ciências de Computação e Matemática Computacional) - Instituto de Ciências Matemáticas e de Computação (ICMC/USP), São Carlos SP.

Com o crescimento do volume e dos tipos de dados, a necessidade de analisar e entender o que estes representam e como estão relacionados tem se tornado crucial. Técnicas de visualização baseadas em projeções multidimensionais ganharam espaço e interesse como uma das possíveis ferramentas de auxílio para esse problema, proporcionando um forma simples e rápida de identificar padrões, reconhecer tendências e extrair características antes não óbvias no conjunto original. No entanto, a projeção do conjunto de dados em um espaço de menor dimensão pode não ser suficiente, em alguns casos, para responder ou esclarecer certas perguntas feitas pelo usuário, tornando a análise posterior à projeção crucial para a correta interpretação da visualização observada. Logo, a interatividade, aplicada à necessidade do usuário, é uma fator essencial para análise. Neste contexto, este projeto de mestrado tem como principal objetivo criar metáforas visuais baseadas em atributos, através de medidas estatísticas e artefatos para detecção de ruídos e grupos similares, para auxiliar na exploração e análise dos dados projetados. Além disso, propõe-se disponibilizar, em navegadores Web, as técnicas de visualização de dados multidimensionais desenvolvidas pelo Grupo de Processamento Visual e Geométrico do ICMC-USP. O desenvolvimento do projeto como plataforma Web inspira-se na dificuldade de instalação e execução que certos projetos de visualização possuem, como problemas causados por diferentes versões de IDEs, compiladores e sistemas operacionais. Além disso, o fato do projeto estar disponível online para execução tem como propósito facilitar o acesso e a divulgação das técnicas propostas para o público geral.

Palavras-chave: Visualização, Projeção Multidimensional, Análise de Atributos, Exploração de Dados, Interatividade. 



\section{ABSTRACT}

LUCAS PAGLIOSA. Visualização e exploração de dados multidimensionais na web. 2015. 105 f. Dissertação (Mestrado em Ciências - Ciências de Computação e Matemática Computacional) - Instituto de Ciências Matemáticas e de Computação (ICMC/USP), São Carlos SP.

With the growing number and types of data, the need to analyze and understand what they represent and how they are related has become crucial. Visualization techniques based on multidimensional projections have gained space and interest as one of the possible tools to aid this problem, providing a simple and quick way to identify patterns, recognize trends and extract features previously not obvious in the original set. However, the data set projection in a smaller space may not be sufficient in some cases to answer or clarify certain questions asked by the user, making the posterior projection analysis crucial for the exploration and understanding of the data. Thus, interactivity in the visualization, applied to the user's needs, is an essential factor for analysis. In this context, this master project's main objective consists to create visual metaphors based on attributes, through statistical measures and artifacts for detecting noise and similar groups, to assist the exploration and analysis of projected data. In addition, it is proposed to make available, in Web browsers, the multidimensional data visualization techniques developed by the Group of Visual and Geometric Processing at ICMC-USP. The development of the project as a Web platform was inspired by the difficulty of installation and running that certain visualization projects have, mainly due different versions of IDEs, compilers and operating systems. In addition, the fact that the project is available online for execution aims to facilitate the access and dissemination of technical proposals for the general public.

Key-words: Visualization, Multidimensional Projection, Attribute Analysis, Data Exploration, Interactivity. 



\section{LISTA DE ILUSTRAÇÕES}

Figura 1 - Scatterplot matrix do conjunto de dados Iris. Cada matriz mostra a relação entre dois atributos.

Figura 2 - Coordenadas paralelas. Apesar de todos atributos serem visualizados simultaneamente, a sobreposição pode ser um fator que dificulta a identificação de estruturas nesta visualização. . . . . . . . . . . . . . . . 33

Figura 3 - Séries temporais mostram a evolução de dados ao longo do tempo. . . . . . 33

Figura 4 - A posição de um ponto é dada pela interseção dos círculos formados por dois pontos já projetados. . . . . . . . . . . . . . . 35

Figura 5 - Exemplo do ajuste iterativo de uma partícula pelo modelo híbrido de Morrison. 36

Figura 6 - Matriz com pontos de controle. . . . . . . . . . . . . 38

Figura 7 - Interação na PLP. . . . . . . . . . . . . . . . . . . 39

Figura 8 - LAMP apresenta baixa oscilação de stress em relação à variação do número de pontos de controle utilizados. . . . . . . . . . . . . . . . 42

Figura 9 - Código em HTML e árvore gerada pelo DOM. . . . . . . . . . . . . . . 45

Figura 10 - Exemplos de gráficos feitos com D3 . . . . . . . . . . . . . . . . 46

Figura 11 - Exemplos de filtros com Crossfilter. . . . . . . . . . . . . . . . . . 47

Figura 12 - Exemplo de agregação com Crossfilter . . . . . . . . . . . . . . . . . . . 47

Figura 13 - Visualizações através de OpenedEyes. . . . . . . . . . . . . . . . . . . . 49

Figura 14 - Exemplos de redução do número de elementos por binned aggregation e filtragem. . . . . . . . . . . . . . . . . . . 4 49

Figura 15 - Interface de imMens para instâncias com 5 dimensões: x, y, mês, hora e dia 50

Figura 16 - Exemplo de construção de um nanocube com 5 instâncias. . . . . . . . . . . 51

Figura 17 - Estrutura de indexação acumulativa de tempo. . . . . . . . . . . . . 52

Figura 18 - Identificação de grupos em Just-in-Time. . . . . . . . . . . . . . . . . . 54

Figura 19 - Identificação de tendências de um grupo. . . . . . . . . . . . . . . . 55

Figura 20 - Análise de dimensão (e. g. cilindros) de um grupo em Just-in-Time . . . . . . 55

Figura 21 - Nó como uma matriz de projeções. . . . . . . . . . . . . . . . . 56

Figura 22 - Exploração de subespaços de dimensões. . . . . . . . . . . . . . . . 57

Figura 23 - Criação de nós na árvore. . . . . . . . . . . . . . . . . . 58

Figura 24 - Exemplo de análise proposta em Brushing Dimensions . . . . . . . . . . . . 59

Figura 25 - Estensões de análise de atributos para coordenadas paralelas e séries temporais. 60

Figura 26 - Regiões da projeção. . . . . . . . . . . . . . . . . . . . 63

Figura 27 - Grade construída sobre o retângulo envolvente da projeção. . . . . . . . . . 63 
Figura 28 - Relevância de uma célula. . . . . . . . . . . . . . . . . 65

Figura 29 - Primeira métrica visual para relevância de regiões da projeção. . . . . . . . 66

Figura 30 - Segunda métrica visual mostra a relevância de um atributo em toda a projeção. 66

Figura 31 - Variância das dimensões em diferentes regiões da projeção. Cada histograma contém um ponteiro, ilustrado por um pequeno retângulo preto, para que o usuário possa manipular e escolher o melhor posicionamento do histograma no espaço visual. . . . . . . . . . . . . . . . . . . . . . . 68

Figura 32 - Detalhes da distribuição de um conjunto de dados são mostrados. . . . . . . 69

Figura 33 - Detalhes da distribuição de uma dimensão. . . . . . . . . . . . . . . . . 70

Figura 34 - Ideia inicial de agrupamento por variância. . . . . . . . . . . . . . . 70

Figura 35 - A variância de um subconjunto de pontos pode ser maior que a variância de todo o conjunto. . . . . . . . . . . . . . . 71

Figura 36 - Cada célula é representada por um vetor $m$-dimensional de variâncias. . . 72

Figura 37 - Formação de grupos com maior similaridade de variância. . . . . . . . . . . 73

Figura 38 - Distância do cosseno entre células. . . . . . . . . . . . . . . 73

Figura 39 - Diferentes aplicações da ASV . . . . . . . . . . . . . . . 74

Figura 40 - Exemplo do agrupamento dado pelo DBSCAN com minPts $=3$. . . . . . 76

Figura 41 - Remoção das $k-1$ arestas da MST da projeção. . . . . . . . . . . . . . . 76

Figura 42 - Da esquerda pra direita: diferentes grupos dado pelo DBSCAN, $\operatorname{com} k=$

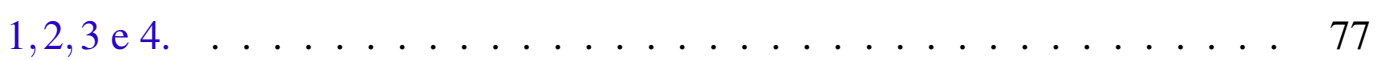

Figura 43 - Exemplos de grupos formados pelo DBSCAN. . . . . . . . . . . . . . 77

Figura 44 - Algoritmo de geração de mapas GMap. . . . . . . . . . . . . . . . . 78

Figura 45 - Diferentes raios de influência do GMap . . . . . . . . . . . . . . . . . 79

Figura 46 - Métrica de qualidade SNP . . . . . . . . . . . . . . . 80

Figura 47 - O status apresenta o registro de todas as operações realizadas pelo programa. 81

Figura 48 - Leitura de arquivo, escolha do método de projeção e função distância utilizada. 81

Figura 49 - Relação entre classes e instâncias da projeção. . . . . . . . . . . . . . . . 82

Figura 50 - Menu contendo os parâmetros da primeira e segunda métrica visual de análise de atributos. . . . . . . . . . . . . . . . . . 82

Figura 51 - Escolha de parâmetros. . . . . . . . . . . . . . . 83

Figura 52 - Seleção manual de regiões por células da grade. . . . . . . . . . . . . 83

Figura 53 - Projeção de diferentes distribuições Gaussianas para $n=3$. . . . . . . . 87

Figura 54 - Análise dos grupos pela ASV . . . . . . . . . . . . . . . 87

Figura 55 - Interação e exploração para identificação de grupos. . . . . . . . . . . . . 88

Figura 56 - Diferentes tamanhos de células podem mostrar as mesmas informações sobre o arquivo. . . . . . . . . . . . . . . . . . . . 89

Figura 57 - Detecção de grupos agregados. . . . . . . . . . . . . . . . . 90

Figura 58 - Análise dos grupos pela ASV . . . . . . . . . . . . . . . . 91

Figura 59 - Remoção de pontos mal projetados pela métrica SNP. . . . . . . . . . . . . 92 
Figura 60 - Identificação de grupos e análise do conjunto Iris. . . . . . . . . . . . . . 93

Figura 61 - Seleção de células para criação manual de grupos. . . . . . . . . . . . . . . 94

Figura 62 - Identificação de grupos e análise do conjunto Wine. . . . . . . . . . . . . . 95

Figura 63 - Análise da relevância dos atributos do conjunto Wine. . . . . . . . . . . . 95 



\section{LISTA DE ALGORITMOS}

Algoritmo 1 - Descrição da função Procurar. . . . . . . . . . . . . . . . . . . . 74

Algoritmo 2 - Algoritmo ASV de detecção de grupos similares. . . . . . . . . . . 75 

Tabela 1 - Sumário das técnicas de projeção multidimensional estudadas. . . . . . . . 42

Tabela 2 - Transformações de dados $f$ e dimensões $s \ldots \ldots \ldots$. . . . . . . 57

Tabela 3 - Conjunto de dados utilizados como casos de teste nos experimentos realizados. 86

Tabela 4 - Características dos atributos (em ordem) do arquivo Winconsin Breast Cancer (Original) . . . . . . . . . . . . . . . . . 91

Tabela 5 - Características dos atributos (em ordem) do arquivo Iris. . . . . . . . . . 93 



\section{LISTA DE ABREVIATURAS E SIGLAS}

$k \mathrm{NN} \ldots . . k$ Nearest Neighbors

AJAX .... Asynchronous JavaScript and XML

ASV ..... Agrupamento por Similaridade de Variância

CSS ...... Cascate Style Sheets

D3 ...... Data-Driven Documents

DBSCAN . Density-Based Spatial Clustering of Applications with Noise

DMR ..... Dimensão Mais Relevante

DOM .... . Document Object Model

HTML ... Hypertext Markup Language

$\mathrm{IQR} \ldots .$. Interquartile Range

JSP ..... Java Server Pages

LAMP ... Local Affine Multidimensional Projection

LSP ..... Least Square Projection

MDS ..... Multidimensional Scaling

PCA .... Principal Component Analysis

PLMP ... Part-Linear Multidimensional Projection

PLP ...... Piece wise Laplacian-based Projection

SNP ...... Smooth Neighborhood Preservation

SVG ..... Scalable Vector Graphics

W3C ..... World Wide Web Consortium

XML ..... eXtensible Markup Language 

INTRODUÇÃO $\ldots \ldots \ldots \ldots \ldots \ldots \ldots \ldots$

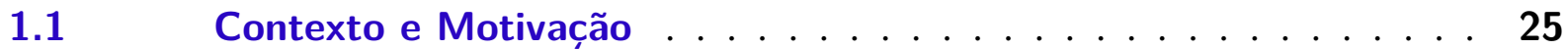

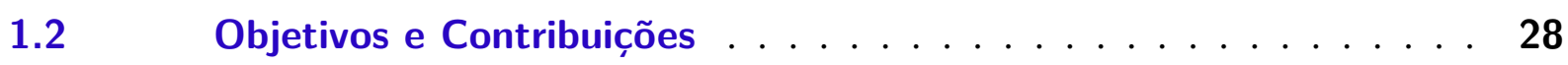

$1.3 \quad$ Organização da Monografia . . . . . . . . . . . . 29

2 FUNDAMENTOS E TRABALHOS RELACIONADOS . . . . . . 31

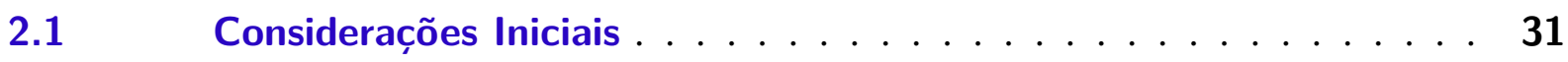

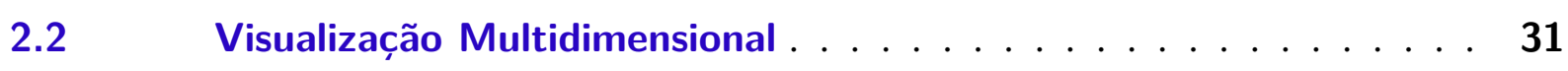

$2.3 \quad$ Projeções Multidimensionais . . . . . . . . . . . . . . . 33

$2.4 \quad$ Conceitos e Ferramentas Web . . . . . . . . . . . . . 41

2.4.1 Linguagens de Marcação . . . . . . . . . . . . . . . . . . . 43

$2.4 .2 \quad D O M \ldots \ldots \ldots \ldots \ldots \ldots \ldots \ldots \ldots$

2.4.3 Páginas Dinâmicas . . . . . . . . . . . . . . . . . 44

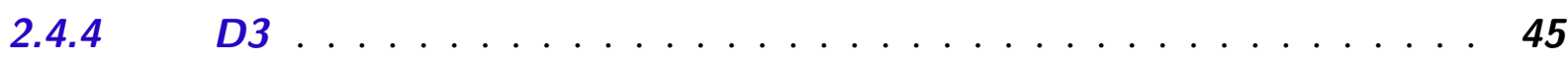

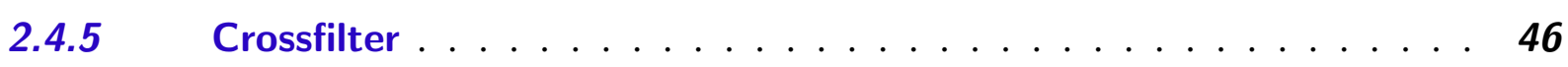

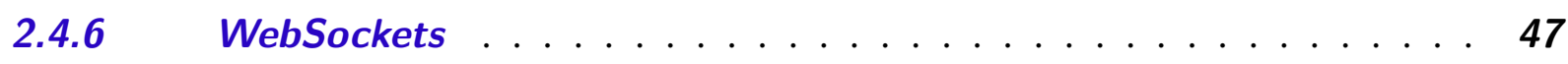

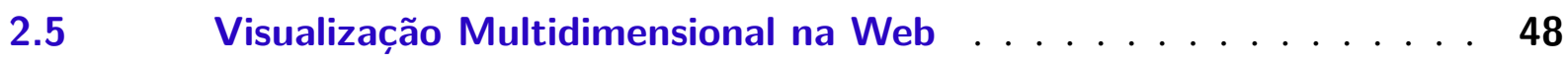

$2.6 \quad$ Análise por Atributo com Projeções Multidimensionais . . . . . . . 52

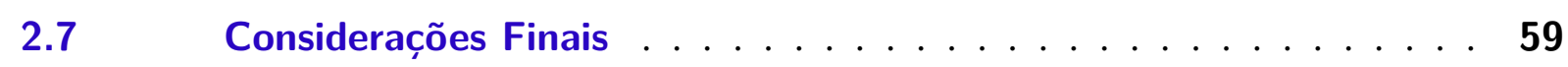

3 ANÁLISE DE DADOS BASEADA EM ATRIBUTOS . . . . . . . . 61

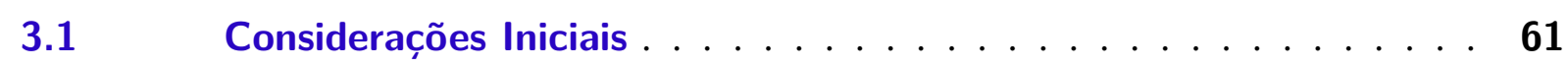

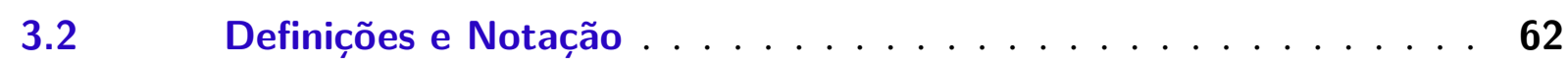

3.3 Metáforas Baseadas em Atributos . . . . . . . . . . . . . 64

3.4 Agrupamento por Similaridade de Variância . . . . . . . . 69

3.5 Técnicas e Ferramentas Auxiliares . . . . . . . . . . . 74

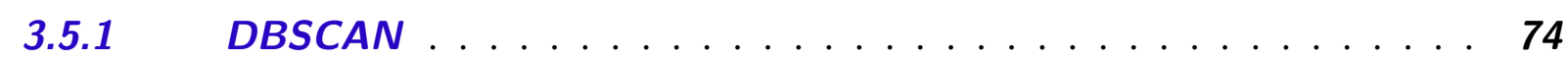

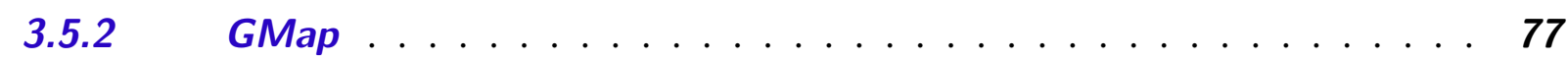

3.5.3 Preservação de Vizinhaça Suave . . . . . . . . . . . . . 78

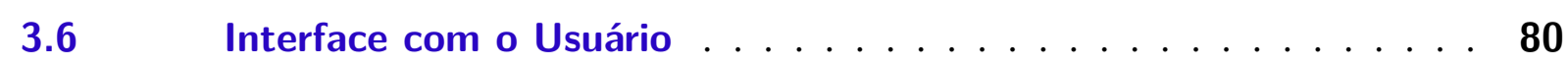

$3.7 \quad$ Considerações Finais $\ldots \ldots \ldots \ldots$. . . . . . . . 83

$4 \quad$ RESULTADOS $\ldots \ldots \ldots \ldots \ldots \ldots$

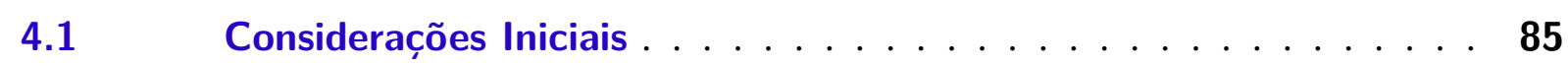




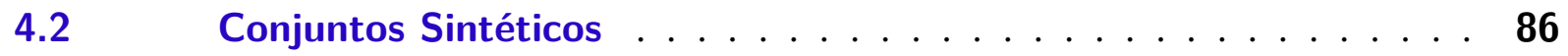

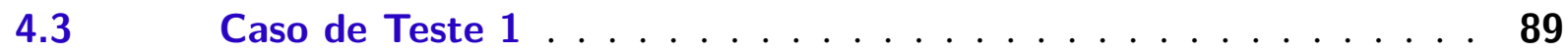

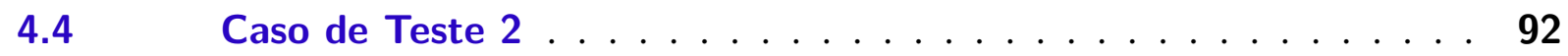

$4.5 \quad$ Casos de Teste $3 \ldots \ldots \ldots$. . . . . . . . . . . . . . . . . 94

4.6 Considerações Finais $\ldots \ldots \ldots \ldots \ldots$

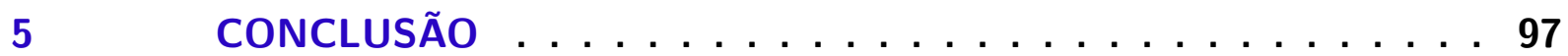

$5.1 \quad$ Resultados Obtidos . . . . . . . . . . . . . . . . . . . . 97

5.2 Trabalhos Futuros . . . . . . . . . . . . . . . . . . . . . . . 98

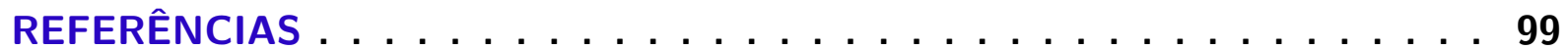




\section{1}

\section{INTRODUÇÃO}

\subsection{Contexto e Motivação}

Um dos desafios atuais na área de Computação é o processamento de dados multimodais massivos contendo textos, imagens, vídeos, músicas e números. Esses dados podem ser oriundos das mais diversas fontes, como produção científica e literária, notícias, monitoramento e sensoriamento remoto, simulações, experimentos, entre outros. A complexidade na análise e interpretação de tais conjuntos de dados advém não somente do tamanho dos conjuntos e diversidade de fontes e formatos, mas também do número de atributos associados a cada instância ou elemento do conjunto. Quando caracterizados por atributos numéricos, tais dados são chamados multidimensionais, pois podem ser interpretados como pontos em um espaço $m$-dimensional, onde $m$ é o número de atributos.

Considerando a capacidade visual humana de reconhecer padrões a partir de relações de similaridade, proximidade e fecho, uma forma eficiente de compreender esses dados e seus relacionamentos é transformá-los em imagens e então exibi-los em algum dispositivo gráfico, tarefa principal da área de Visualização. Há uma variedade de técnicas de visualização que dependem do tipo de dado e do tipo de análise a ser feita. Para dados $m$-dimensionais, as chamadas projeções multidimensionais têm se tornado uma das mais atrativas ferramentas de visualização, pois permitem mapear os dados de um espaço de alta dimensão para um espaço visual preservando as estruturas de vizinhança entre as instâncias de dados.

O Grupo de Processamento Visual e Geométrico (GPVG) do ICMC-USP tem sido referência no desenvolvimento de técnicas de projeção multidimensional, dentre as quais se pode citar a Least Square Projection (LSP) (PAULOVICH et al., 2008), Part-Linear Multidimensional Projection (PLMP) (PAULOVICH; SILVA; NONATO, 2010), Piece wise Laplacian-based Projection (PLP) (PAULOVICH et al., 2011), e Local Affine Multidimensional Projection (LAMP) (JOIA et al., 2011). Cada uma dessas técnicas possui particularidades, sendo a eficácia 
dependente do tipo de dado a ser manipulado e da aplicação alvo.

As técnicas de projeção supracitadas estão disponíveis em uma plataforma Java de visualização de dados desenvolvida no ICMC-USP chamada VisPipeline. A utilização do código para desenvolvimento de programas de visualização de dados requer a instalação da plataforma, ou de alguns de seus módulos, no computador do desenvolvedor ou do usuário final. A base de dados a ser manipulada pela aplicação de visualização também deve estar armazenada localmente. A necessidade da instalação em um computador local restringe o uso das técnicas de visualização via projeção multidimensional desenvolvidas no ICMC-USP a usuários especializados, dificultando sua utilização por outras comunidades e usuários fora do grupo.

Outro fator que dificulta o acesso ou interesse do público geral por técnicas de projeção multidimensional ocorre no período de análise da visualização. Por mais comum que seja a classificação de grupos e instâncias pelos princípios de Gestalt (CHANG; NESBITT; WILKINS, 2007), principalmente em função da capacidade humana em reconhecimento de similaridades, a análise de certas projeções pode não ser trivial para o usuário. A identificação de agrupamentos e a visualização de estruturas similares podem nem sempre ser suficientes para explicar e analisar os dados projetados. Logo, pode se tornar necessário um estudo mais refinado dos dados após a projeção, em especial dos grupos formados, com uma explicação mais precisa de como e por que tais instâncias são similares. Informações como o intervalo dos pontos e medidas estocásticas como variância, média e covariância entre atributos, tanto no espaço original quanto no espaço visual, podem ser úteis para especificar as diferenças e o comportamento de cada grupo formado.

A fim de proporcionar maiores informações sobre os dados projetados, métodos de sumarização consistem em agrupar instâncias similares e visualizar um sumário ou um representante de cada grupo, como word tags (CHOO et al., 2013; PAULOVICH et al., 2012; WU et al., 2011), textual snippets (GOMEZ-NIETO et al., 2014) e thumbnail pictures (STEIGER et al., 2014). Técnicas de análise de atributos, por sua vez, também agrupam pontos no espaço visual de acordo com a sua similaridade, revelando visualmente atributos relevantes em cada grupo. O método proposto por Kandogan (2012) classifica e destaca os melhores atributos em cada grupo. Joia, Petronetto e Nonato (2015) fazem uso da decomposição de valores singulares e de word clouds para identificar e visualizar os atributos mais importantes. Broeksema, Telea e Baudel (2013) colorem partições de Voronoi (AURENHAMMER, 1991) para descobrir atributos relevantes de grupos de instâncias similares. Alternativamente, ferramentas de exploração de grupos multidimensionais podem ser aplicadas após a projeção. Cao et al. (2011), por exemplo, utilizam diagramas de Voronoi e treemaps (SHNEIDERMAN, 1991) para modelar a distribuição dos dados em cada grupo. Seo e Shneiderman (2004) propõem uma ferramenta onde o usuário seleciona uma característica de ranqueamento para exploração uni e bidimensional de dimensões e pares de dimensões, respectivamente. Henry, Fekete e McGuffin (2007) combinam uma representação de matrizes de grafos e grafos tradicionais para encontrar padrões e relacionamentos entre grupos de nós selecionados. 
A interatividade do usuário com toda a ferramenta também é um fator importante na exploração e análise visual dos dados. Apesar de algumas técnicas de projeção multidimensional permitirem recursos interativos, tanto para diminuir tempo de processamento (INGRAM; MUNZNER; OLANO, 2009; PAULOVICH; SILVA; NONATO, 2010), como para introduzir comportamentos locais durante o mapeamento (JOIA et al., 2011; PAULOVICH et al., 2011), não foi encontrada na literatura (até a data de escrita desta dissertação) alguma técnica de projeção multidimensional que permita um alto nível de interatividade com o usuário em todos os níveis do processo de redução de dimensionalidade, principalmente após a projeção, onde a análise realmente é feita.

Projeções multidimensionais tentam preservar as distâncias durante o mapeamento de modo que a vizinhança de um ponto tenda a ser a mesma do espaço original no espaço visual. No entanto, devido aos erros de projeção, tal vizinhança não é sempre precisamente preservada, dificultando a interpretação e a acurácia da projeção. Para aumentar a confiança da projeção, alguns mecanismos foram propostos para visualizar distorções introduzidas durante o processo de redução de dimensionalidade (AUPETIT, 2007; LESPINATS; AUPETIT, 2011; HEULOT; AUPETIT; FEKETE, 2013; MARTINS et al., 2014). Tais erros também dependem da técnica de projeção multidimensional utilizada, cuja efetividade varia de acordo com o tipo de dado analisado. Técnicas recentes como Projection Inspector (PAGLIOSA et al., 2015) e a baseada em grafos proposta por Motta et al. (2015) usam recursos visuais e modelos de grafos para avaliar e comparar distintos métodos de projeções para informar ao usuário sobre o comportamento local e/ou global das técnicas de projeção.

Além de distorções visuais causadas por erros da projeção, outro fator que influencia tanto na qualidade da projeção quanto no processo de análise são os ruídos, gerados por erros durante a coleta ou por instâncias com características atípicas ao esperado. Dentre as técnicas de identificação desses artefatos (HODGE; AUSTIN, 2004), poucas foram aplicadas a projeções multidimensionais de forma interativa, em que o usuário pode especificar e dar margem, isto é, especificar de acordo com sua necessidade ou aplicação, o que é ou não um outlier.

Não obstante todas as restrições citadas acima, não é incomum usuários (com ou sem conhecimentos sobre os dados) quererem explorar outros tipos de estruturas ou agrupamentos diferentes aos formados pela projeção, principalmente em regiões onde não existem grupos bem definidos. Dessa maneira, algoritmos de agrupamento aplicados sobre a projeção poderiam auxiliar a visualização e a exploração de dados, aplicados tanto no espaço original quanto no espaço visual. Técnicas de agrupamento de dados (XU; WUNSCH II, 2005), incluindo a formação de grupos de forma manual pelo usuário, podem ser úteis na análise dos dados após a projeção.

Considerando-se as dificuldades existentes na exploração de dados multidimensionais, este projeto de mestrado propõe a criação de metáforas visuais para auxiliar a análise dos dados projetados. Para acessar os recursos desenvolvidos, implementou-se uma ferramenta de 
visualização cujas metáforas visuais podem ser aplicadas sobre diferentes regiões especificas do espaço visual, estruturadas por alguma técnica de particionamento escolhida pelo usuário. A ideia consistiu em criar um fluxo de execução em que diferentes componentes (escolha da técnica de projeção, particionamento do espaço, variabilidade dos dados e análise) podem ser facilmente modificados de acordo com a necessidade de exploração do usuário. Por sua vez, os motivos que justificam disponibilizar a ferramenta através de um navegador Web podem ser descritos como:

- A Web é uma fonte incessante de dados, publicados em sítios especializados e/ou armazenados em sistemas de nuvem, que podem ser acessados de qualquer dispositivo conectado à Internet, sem necessidade de armazenamento local.

- Aplicações Web podem ser virtualmente executadas por todo dispositivo equipado com um navegador. De fato, a Internet, combinada com a última geração de navegadores, oferece uma promissora plataforma para criação de programas interativos de visualização de dados multidimensionais que está ao alcance de todos. Esses programas podem ser potencialmente utilizados por pesquisadores, acadêmicos e profissionais em qualquer parte do mundo, independentemente do tipo de dispositivo (desktop, laptop, tablet ou smartphone) ou sistema operacional (Windows, Mac, Linux), sem necessidade de instalação de quaisquer programas ou bibliotecas.

- A publicação de visualizações na Web permite rapidamente seu compartilhamento com um público global.

- A implementação do projeto tanto na parte do cliente quanto no servidor possibilita o uso da ferramenta de diversas formas. Entre elas, o usuário pode escolher entre uma rápida consultoria local de dados ou a análise de maiores volumes de dados, processada no servidor.

Vale salientar que existem poucas soluções de visualização de dados que funcionem em um navegador Web, em particular envolvendo projeções multidimensionais, sendo este um dos aspectos originais do projeto.

\subsection{Objetivos e Contribuições}

Os objetivos específicos deste trabalho de mestrado são:

01 Estudar e determinar como os atributos dos dados estão relacionados e impactam nas estruturas da projeção.

02 Propor metáforas visuais para identificação e ranqueamento de atributos mais importantes em regiões da projeção. 
O3 Implementar e apresentar métricas de detecção de ruídos e grupos similares;

O4 Desenvolver uma aplicação para visualização interativa baseada em projeções multidimensional em navegadores Web.

O5 Disponibilizar ferramentas para exploração e análise dos dados.

Logo, dentre as principais contribuições esperadas deste projeto destacam-se:

C1 Alertar a comunidade científica da área de Visualização para a importância da interatividade e da análise de atributos no processo de análise.

C2 Construir uma ferramenta de visualização e análise de dados multidimensionais, baseada em atributos.

C3 Disponibilizar para o público uma ferramenta de visualização desenvolvida em navegadores Web, a ser utilizada em diferentes tipos de dispositivos.

\subsection{Organização da Monografia}

O restante dessa monografia está estruturada como segue.

- No Capítulo 2 são apresentados os trabalhos relevantes na área de Visualização, em especial as técnicas de projeção multidimensional do estado da arte, além de trabalhos que propõem metáforas visuais que tentam explorar ou relacionar os atributos dos dados com a visualização. Conceitos e ferramentas Web utilizadas para a implementação deste projeto de mestrado também são descritos.

- O Capítulo 3 especifica como a ferramenta foi criada e quais as suas funcionalidades, com detalhes sobre as metáforas visuais e os métodos propostos para agrupamento e detecção de ruídos.

- No Capítulo 4 são descritos os experimentos realizados e os resultados obtidos, comparados com outros trabalhos relacionados do estado da arte. Foram realizados testes com todas as possíveis opções de execução do pipeline montado pelo usuário, mostrando como a ferramenta pode ser usada em diversos casos.

- Por fim, no Capítulo 5 são apresentadas as conclusões sobre o trabalho, com suas principais contribuições e limitações. Possíveis trabalhos futuros são sugeridos. 



\section{FUNDAMENTOS E TRABALHOS RELACIONADOS}

\subsection{Considerações Iniciais}

Neste capítulo são descritos os trabalhos mais relevantes na área de Visualização (Seção 2.2), mais especificamente aqueles relacionados às projeções multidimensionais, dando foco às técnicas desenvolvidas pelo Grupo de Processamento Visual e Geométrico do ICMC-USP (Seção 2.3). A Seção 2.4 apresenta os principais conceitos e ferramentas de programação Web contemporânea utilizadas neste projeto, usados para a criação da aplicação Web e implementação das metáforas propostas. Por fim, alguns trabalhos de análise de atributos com projeções multidimensionais são mostrados na Seção 2.5 .

\subsection{Visualização Multidimensional}

Existem diversas áreas científicas como Medicina, Física, Matemática e Biologia que necessitam e/ou desenvolvem aplicações que contribuem para o desenvolvimento da Visualização. Apesar da inovação e aprimoramento de metáforas visuais envolvendo trabalhos científicos e comerciais, a maioria destes derivam ou são modificações de ideias e algoritmos que formaram a base da visualização de dados, dentre os quais podemos listar scatterplots (BECKER; CLEVELAND, 1987), coordenadas paralelas (INSELBERG; DIMSDALE, 1990) e séries temporais (BOX; JENKINS, 1994). Uma descrição mais detalhada destas e de outras técnicas podem ser encontradas em surveys como (CHEN; HARDLE; UNWIN, 2008; WARD; GRINSTEIN; KEIM, 2010; WONG; BERGERON, 1997).

Scatterplot é um gráfico formado por dois eixos transversais onde cada eixo representa um atributo, e as instâncias são mapeadas neste espaço com base nos dois atributos escolhidos. Para dados com um número maior de dimensões, alguns destes ainda podem ser representados 
por meio de cores, glyphs ou texturas neste mesmo espaço. Alternativamente, as combinações de atributos podem ser organizados dois a dois em uma scatterplot matrix ou SPLOM. Geralmente, atribua-se outro tipo de informação ao longo da diagonal principal (ou secundária) da matriz, como por exemplo o nome de cada atributo, como ilustrado na Figura 1. Contudo, mesmo com o uso de SPLOM, esta técnica não é adequada para dados de dimensões altas ou quando desejase analisar relações e tendências entre todas dimensões simultaneamente, sendo comumente utilizada como uma visualização complementar para detalhar pares de dimensões selecionadas.

Figura 1 - Scatterplot matrix do conjunto de dados Iris. Cada matriz mostra a relação entre dois atributos.

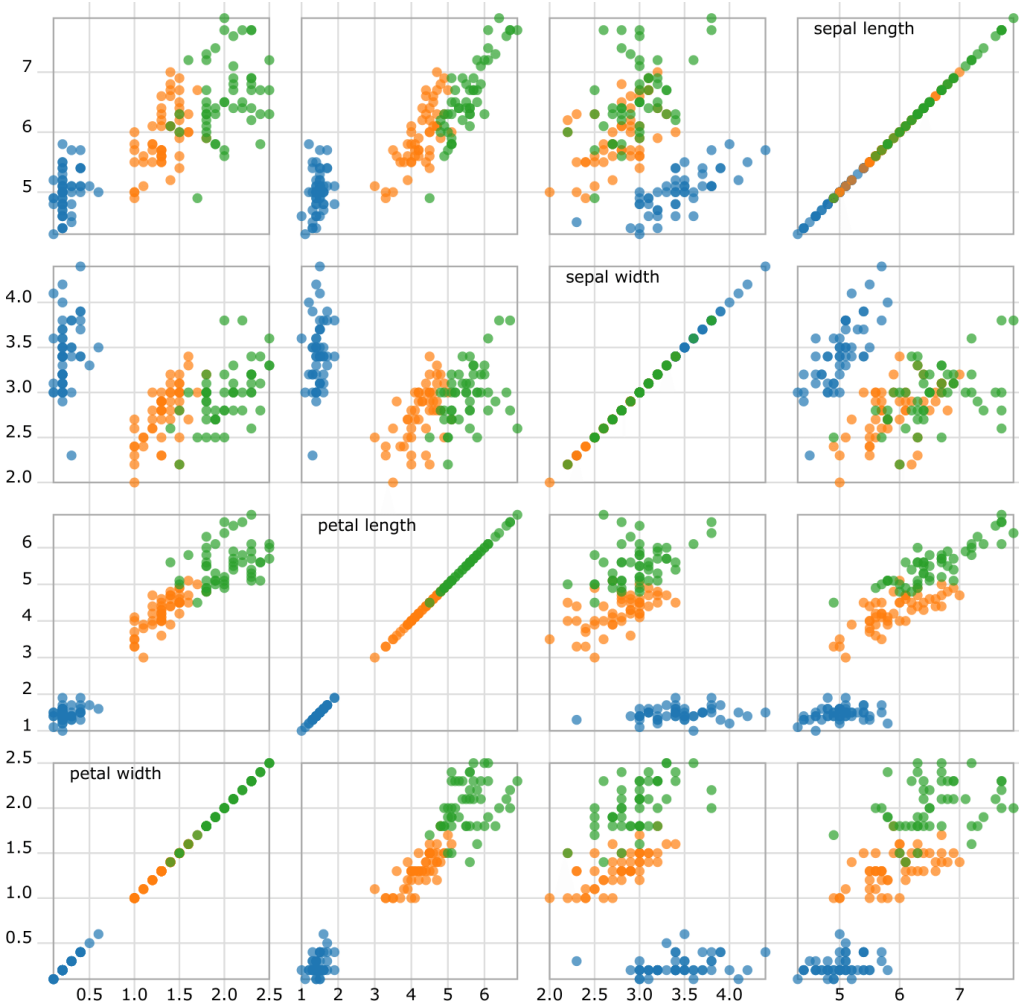

Fonte: Bostock, Ogievetsky e Heer (2011).

$<$ http://bl.ocks.org/mbostock>

A visualização por coordenadas paralelas é capaz de representar um número maior de variáveis contínuas ou discretas simultaneamente, quanto comparada aos scatterplots, uma vez que todas as dimensões são representadas por eixos verticais paralelos entre si, como mostrado na Figura 2. No entanto, a ordem dos eixos influencia no resultado da visualização, de modo que transpondo a ordem dos mesmos pode camuflar ou dificultar a identificar de relações e padrões outrora mais claros, e vice-versa. O formato e a escala como os eixos são apresentados também são importantes para o resultado final. Além disso, algumas sobreposições são inevitáveis, sendo aconselhável o uso de transparências ou métodos mais sofisticados de densidade ou agregação (DASGUPTA; KOSARA; GOSINK, 2012; HEINRICH; WEISKOPF, 2012).

Séries temporais, mostradas na Figura 3, expõem dados que variam ao longo do tempo, respeitando alguma ordem temporal. Neste caso, a dimensão do tempo pode estar inserida 
Figura 2 - Coordenadas paralelas. Apesar de todos atributos serem visualizados simultaneamente, a sobreposição pode ser um fator que dificulta a identificação de estruturas nesta visualização.

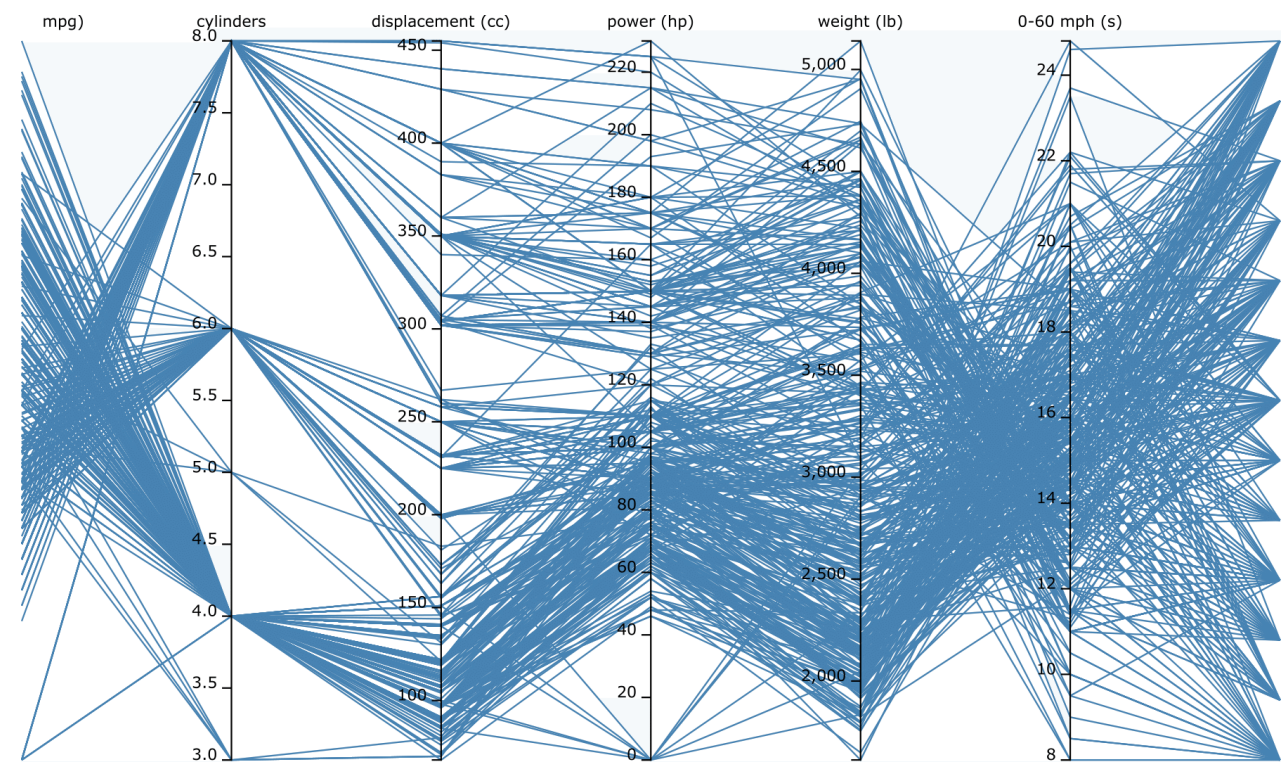

Fonte: Bostock, Ogievetsky e Heer (2011).

$<\mathrm{http}: / /$ bl.ocks.org/mbostock>

na visualização, e relações entre instâncias no decorrer de um período podem ser facilmente analisadas, tornando esse tipo de visualização importante para previsões, estimativas, tendência ou detecção de ruídos.

Figura 3 - Séries temporais mostram a evolução de dados ao longo do tempo.

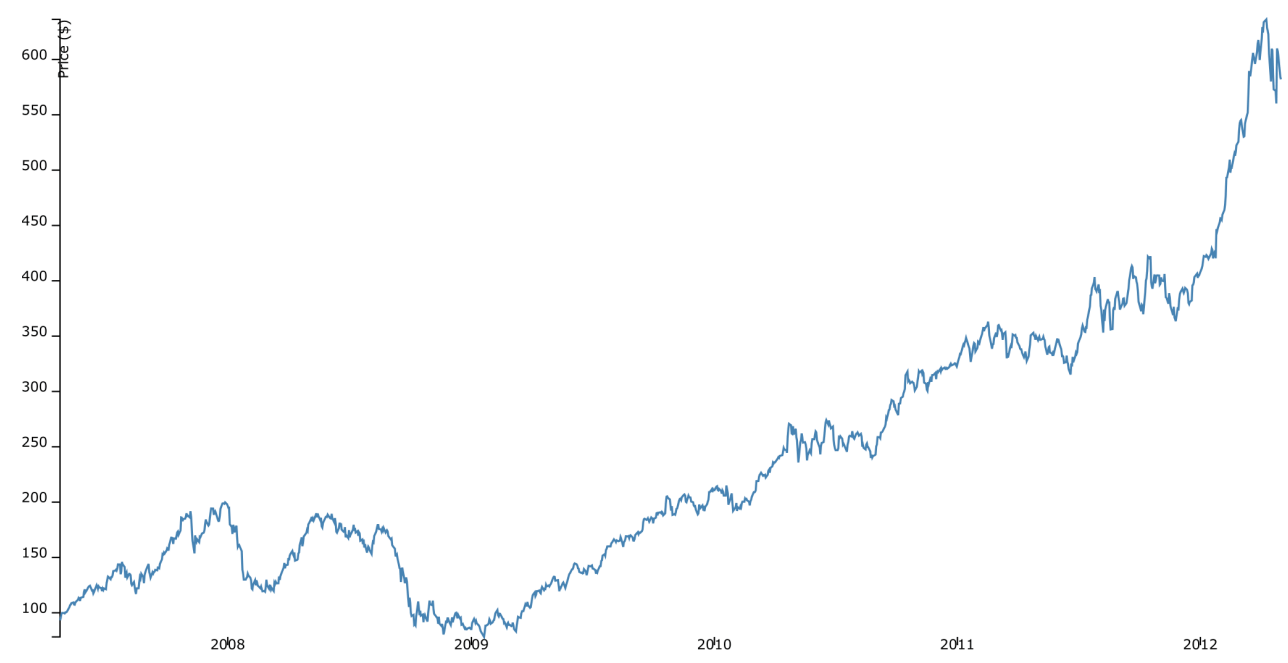

Fonte: Bostock, Ogievetsky e Heer (2011).

$<\mathrm{http}: / /$ bl.ocks.org/mbostock>

\subsection{Projeções Multidimensionais}

Seja $U$ um conjunto de dados no espaço Euclidiano $\mathbb{R}^{m}$ onde o atributo espacial não está presente. À medida que a dimensionalidade $m$ aumenta, a dificuldade de interpretação e de 
análise destes dados também aumenta. Mapear $U$ para um espaço visual bi ou tri-dimensional, preservando as similaridades entre instâncias, tem como intuito facilitar a percepção e a busca por padrões e estruturas. Este processo recebe o nome de redução ou projeção multidimensional. Nesta seção serão apresentados os principais artigos relacionados a redução de dimensionalidade, desde trabalhos seminais até projetos mais recentes do estado da arte.

Sammon (1969) desenvolveu um algoritmo chamado Sammon's Mapping que mapeia um espaço $m$-dimensional em um espaço de menor dimensão minimizando a função de stress

$$
E=\frac{1}{\sum_{i<j} \delta_{i j}} \sum_{i<j} \frac{\left(\delta_{i j}-d_{i j}\right)^{2}}{\delta_{i j}}
$$

sendo $d_{i j}$ e $\delta_{i j}$ a distância entre as instâncias $i$ e $j$ no espaço visual e original, respectivamente. Tal como proposto pelo autor, a minimização de $E$ é feita através do método do gradiente descendente, apesar de outros métodos de otimização poderem ser utilizados. Inicialmente, as instâncias são mapeadas no espaço visual (por exemplo aleatoriamente) e, a fim de minimizar o stress, as novas posições das instâncias são calculados. Este procedimento é realizado até que as diferenças das distâncias entre ambos espaços convirjam para um limiar de erro pré-definido ou quando se atingi um número máximo de iterações. Apesar de esta técnica ser concebida para reduzir a dimensionalidade dos dados, ela também pode ser utilizada para auxiliar outras técnicas de visualização, uma vez que o stress é uma métrica muito usada para comparar a qualidade de projeções.

Apesar de projetar os pontos adequadamente baseado na distância original, esta técnica possui complexidade $O\left(n^{3}\right)$, em que $n$ é o número de pontos, uma vez que o cálculo do stress é $O\left(n^{2}\right)$ e são estimados em média $n$ iterações para garantir convergência. Além disso, é necessário refazer todo o processo caso novas instâncias forem adicionadas.

Para reduzir a complexidade desse método, Pekalska et al. (1999) definiram uma abordagem em que uma amostra dos dados é projetada usando a técnica de Sammon (1969), e as demais instâncias são posicionadas usando uma das três seguintes formas de interpolação: triangulação, redes neurais ou transformação linear. O método de triangulação, mostrado na Figura 4, mapeia uma nova instância $\mathbf{p}_{k}$ para um espaço bidimensional de tal forma que a distância deste ponto para outros dois $\mathbf{p}_{i}$ e $\mathbf{p}_{j}$, previamente projetados, possa ser exatamente preservada. Segundo o autor, se existem $n$ pontos em um espaço $m$-dimensional, estes podem ser mapeados em um plano de forma que $2 n-3$ das $n(n-1) / 2$ distâncias sejam exatamente preservadas. A abordagem por meio de redes neurais (HAYKIN, 2001), por sua vez, utiliza o espaço original como conjunto de treinamento e a projeção dada pelo Sammon's Mapping como saída esperada. A última proposta, a transformação linear, tem por objetivo resolver o sistema

$$
\mathbf{D} \times \mathbf{V}=\mathbf{Y}
$$

em que D é a matriz formada pelas distâncias $\delta_{i j}$ no espaço original entre os pontos de amostra 
Figura 4 - A posição de um ponto é dada pela interseção dos círculos formados por dois pontos já projetados.

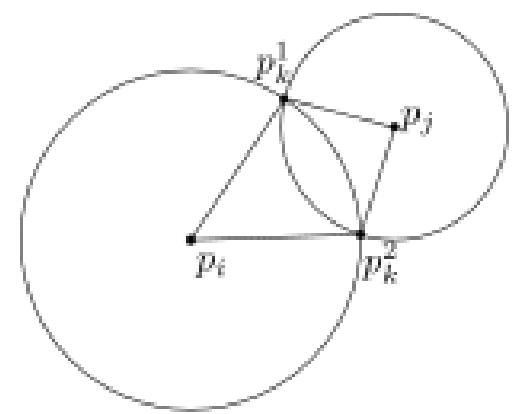

(a) $\mathrm{O}$ ponto $\mathbf{p}_{k}$ é projetado em $\mathbf{p}_{k}^{1}$ ou $\mathbf{p}_{k}^{2}$.

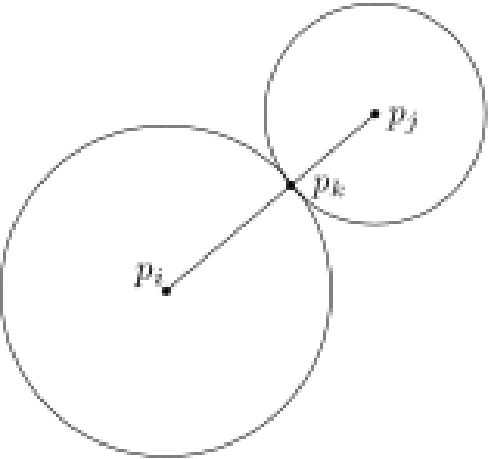

(b) $\mathbf{p}_{k}$ é dado pela interseção dos dois círculos.

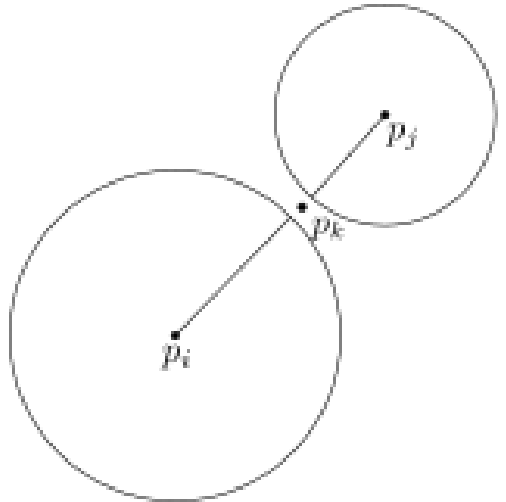

(c) $\mathbf{p}_{k}$ é posicionado pela interpolação dos raios dos círculos.

projetados e $\mathbf{Y}$ a matriz que contém as coordenadas da projeção dessas amostras. Os demais pontos são projetados utilizando a matriz de transformação $\mathbf{V}$ como modelo.

Outras técnicas de projeção multidimensional como as propostas em (CHALMERS, 1996), (MORRISON; ROSS; CHALMERS, 2002) e (TEJADA; MINGHIM; NONATO, 2003) (descritas adiante), fazem uso de um sistema baseado em molas (EADES, 1984) para determinar a posição de um elemento no espaço visual. Inicialmente, todos os pontos são projetados de alguma forma, por exemplo, aleatoriamente ou por triangulação. Uma vez projetados, cada ponto $\mathbf{p}_{i}$ é ajustado (repelido ou atraído) em relação aos demais pontos $\mathbf{p}_{j}$ usando alguma métrica de similaridade. No caso tradicional do modelo baseado em molas, tal métrica é dada pela força

$$
\mathscr{F}_{i j}=d_{i j}-\delta_{i j}
$$

Com isso, pontos mais próximos no espaço original se atraem e pontos mais distantes se repelem. Pela segunda lei de Newton, a nova posição $\mathbf{p}_{i}^{\prime}$ do ponto $\mathbf{p}_{i}$ é dada integrando a força aplicada a cada ponto sobre a massa da partícula $i$ :

$$
\begin{gathered}
f=m \times a \Rightarrow a=f / m \\
\mathbf{p}_{i}^{\prime}=\iint \mathscr{F}_{i j} / m_{i} .
\end{gathered}
$$

Esse processo se repete até um número máximo de iterações, geralmente $n$, em que $n$ é o número de pontos, ou quando ocorre uma estabilização das forças entre iterações. Apesar da Equação 2.4 poder ser resolvida por meio de métodos iterativos para resolução numérica de equações diferenciais ordinárias, como por exemplo através do método de Range-Kutta (CARTWRIGHT; PIRO, 1992), e como $\mathscr{F}$ é aplicada entre todos os pontos, o modelo baseado em molas possui complexidade computacional de $O\left(n^{3}\right)$, o que pode inviabilizar o uso da técnica para grandes volumes de dados.

Chalmers (1996) propõe uma aproximação ao modelo de molas de forma a posicionar os elementos adequadamente, mas não levando em conta todos os pontos no espaço. Para cada ponto $\mathbf{p}_{i}$, dois subgrupos $V_{i}$ e $S_{i}$, de tamanho constante $k$ e $k^{\prime}$, respectivamente, são criados. O 
primeiro é mantido através das iterações, contendo os $k$ elementos atualmente mais próximos de $\mathbf{p}_{i}$. Uma variável $d_{\max }$ indica a maior distância em $V_{i}$. A cada iteração, pontos $j$ disjuntos a $V_{i}$ são selecionados aleatoriamente para preencher $S_{i}$. Caso $d_{i j}<d_{\max }$, o elemento $j$ substitui o maior elemento em $V_{i}$ e $d_{\max }$ é atualizado. Caso contrário, $j$ é adicionado a $S_{i}$. Uma vez selecionados $k^{\prime}$ pontos em $S_{i}$, a força sobre o ponto $\mathbf{p}_{i}$ na atual iteração é dada por

$$
F_{i}=\sum_{v \in V_{i}} \mathscr{F}_{i v}+\sum_{s \in S_{i}} \mathscr{F}_{i s}
$$

Pelo fato de $k$ e $k^{\prime}$ serem constantes, todos os pontos são ajustados em tempo linear. Processado em média por $n$ iterações, o algoritmo tem complexidade de $O\left(n^{2}\right)$.

Morrison, Ross e Chalmers (2002) otimizaram o método de Chalmers (1996) aplicando o princípio de amostragem e interpolação. Primeiro, uma amostra $S$ de tamanho $\sqrt{n}$ é projetada no espaço bidimensional usando o método convencional de Chalmers. Os demais pontos são definidos como segue (ver Figura 5): para cada ponto $\mathbf{p}_{i} \notin S$, este é mapeado no ponto $\mathbf{p}_{i 1}$ sobre a circunferência de raio $\delta_{i s}$ e centro $\mathbf{p}_{s}$, em que $\mathbf{p}_{s} \in S$ é o ponto mais próximo de $\mathbf{p}_{i}$.

Figura 5 - Exemplo do ajuste iterativo de uma partícula pelo modelo híbrido de Morrison.

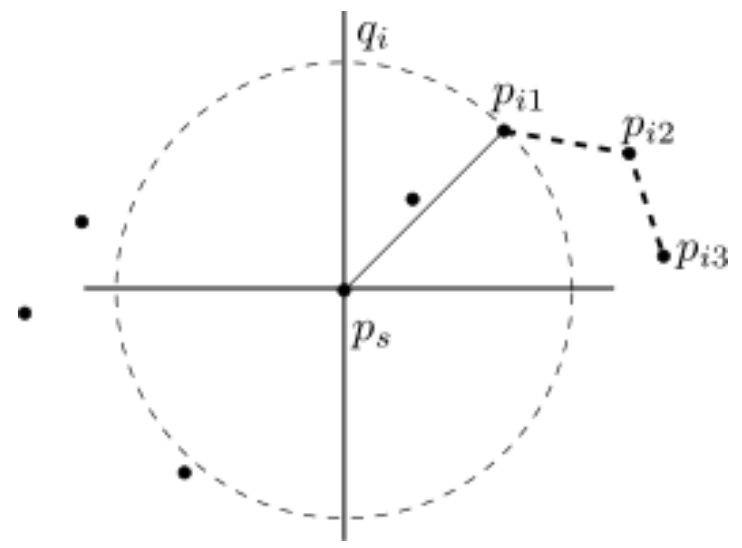

Fonte: Adaptada de Morrison, Ross e Chalmers (2002).

O quadrante $q_{i}$ do círculo na Figura 5 pode ser encontrado minimizando a diferença entre as distâncias dos pontos projetados e as distâncias originais. Finalmente, um vetor com um número constante de elementos selecionados aleatoriamente de $S$ é usado para redefinir a posição de $\mathbf{p}_{i}$, tal como descrito pela Equação 2.5. Esta última etapa é ainda processada em um número constante de iterações para definir a melhor posição de $\mathbf{p}_{i}$, passando por $\mathbf{p}_{i 2}$ e acabando, eventualmente, em $\mathbf{p}_{i 3}$. Essa técnica exige um tempo computacional de $O(n)$ para a projeção das amostras ( $\sqrt{n}$ pontos projetados por Chalmers) e $O(n \sqrt{n})$ para a projeção dos demais pontos, uma vez que cada um $\operatorname{dos} n-\sqrt{n}$ pontos restantes são comparados com $S$. Portanto, o custo computacional total exigido é $O\left(n^{3 / 2}\right)$.

Force Scheme (TEJADA; MINGHIM; NONATO, 2003) é outra técnica baseada em molas. No entanto, o ajuste iterativo dos pontos ocorre de maneira inversa. Ao invés de cada 
ponto $\mathbf{p}_{i}$ mover na direção dos seus vizinhos $\mathbf{p}_{j}$, são os pontos $\mathbf{p}_{j}$ que se movem na direção de $\mathbf{p}_{i}$. A força aplicada sobre cada vizinho é proporcional a alguma fração de $\Delta$, dada por

$$
\Delta=\frac{\delta_{i j}-\delta_{\min }}{\delta_{\max }-\delta_{\min }}-d_{i j}
$$

em que $\delta_{\min }$ e $\delta_{\max }$ são maior e menor distância no espaço $m$-dimensional, respectivamente. Dessa forma, cada ponto é repelido ou atraído na direção de um vizinho respeitando as distâncias no espaço original. Essa estratégia mostra que são necessárias menos iterações para que ocorra uma estabilização dos pontos na projeção, quando comparada às técnicas de força por molas, uma vez que todos os pontos se movem em relação a um único referencial em cada iteração, sendo possível considerar o número de iterações constante. Apesar dessa abordagem gerar resultados mais precisos, ela tem um custo computacional de $O\left(n^{2}\right)$.

Paulovich et al. (2008) propuseram a técnica LSP (Least-Square Projection), cujo objetivo é criar uma superfície na qual os dados são agrupados por relações de proximidade. Na primeira de suas duas partes, uma amostra contendo $c$ dos $n$ pontos do espaço original, chamados pontos de controle, é projetada por Multidimensional Scaling (MDS) (COX; COX, 2000) no espaço visual. Tais pontos devem ser selecionados de forma a melhor representar a distribuição dos dados em $\mathbb{R}^{m}$. Para isso, os autores propuseram dividir o espaço em $c$ grupos usando $k$-medoids (BERKHIN, 2006) e escolhendo os pontos mais próximos a cada medoide como pontos de controle. A segunda parte da técnica consiste em montar a matriz Laplaciana $\mathbf{L}_{n \times n}$ :

$$
L_{i j}=\left\{\begin{array}{cl}
1 & i=j \\
-\frac{1}{k_{i}} & \mathbf{p}_{j} \in V_{i}, \\
0 & \text { caso contrário, }
\end{array}\right.
$$

sendo $V_{i}$ o conjunto formado pelos $k_{i}$ vizinhos do ponto $\mathbf{p}_{i}$.

Os demais pontos são projetados resolvendo, por mínimos quadrados, o sistema

$$
\mathbf{A x}=\mathbf{b}
$$

sendo A a matriz retangular $(n+c) \times n$ (Figura 6) dada por

$$
\mathbf{A}=\left(\begin{array}{l}
\mathbf{L} \\
\mathbf{C}
\end{array}\right), \quad c_{i j}= \begin{cases}1 & \text { se } \mathbf{p}_{j} \text { é um ponto de controle } \\
0 & \text { caso contrário }\end{cases}
$$

e b o vetor

$$
b_{i}= \begin{cases}0 & i \leq n, \\ x_{\mathbf{p}_{c i}} & n<i \leq n+c,\end{cases}
$$

em que $x_{\mathbf{p}_{c i}}$ é uma das coordenadas cartesianas do ponto de controle $\mathbf{p}_{c i}$. Após resolver a Equação 2.8, o vetor $\mathbf{x}$ contém as coordenadas dos demais pontos no espaço visual.

Esta técnica em geral necessita de poucos, mas bem selecionados, pontos de controle. No entanto, por considerar todos os pontos na construção da LSP, a interatividade nesse método pode 
Figura 6 - Matriz A com pontos de controle $\mathbf{p}_{3}$ e $\mathbf{p}_{6}$. O conjunto $V_{i}$ contém os vizinhos do ponto $i$.

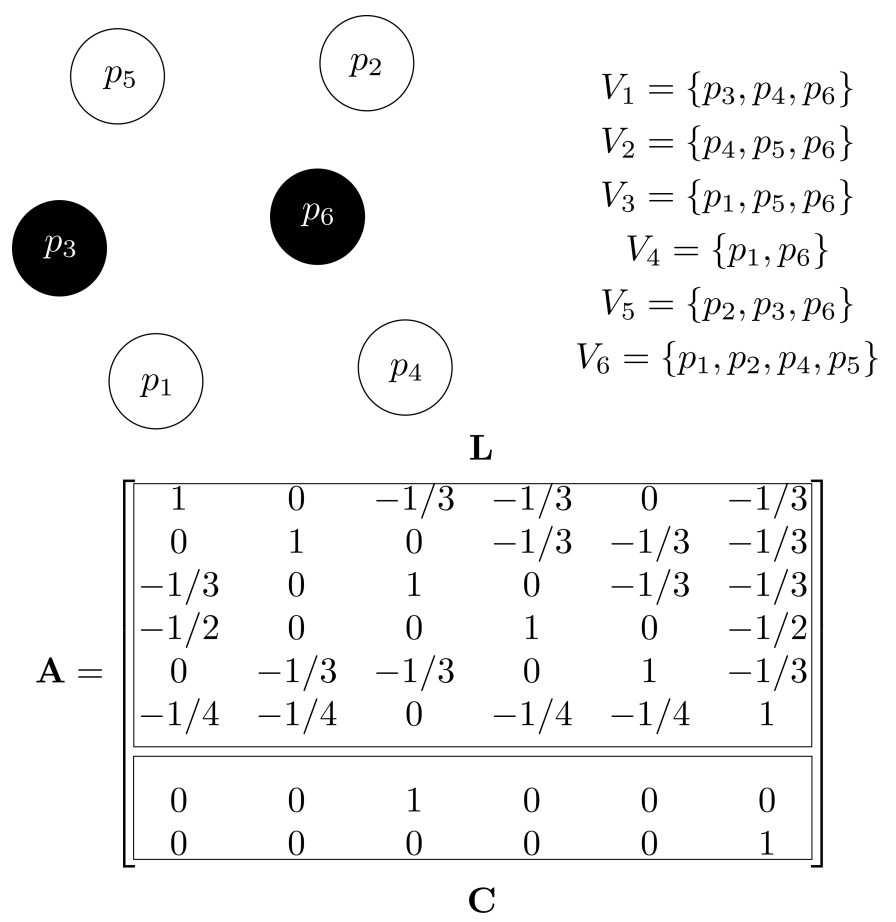

Fonte: Adaptada de Paulovich et al. (2008).

se tornar inviável para grandes conjuntos de dados, devido a necessidade de um reprocessamento, incluindo o cálculo de vizinhança e solução do sistema linear, a cada interação. O gargalo desse método está na busca pelos vizinhos mais próximos para a criação da matriz L. Aproveitando a estrutura gerada pelos $c$ grupos, tal busca pode ser otimizada analisando somente os pontos nos $k$ grupos mais próximos, de modo que com $\sqrt{n}$ grupos, o método apresenta complexidade computacional de $O\left(n^{3 / 2}\right)$.

A fim de proporcionar maior interatividade para a projeção, Paulovich et al. (2011) propuseram a técnica PLP (Piece wise Laplacian-based Projection) baseada em três passos: amostragem, construção do grafo de vizinhança e solução do sistema linear Laplaciano. A primeira consiste em dividir o espaço em grupos a partir de $c$ pontos de controle. A segunda etapa consiste em gerar um grafo de vizinhança $N D_{i}$ para cada grupo $D_{i}$, de tal forma que as instâncias $\mathbf{p}_{i}, \mathbf{p}_{j} \in D_{i}$ estejam ligadas por uma aresta em $N D_{i}$ se pelo menos uma das duas está entre as $k$ vizinhas mais próximas da outra (CUNNINGHAM; DELANY, 2007). Assim, se $\mathbf{p}_{i}$ é uma instância pertencente a $D_{i}$, então $\operatorname{Viz}\left(\mathbf{p}_{i}\right)=\left\{\mathbf{p}_{i 1}, \ldots, \mathbf{p}_{i k}\right\}$ é o conjunto de nós conectados a $\mathbf{p}_{i}$ em $N D_{i}$. Por fim, a última etapa consiste em resolver o sistema linear

$$
\mathbf{L x}=\mathbf{0} ; \quad \mathbf{L y}=\mathbf{0},
$$

sendo $\mathbf{x}$ e $\mathbf{y}$ vetores de coordenadas no espaço visual e $\mathbf{L}$ é a matriz Laplaciana dada por

$$
L_{i j}= \begin{cases}1 & i=j \\ -\alpha_{i j} / \alpha_{i}^{*} & \mathbf{p}_{j} \in \operatorname{Viz}\left(\mathbf{p}_{i}\right) \\ 0 & \text { caso contrário }\end{cases}
$$


sendo $\alpha_{i}^{*}=\sum_{\mathbf{p}_{i j} \in V i z\left(\mathbf{p}_{i}\right)} \alpha_{i j}$. O peso $\alpha_{i j}$ pode ser atribuído como o inverso da distância entre $\mathbf{p}_{i} \mathrm{e}$ $\mathbf{p}_{j}$ ou simplesmente como 1 .

Apesar da similaridade de distância entre pontos de controle ser mantida em nível global, respeitando as distâncias entre os grupos, as relações de vizinhanças são locais. Desse modo, a PLP diminui o custo computacional presente na LSP e dá maior suporte à interação, conforme ilustrado na Figura 7. Caso o usuário explore e decida mover a instância $\mathbf{p}_{i}$ do grupo $D_{i}$ para o grupo $D_{j}$, apenas as relações de vizinhança destes grupos são atualizadas. Assim como a LSP, o custo computacional dessa técnica se baseia na busca pela vizinhança de cada ponto. Esta técnica possui complexidade computacional $O\left(n^{3 / 2}\right)$.

Figura 7 - Interação na PLP.

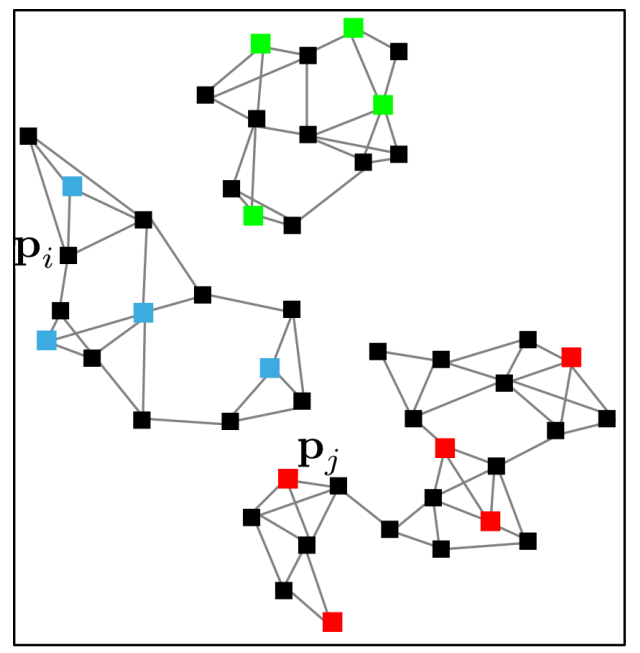

(a) Projeção.

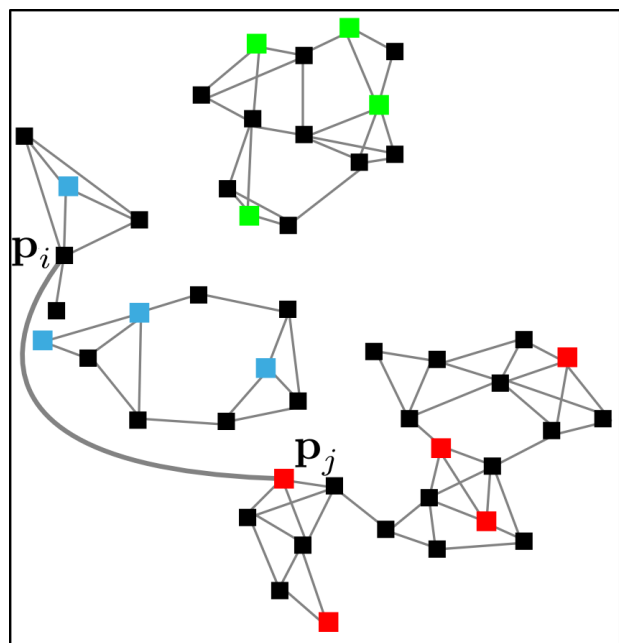

(c) Os grafos de vizinhança são atualizados para refletir a nova relação entre vizinhos.

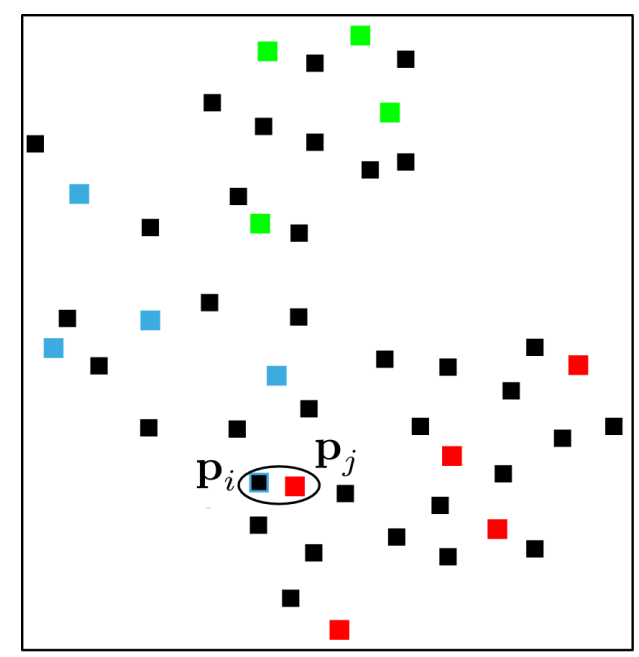

(b) Usuário pode modificar a posição de uma instância projetada.

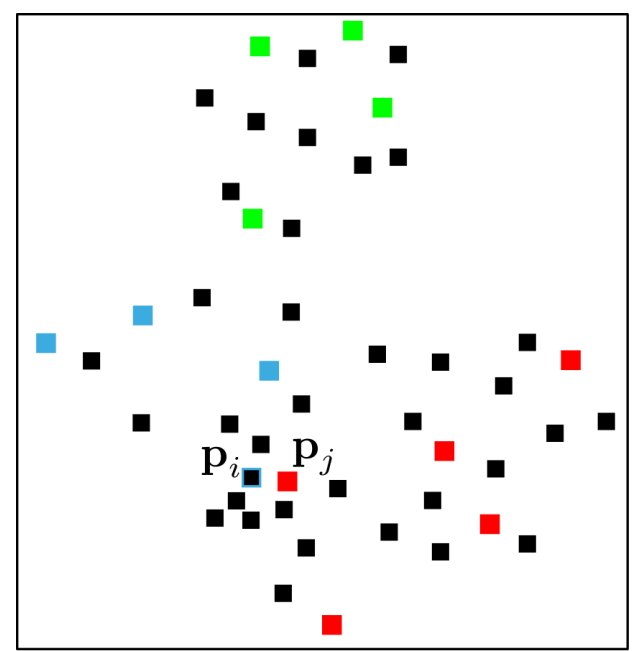

(d) Projeção atualizada.

Fonte: Adaptada de Paulovich et al. (2011). 
2010) é uma técnica simples mas capaz de processar grande quantidade de dados, similar à técnica de Pekalska, em que uma amostra é projetada no espaço visual e um operador de interpolação é encontrado. Tal operador $\Phi$ deve satisfazer

$$
\Phi=\underset{\hat{\Phi} \in \mathscr{L}_{m, p}}{\arg \min }\left\{\frac{1}{D} \sum_{i j}\left(\boldsymbol{\delta}\left(\mathbf{x}_{i}, \mathbf{x}_{j}\right)-d\left(\hat{\Phi}\left(\mathbf{x}_{i}\right), \hat{\Phi}\left(\mathbf{x}_{j}\right)\right)\right)^{2}\right\}
$$

em que $\mathscr{L}_{m, p}$ é o espaço de transformações lineares de $\mathbb{R}^{m}$ para $\mathbb{R}^{p}$ e $D=\sum_{i j} \delta\left(\mathbf{x}_{i}, \mathbf{x}_{j}\right)^{2}$.

Dado um subconjunto de $k$ pontos já projetados $\left\{\mathbf{p}_{1}, \ldots, \mathbf{p}_{k}\right\}, k \ll n, n$ sendo o número total de pontos, o mapeamento ideal $\Phi$ sobre o ponto $\mathbf{x}_{i}, i \in[1, k]$ deve satisfazer:

$$
\Phi\left(\mathbf{x}_{i}\right)=\mathbf{p}_{i}
$$

para cada ponto $i=1, \ldots, k$. Mais precisamente:

$$
\begin{gathered}
\phi_{1,1} x_{1,1}+\cdots+\phi_{1, m} x_{1, m}=p_{1,1} \\
\phi_{1,1} x_{2,1}+\cdots+\phi_{1, m} x_{2, m}=p_{2,1} \\
\vdots \\
\phi_{1,1} x_{k, 1}+\cdots+\phi_{1, m} x_{k, m}=p_{k, 1}
\end{gathered}
$$

em que $\phi_{i, j}$ é a entrada da matriz $\Phi$ na linha $i$ e coluna $j$. Reescrevendo a Equação 2.15 como $\mathbf{L} \phi=\mathbf{b}$, sendo a dimensão de $\mathbf{L}$ igual a $k \times m$, a solução do sistema é obtida resolvendo

$$
\mathbf{L}^{T} \mathbf{L} \phi=\mathbf{L}^{T} \mathbf{b}
$$

Os autores também demonstram que a medida de stress estabiliza quando a quantidade de pontos amostrais é próxima de $\sqrt{n}$, permitindo que tais pontos possam ser aleatoriamente projetados inicialmente.

Em (JOIA et al., 2011), a técnica LAMP (Local Affine Multidimensional Projection) foi proposta tendo como principal contribuição a interatividade do usuário. Assim como outras técnicas locais, LAMP utiliza uma amostra do conjunto de dados original, chamados de pontos de controle, e interpola o restante dos pontos a partir da posição dos pontos de controle no espaço visual. Os pontos de controle podem ser projetados de diferentes formas, de acordo com o objetivo da projeção. Métodos envolvendo triangulação (PEKALSKA et al., 1999) geram projeções mais exatas, mas demandam maior custo computacional, enquanto que projeções aleatórias ajustadas por molas (TEJADA; MINGHIM; NONATO, 2003) apresentam custo computacional menor, mas geram resultados com menor acurácia, assim como possíveis diferentes visualizações a cada projeção. Sejam $\mathbf{x} \in \mathbb{R}^{m}$ um elemento do conjunto de dados original, $\mathbf{x}_{i}$ e $\mathbf{p}_{i}$ o $i$-ésimo ponto de controle e sua respectiva projeção no espaço visual $\mathbb{R}^{2}$. Esta técnica calcula, para cada ponto $\mathbf{x}, \mathbf{a}$ transformação afim $f(\mathbf{x})=\mathbf{M x}+\mathbf{t}$ que minimiza:

$$
\sum_{i} \alpha_{i}\left\|f\left(\mathbf{x}_{i}\right)-\mathbf{p}_{i}\right\|^{2}, \quad \mathbf{M}^{T} \mathbf{M}=\mathbf{I}
$$


sendo a matriz $\mathbf{M}$ e o vetor $\mathbf{t}$ incógnitas, I a matriz identidade e $\alpha_{i}$ um peso, definido por

$$
\alpha_{i}=\frac{1}{\left\|\mathbf{x}_{i}-\mathbf{x}\right\|^{2}}
$$

Por manipulação algébrica, em que se elimina a variável t , a minimização da Equação 2.17 pode ser adequadamente mapeada para o Problema Ortogonal de Procrustes (GOWER; DIJKSTERHUIS, 2004), cuja solução é conhecida por

$$
\mathbf{M}=\mathbf{U V}, \quad \mathbf{A}^{T} \mathbf{B}=\mathbf{U D V},
$$

sendo UDV a decomposição de valores singulares (SVD) de $\mathbf{A}^{T} \mathbf{B}$. Uma vez $\mathbf{M}$ calculada, a projeção $\mathbf{p}$ do elemento $\mathbf{x}$ é dada por

$$
\mathbf{p}=f(\mathbf{x})=(\mathbf{x}-\tilde{\mathbf{x}}) \mathbf{M}+\tilde{\mathbf{p}},
$$

com

$$
\tilde{\mathbf{x}}=\frac{\sum_{i} \alpha_{i} \mathbf{x}_{i}}{\alpha}, \quad \tilde{\mathbf{p}}=\frac{\sum_{i} \alpha_{i} \mathbf{y}_{i}}{\alpha}, \quad \alpha=\sum_{i} \alpha_{i}
$$

Independentemente da forma como estes forem inicialmente projetados, o usuário tem a possibilidade de manipular e melhor estabelecer as posições dos pontos de controle, caso necessário. Além disso, a quantidade de pontos de controle exigidos é outra contribuição importante desta técnica. Enquanto técnicas como PLP, PLMP e Pekalska têm restrições com o número mínimo de pontos amostrados, (geralmente $\sqrt{n}$ ), a LAMP é muito mais robusta nesse sentido, mantendo o stress com pouca distorção mesmo quando poucos pontos de controle são usados, conforme ilustrado na Figura 8. No entanto, um fator negativo desta técnica é a exigência de dados mergulhados em um espaço cartesiano (dados com coordenadas), devido à transformação afim presente no método.

A Tabela 1 mostra um resumo das técnicas de projeção multidimensional descritas nesta seção, em ordem cronológica, com suas respectivas complexidades computacionais.

Além das técnicas descritas acima, existem muitos outros métodos de regressão ou projeção multidimensional, como por exemplo (ASIMOV, 1985; HUBER, 1985; JOLLIFFE, 1986; COX; COX, 2000; TENENBAUM; SILVA; LANGFORD, 2000; INGRAM; MUNZNER; OLANO, 2009; FADEL et al., 2015), que já haviam sido propostos ou foram desenvolvidas no decorrer deste trabalho. No entanto, uma descrição de todas estas técnicas foge do propósito deste projeto.

\subsection{Conceitos e Ferramentas Web}

Nesta seção são apresentadas as principais tecnologias estudadas e utilizadas na parte prática deste projeto de mestrado, desde os conceitos necessários para programação na Web até a implementação computacional da ferramenta proposta. 
Figura 8 - LAMP apresenta baixa oscilação de stress em relação à variação do número de pontos de controle utilizados.



Fonte: Joia et al. (2011).

Tabela 1 - Sumário das técnicas de projeção multidimensional estudadas, sendo $n$ e $k$ o número total de instâncias e o tamanho do conjunto de amostra, respectivamente; $c$ indica o número de iterações.

\begin{tabular}{|c|c|c|}
\hline Técnica & Referência & Complexidade \\
\hline Modelo de molas & (EADES, 1984) & $O\left(n^{3}\right)$ \\
Stress & (SAMMON, 1969) & $O\left(n^{3}\right)$ \\
Chalmers & (CHALMERS, 1996) & $O\left(n^{2}\right)$ \\
Pekalska & (PEKALSKA et al., 1999) & $O\left(2 k^{3}+k n\right)$ \\
Hibrido & (MORRISON; ROSS; CHALMERS, 2002) & $O\left(n^{\frac{3}{2}}\right)$ \\
Force Scheme & (TEJADA; MINGHIM; NONATO, 2003) & $O\left(c n^{2}\right)$ \\
LSP & (PAULOVICH et al., 2008) & $O\left(n^{\frac{3}{2}}\right)$ \\
PLMP & (PAULOVICH; SILVA; NONATO, 2010) & $O(n)$ \\
PLP & (PAULOVICH et al., 2011) & $O\left(n^{\frac{3}{2}}\right)$ \\
LAMP & (JOIA et al., 2011) & $O(n k)$ \\
\hline
\end{tabular}

Fonte: Elaborada pelo autor.

Uma aplicação Web típica é um sistema computacional distribuído cliente-servidor. A parte servidor da aplicação é responsável por receber e processar solicitações de um cliente, comumente enviadas através de um navegador Web. O resultado do processamento efetuado pelo servidor é uma página Web, a qual é enviada de volta ao cliente e então exibida no navegador. $\mathrm{O}$ conteúdo de uma página Web (textos, imagens, links, controles, etc.) é definido por elementos descritos em Hypertext Markup Language (HTML), cuja versão mais recente é HTML5 (WANG; FRANK; MOSKOVITS, 2013). Além disso, uma página Web pode usar arquivos Cascate Style Sheets (CSS) (W3C, 2014a) para definir localização, cor, estilo, etc. de seus elementos, caracterizando assim a aparência e o leiaute da página. 
Os elementos de uma página em HTML são organizados em um navegador segundo um modelo denominado Document Object Model (DOM). O DOM (W3C, 2014b) é uma interface de programação de aplicação que define a estrutura lógica de documentos válidos em HTML (e também documentos bem formados em eXtensible Markup Language (XML) (EVJEN et al., 2007)) e o modo pelo qual um documento é acessado e manipulado. Com este modelo, programas podem criar documentos, navegar através de sua estrutura e, dinamicamente, adicionar, modificar ou remover qualquer um de seus elementos. Em uma página em HTML, esses programas podem ser escritos em JavaScript (CROCKFORD, 2008) e embutidos (ou mantidos em arquivos separados e incluídos) na própria página.

JavaScript é a linguagem dos navegadores modernos. Programas escritos em JavaScript podem ser executados na maioria dos computadores (e dispositivos portáteis), uma vez que estes usualmente vêm instalados em navegadores Web, independentemente do sistema operacional. Similarmente, todos os navegadores atuais (com a introdução do IE9 em 2011) podem renderizar Scalable Vector Graphics (SVG) (EISENBERG, 2002), uma linguagem derivada do XML de descrição vetorial de gráficos bidimensionais. A combinação de JavaScript e SVG permite a criação de gráficos sofisticados acessíveis à maioria dos usuários da Internet. Essa combinação por ser realizada a partir da utilização de bibliotecas JavaScript para manipulação de documentos DOM, através do uso de HTML5, SVG e CSS.

Dependendo da complexidade da técnica de projeção, da quantidade de atributos e do tamanho dos conjuntos de entrada, o processamento envolvendo a projeção multidimensional no lado do cliente pode exigir um elevado esforço computacional. Desta forma, uma solução foi dada possibilitando ao usuário escolher executar os procedimentos de leitura e processamento dos dados localmente ou no lado de um servidor. Este serviço Web foi implementado em Java através de servlets e Java Server Pages (JSP) (HALL, 2004) e, após receber do cliente o pipeline de visualização (descrito no Capítulo 3), executa-o no servidor e então retorna ao cliente uma página em HTML contendo a visualização a ser exibida no navegador. Os dados de entrada poderão ser enviados pelo usuário ao servidor por streaming.

A seguir estao descritos, em maiores detalhes, alguns concetos Web importantes para o desenvolvimento deste trabalho.

\subsubsection{Linguagens de Marcação}

A marcação de um texto surgiu como uma maneira de atribuir ao mesmo características não sintéticas, na forma de instruções, responsáveis pela estruturação de partes ou de todo documento, como posicionamento, espaçamento, coloração e formato. Geralmente, tais instruções são omitidas da apresentação final. Uma linguagem de marcação é aquela onde tais instruções existem e são bem definidas, seja pelo uso de tipos, como o Latex, ou pelo uso de tags em arquivos XML (EVJEN et al., 2007). 
Para arquivos Web, HTML (HyperText Markup Language) é uma linguagem de marcação mais utilizada para estruturar e produzir páginas (ver Figura 9a). Com especificação bem estabelecida, estes tipos de documentos são suportados pela maioria dos navegadores Web atuais, um diferenciando ao outro em relação à interpretação e apresentação do documento. A quinta versão do HTML (HALES, 2012) e a renovação dos browsers para acompanhar a tecnologia trouxe importantes mudanças e possibilidades para a programação na Internet, como novas ferramentas multimídia, melhor depurador de erros, maior suporte a gráficos e animações. Tais fatores tendem a eliminar cada vez mais a necessidade de plug-ins, melhorando o desempenho e autonomia dos programas Web.

\subsubsection{DOM}

Antes dos anos 90, cada navegador era responsável por proporcionar ao usuário uma interface (página Web) na qual ele pudesse navegar e interagir. Logo, funções e programas desenvolvidos em determinado navegador não funcionavam ou podiam funcionar de forma inesperada em outros navegadores, ocasionando desconforto tanto para os usuários quanto para os desenvolvedores.

Neste contexto, a World Wide Web Consortium (W3C) (W3C, 2014c), organização que é a principal responsável pela padronização da Web, definiu o DOM (W3C, 2014b) como uma alternativa para unificar a programação na Internet. DOM é um modelo criado para padronizar a elaboração de documentos XML e HTML. Este modelo define a estrutura lógica do documento e como este será acessado e manipulado. Baseada neste modelo, uma API foi criada, com algumas funções já estabelecidas e outras apenas especificando como um procedimento deveria ser realizado, mas deixando livre para os navegadores decidirem a implementação e a linguagem utilizada. As diferentes implementações dessas funções justifica (entre outros fatores) um navegador ser mais rápido que o outro. Apesar de ainda existirem incompatibilidades entre navegadores, a divergência entre os mesmos é cada vez menor.

A principal vantagem do uso do DOM está no fato de sua API representar e entender uma página Web como uma árvore (vide exemplo da Figura 9b), em que cada nó é uma instrução da linguagem ou tag, e existe uma relação de parentalidade entre duas tags se uma contém a outra. Esta abordagem permite realizar operações mais rápidas aos elementos da página, assim como proporciona mais clareza na estrutura e nas relações existentes no documento.

\subsubsection{Páginas Dinâmicas}

Na década de 90, a grande maioria das páginas Web eram criadas integralmente por documentos HTML. Cada ação do usuário exigia que a página fosse atualizada, ou que uma nova página fosse criada. Por menor que fosse a mudança de um elemento, todo o conteúdo da página era reprocessado. Esse processo, além de ineficiente, era desagradável ao usuário: toda a 
Figura 9 - Código em HTML (a) e sua respectiva árvore gerada pelo DOM (b).

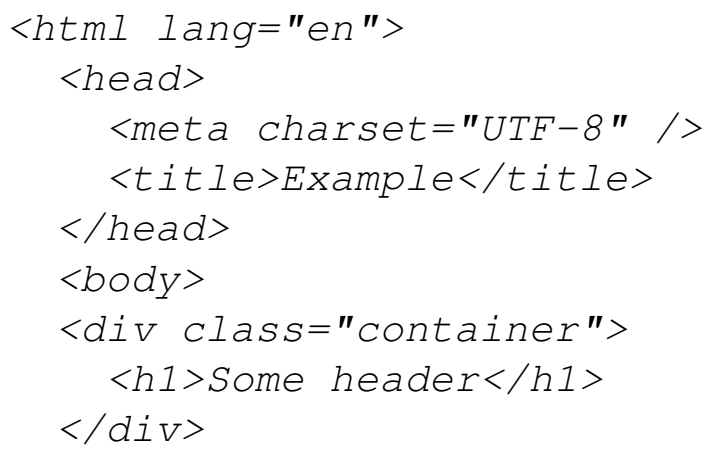

(a) HTML.

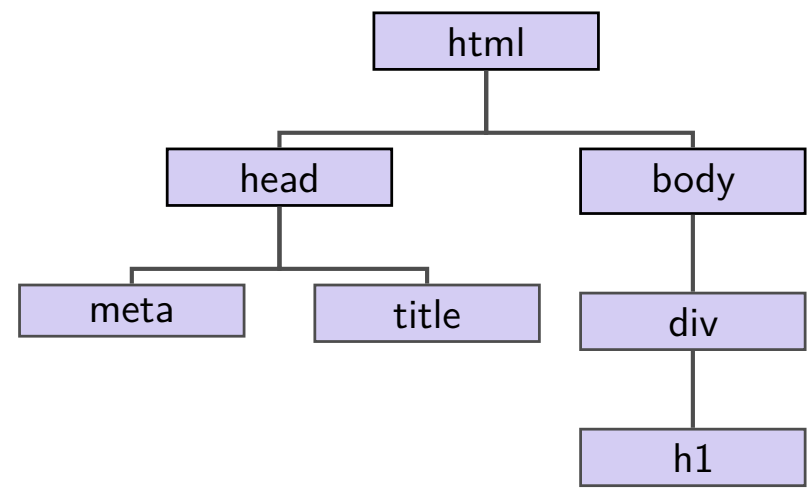

(b) Estrutura do DOM.

Fonte: Elaborada pelo autor.

página desaparecia e depois reaparecia.

Para contornar este problema foram criadas e aperfeiçoadas tecnologias que permitem um processamento assíncrono na Web, descritas a seguir. Para manipulações dinâmicas da página, JavaScript (CROCKFORD, 2008) é a linguagem padrão utilizada atualmente. Apesar da semelhança do nome, JavaScript não tem nenhuma relação com a linguagem Java. Na sua forma mais comum, reside dentro de documentos HTML e fornece níveis de interatividade inacessíveis com HTML simples. Com JavaScript é possível acessar a API do DOM e navegar por sua estrutura, de forma a adicionar, remover e alterar o seu conteúdo dinamicamente.

Para transações de dados entre cliente e servidor sem necessidade de realocação da página, a tecnologia mais comum se chama Asynchronous JavaScript and XML (AJAX), um conjunto de técnicas usadas no lado cliente para criar aplicações Web assíncronas. Com AJAX, aplicações Web podem mandar e receber dados de um servidor sem interferir na exibição e no comportamento de uma página.

\subsubsection{D3}

Data-Driven Documents (D3) (BOSTOCK; OGIEVETSKY; HEER, 2011; BOSTOCK, 2013) é um arcabouço de funções escritas em JavaScript que permite a criação de gráficos (dos mais variados) e a sua associação dinâmica com dados. Formulado principalmente para manipulação de elementos do tipo Scalable Vector Graphics (SVG) (EISENBERG, 2002) do HTML5, D3 proporciona um jeito alternativo (e um pouco mais direto, depois de aprendido) para criar e modificar gráficos, escalas e eixos (MURRAY, 2013). Exemplos de aplicações são mostradas na Figura 10, e variam desde gráficos simples com histogramas e gráficos circulares até exemplos mais complexos, como técnicas de edge bundling, treemaps, visualização de terrenos e modos eficientes de colisão de partículas e construção de grafos. 
Figura 10 - Exemplos de gráficos feitos com D3.
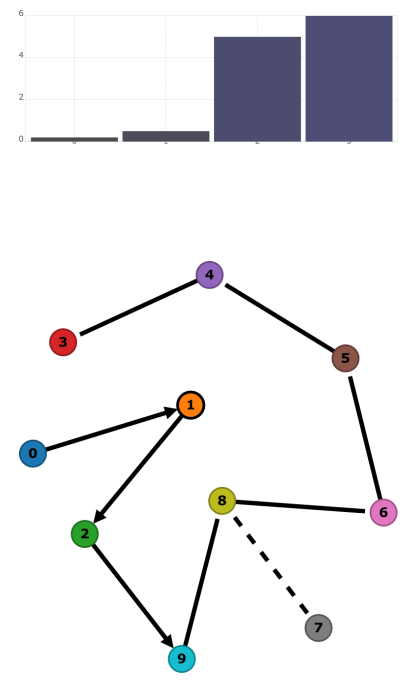
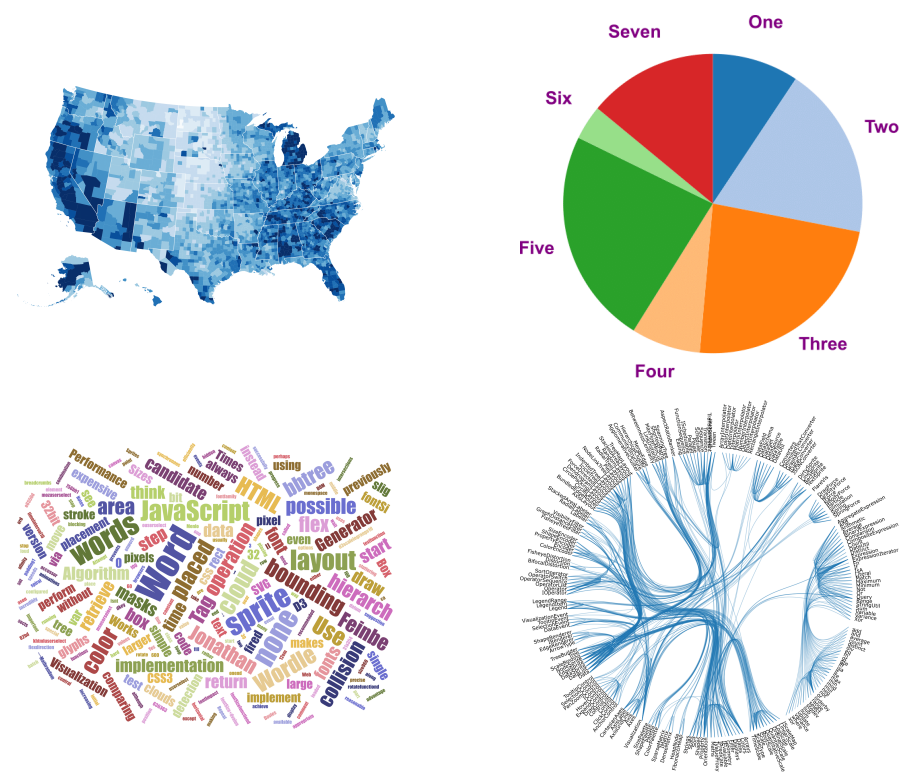

Fonte: Bostock, Ogievetsky e Heer (2011).

$<$ http://bl.ocks.org/mbostock>

\subsubsection{Crossfilter}

Outra biblioteca Web utilizada neste projeto foi o Crossfilter (SQUARE, 2014). Esse conjunto de funções em JavaScript implementa filtros e agregações sobre quantidades massivas de dados. A melhor maneira de explicar o funcionamento do Crossfilter é com um exemplo (veja a Figura 11). Considere que uma página Web de uma agência de aviação mostre dois histogramas $h_{1}$ e $h_{2}$, sendo que $h_{1}$ contém a quantidade de voos realizados em determinada hora e $h_{2}$ a quantidade (em minutos) de atraso de chegada das aeronaves. Com o uso de Crossfilter, aplica-se relações de filtros entre ambos histogramas, de modo a visualizar possíveis relações entre as variáveis analisadas (número de voos e atrasos). Pode-se, por exemplo, selecionar um horário de $h_{1}$ e ver quais são os atrasos mais frequentes em $h_{2}$. Do mesmo modo, pode-se selecionar um intervalo de tempo aceitável de atraso em $h_{2}$ e analisar qual período do dia em $h_{1}$ este tipo de voo ocorre com mais frequência.

No entanto, a principal utilização do Crossfilter se dá pela rápida sumarização dos dados por meio de alguma função de agregação. Seja, por exemplo, a mesma função soma (quantidade de casos observados) utilizada pelo histograma $h_{1}$. Uma agregação sobre esta função ocorre quando esta é aplicada sobre várias instâncias de filtros simultaneamente (no exemplo dado, cada barra do histograma é uma instância), conforme ilustrado na Figura 12. Da mesma forma, pode-se analisar, por exemplo, quais os atrasos mais frequentes da companhia entre 10 e 19 horas, aplicando-se uma agregação sobre $h_{2}$. 
Figura 11 - Exemplos de filtros com Crossfilter.

Time of Day

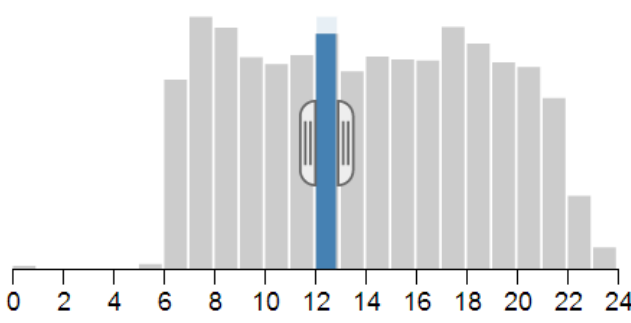

Arrival Delay (min.)

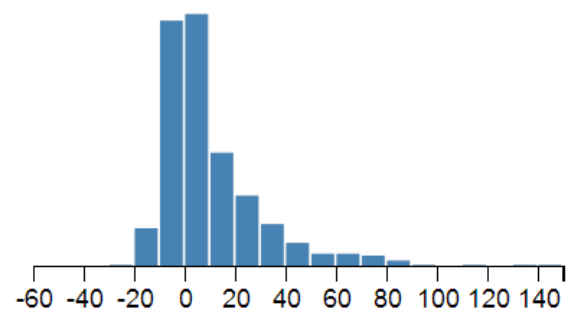

(a) O histograma $h_{2}$ reflete a ação de $h_{1}$. No exemplo, são mostrados os atrasos que ocorrem ao meio dia.

Time of Day

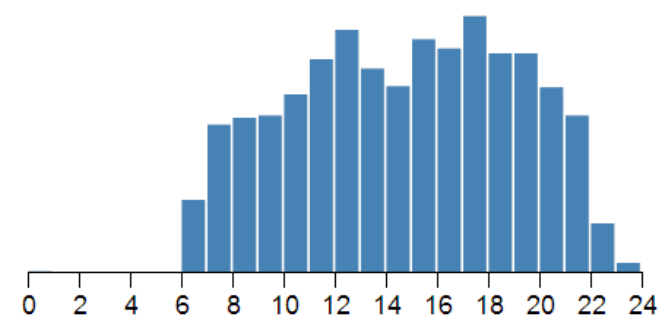

Arrival Delay (min.)

(b) O histograma $h_{1}$ reflete a ação de $h_{2}$. No exemplo, são mostrados os horários do dia em que ocorrem atrasos de voos de 20 minutos.

Fonte: Square (2014).

Figura 12 - Exemplo de agregação com Crossfilter.

Time of Day

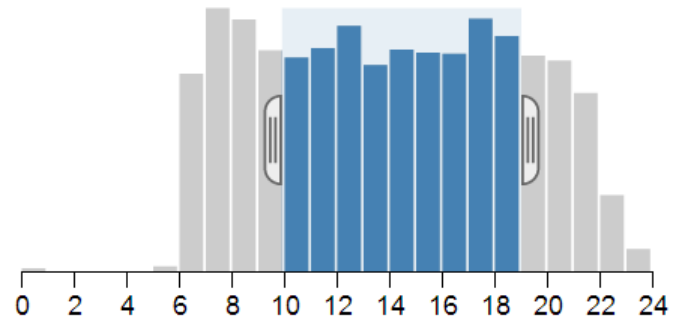

Fonte: Square (2014).

Arrival Delay (min.)

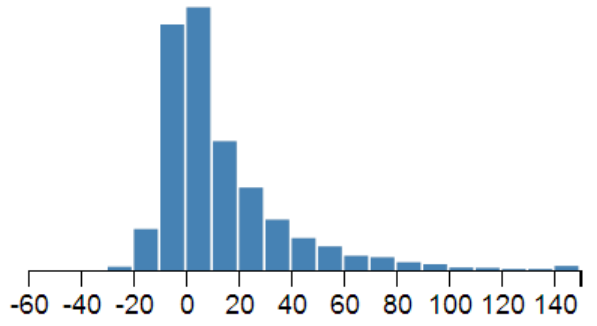

\subsubsection{WebSockets}

A comunicação entre cliente e servidor está cada vez mais presente e importante nos dias de hoje. A necessidade de um meio de comunicação estável entre ambas partes resultou na criação de sockets para a Internet, ou WebSockets (WANG; FRANK; MOSKOVITS, 2013; KAAZING, 2014). Esta tecnologia ainda está em desenvolvimento, e apesar de ser suportada e possuir protocolo especificado pela HTML5, no momento da pesquisa existiam múltiplas implementações e políticas entre servidores e IDEs.

WebSockets garantem a comunicação entre ambas as partes, cliente e servidor, sobre um único socket. Antes desta tecnologia, tal comunicação se dava por técnicas como polling ou long 
polling, reenviando mensagens HTTP (W3C, 2014d) por um período de tempo (perguntando se o servidor já tinha a resposta) ou a cada nova requisição, gerando tráfico desnecessário de rede e latência. Com WebSockets, a comunicação contínua de dados se torna mais rápida e confiável, uma vez que todos os dados são transmitidos por apenas uma única conexão.

\subsection{Visualização Multidimensional na Web}

Com o desenvolvimento da programação Web diversos trabalhos foram propostos através da Internet, beneficiando-se da facilidade de uso e da interatividade cada vez maior dos usuários. Nesta seção são apresentadas ferramentas de visualização multidimensional que foram projetadas para serem usadas através da Web.

Almeida e Opolinário (2013) propuseram OpenedEyes, uma ferramenta escrita em JavaScript destinada à visualização de dados multidimensionais na Web. Assim como no caso do D3 (Subseção 2.4.4) e Crossfilter (Subseção 2.4.5), o usuário deve usá-la em conjunto com outros programas, podendo estender novas funções a partir da estrutura básica fornecida. Por padrão, existem quatro tipos de visualizações à disposição do usuário, ilustradas na Figura 13. A primeira (Figura 13a) implementa um gráfico de bolhas ou bubbles chart, tal que cada instância é representada por um círculo no espaço bidimensional. Tal como proposto, apenas quatro dimensões do conjunto de dados podem ser visualizadas, caracterizadas pelo tamanho, cor e coordenadas dos círculos. Na segunda opção (Figura 13b), todas as dimensões do conjunto de dados podem ser visualizadas simultaneamente por coordenadas paralelas. A terceira visualização (Figura 13c) mostra um mapa de Choropleth (CUFF; MATTSON, 1982), cujas regiões são preenchidas por diferentes tonalidades de cor, conforme alguma dimensão do conjunto de dados. Por fim, a última técnica (Figura 13d) calcula distâncias pelo globo, mensuradas por alguma dimensão. As dimensões utilizadas como atributo em cada visualização são especificadas pelo usuário, durante a execução da aplicação ou antes dela.

Além de gerar visualizações úteis de maneira fácil e prática, OpenedEyes aceita instâncias com atributos temporais, podendo animar a visualização conforme a linha do tempo dos dados. No entanto, apesar da técnica de coordenadas paralelas se mostrar adequada em alguns casos (ver Seção 2.2), a ferramenta como um todo não é capaz de visualizar conjuntos de dados de grande dimensionalidade. Além disso, a dependência de atributos espaciais para a terceira e quarta visualização acaba por inviabilizar tais técnicas, quando as coordenadas das instâncias não fazem parte do conjunto de dados.

imMens (LIU; JIANG; HEER, 2013) é uma ferramenta que processa dados na Web usando D3 e WebGL (PARISI, 2012) para renderização na GPU. Para evitar a desordem e oclusão de instâncias resultante do processo de visualização de grandes quantidades de dados, imMens diminui o número de elementos a serem visualizados por meio de sumarizações do espaço, de tal forma que as instâncias sejam representadas por regiões, ao invés de pontos. Essa 
Figura 13 - Visualizações através de OpenedEyes.

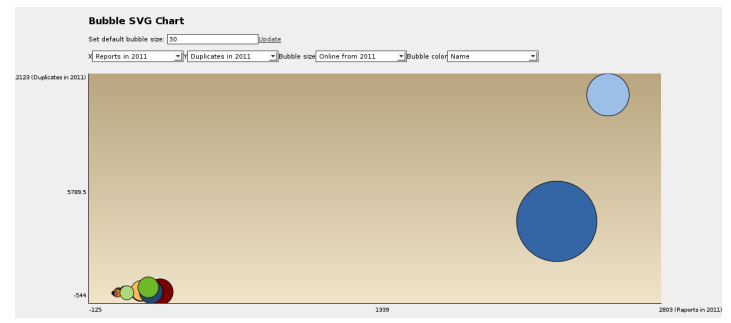

(a) Bubble chart.

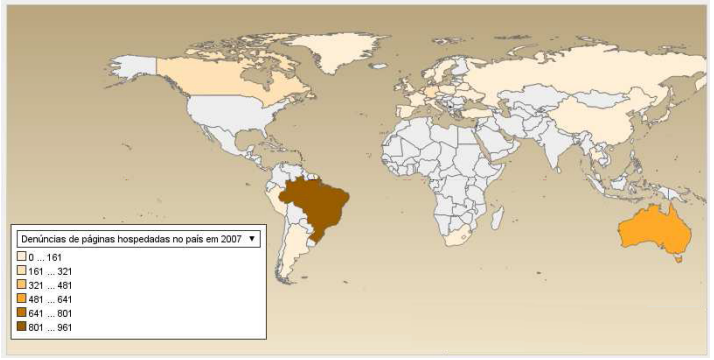

(c) Mapa de Choropleth.

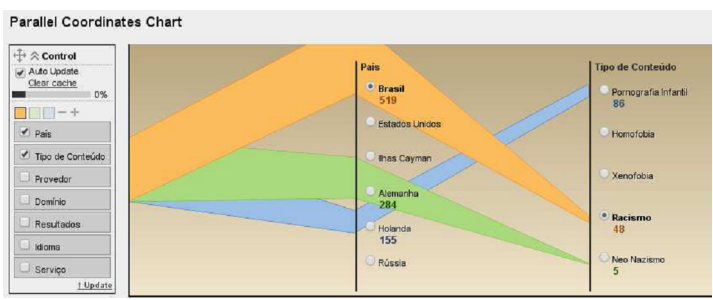

(b) Coordenadas paralelas.

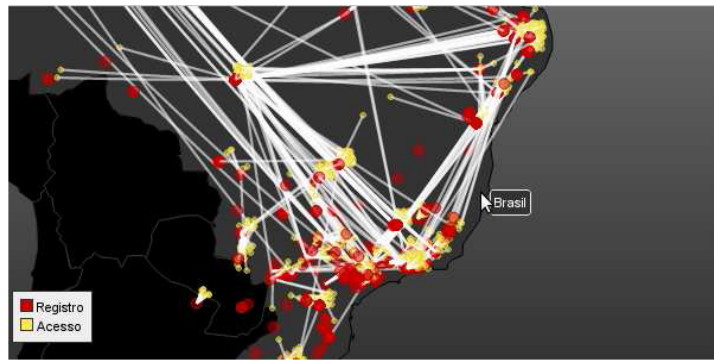

(d) Distâncias entre determinadas instâncias.

Fonte: Almeida e Opolinário (2013).

técnica é conhecida como agregação de cestos ou binned aggregation, ilustrada na Figura 15.

Figura 14 - Exemplos de redução do número de elementos por binned aggregation (a). A filtragem (b) de dados pode resultar em perda de informações importantes, assim como ainda estar sujeito a clutter.

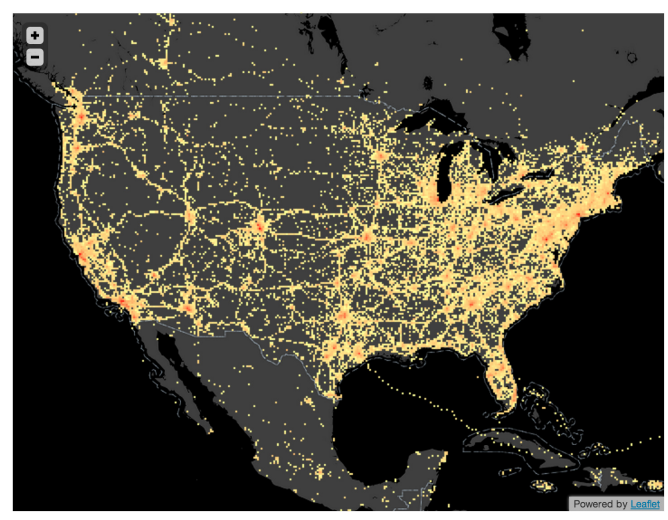

(a) Binned aggregation.

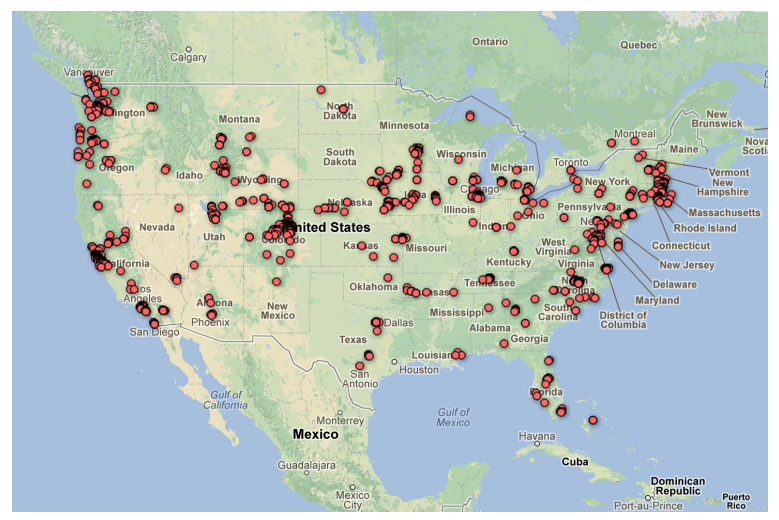

(b) Filtragem de dados.

Fonte: Liu, Jiang e Heer (2013).

Dado um conjunto de dados $m$-dimensional contendo os atributos espaciais $x, y$ de cada instância, estes são mapeados em um mapa enquanto os demais atributos são sumarizados por histogramas para interação do usuário, conforme ilustrado na Figura 15. Apesar de todas as instâncias serem mapeadas, somente as instâncias relacionadas com os intervalos selecionados pelos outros atributos são mostrados, e vice-versa.

Todas as possíveis combinações entre dimensões são armazenadas para uma rápida busca por relações e consultas. Para armazenar e processar estas combinações, imMens utiliza o 
Figura 15 - Interface de imMens para instâncias com 5 dimensões: x, y, mês, hora e dia.

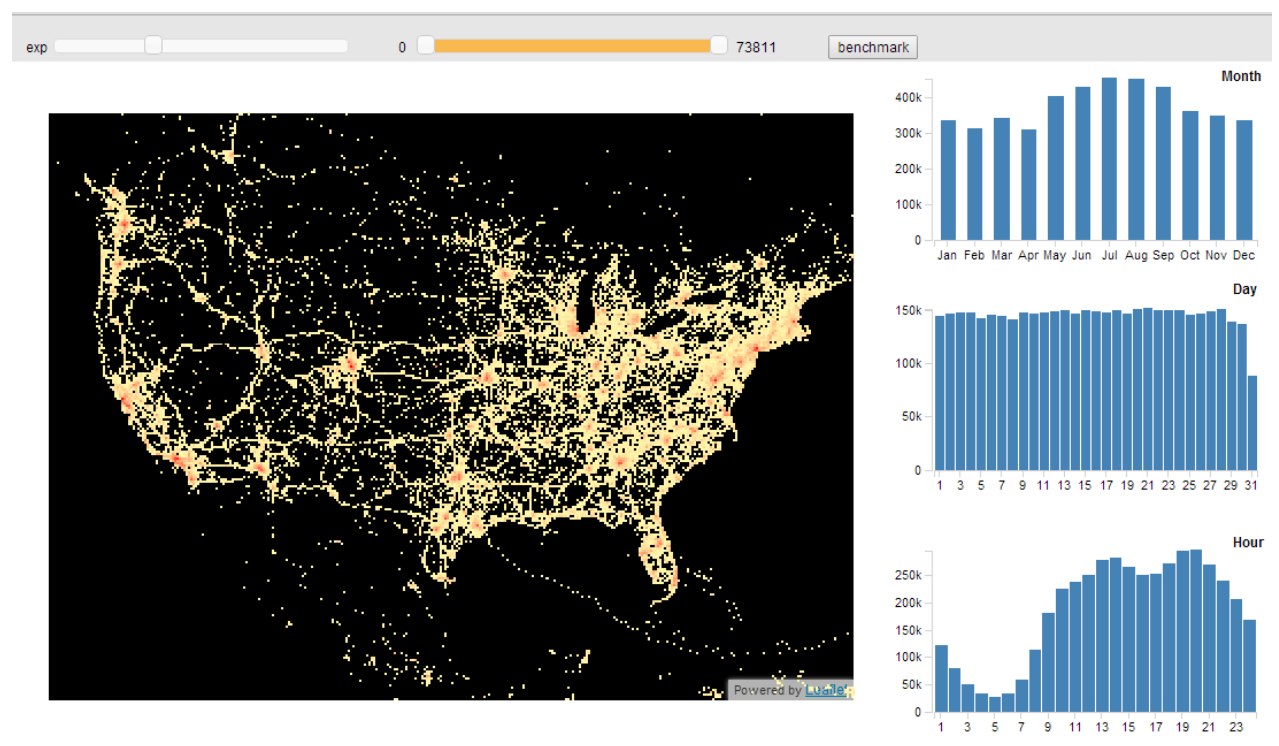

Fonte: Liu, Jiang e Heer (2013).

$<$ http://www.zcliu.org/imMens-demo/brightkite/>

conceito de cubos de dados (GRAY et al., 1997; SISMANIS et al., 2002). Um cubo de dados é uma coleção hierárquica de cuboides, em que um cuboide pode ser visto como uma matriz $m$-dimensional. As dimensões de um cuboide são definidas em termos de certos atributos dos dados, chamados atributos de dimensão. Dados os valores dos atributos de dimensão de uma instância de dados, estes são usados para localizar uma célula dentro do cuboide, cujo conteúdo é definido por outros atributos dos dados, chamados atributos de medida ou de fato. Estes atributos não são independentes, mas computados em termos dos atributos de dimensão, com uso de uma função de agregação (soma, média, desvio padrão, etc.). Tal estrutura foi proposta para otimizar a capacidade de representação e armazenamentos de grandes quantidades de dados, além de aprimorar a busca por determinados conjuntos de instâncias, identificados por alguma lista de atributos, incluindo características geográficas e/ou temporais.

Quando uma consulta é realizada, por exemplo, selecionado um intervalo $I$ do atributo Day, os valores dos cubo pertencentes à região do espaço restringido por $I$ são sumarizados e os resultados são renderizados e refletidos nos demais atributos. Logo, apenas as instâncias que ocorreram entre os dias I são mostradas. O usuário pode realizar diferentes e simultâneas consultas restringindo outros atributos. Apesar de processar grandes quantidades de dados de forma relativamente rápida, esta ferramenta não se aplica para instâncias com muitas dimensões, uma vez que a construção dos cubos de dados seria impraticável, já que o armazenamento das matrizes $m$-dimensionais exige um elevado consumo de memória.

Focando exatamente na otimização do uso de memória, Lins et al. propuseram os Nanocubes (LINS; KLOSOWSKI; SCHEIDEGGER, 2013), uma técnica também baseada em sumarização de instâncias por agregação de cestos, mas capaz de executar na memória de um laptop com até mesmo bilhões de instâncias. A ferramenta proposta tem como finalidade 
tratar dados multidimensionais com características espaço-temporais, onde cubos de dados são representados hierarquicamente, na forma de árvores.

Figura 16 - Exemplo de construção de um nanocube com 5 instâncias.
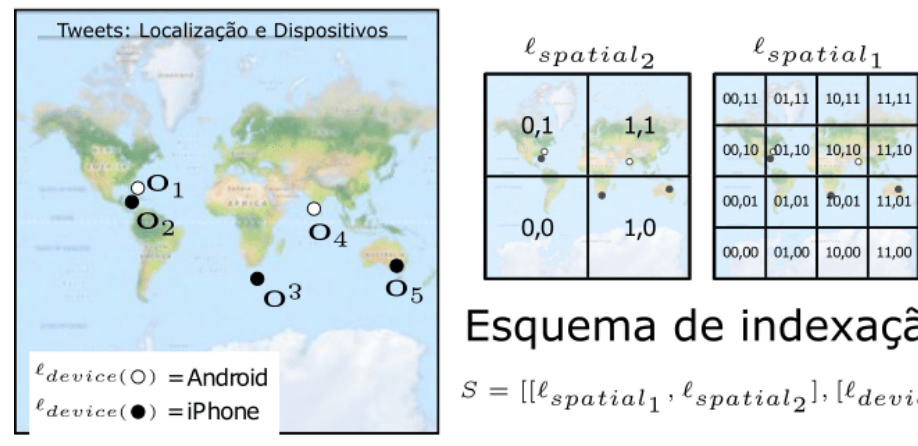

Esquema de indexação

$S=\left[\left[\ell_{\text {spatial }_{1}}, \ell_{\text {spatial }_{2}}\right],\left[\ell_{\text {device }}\right]\right]$

(a) Instâncias e esquema de indexação.

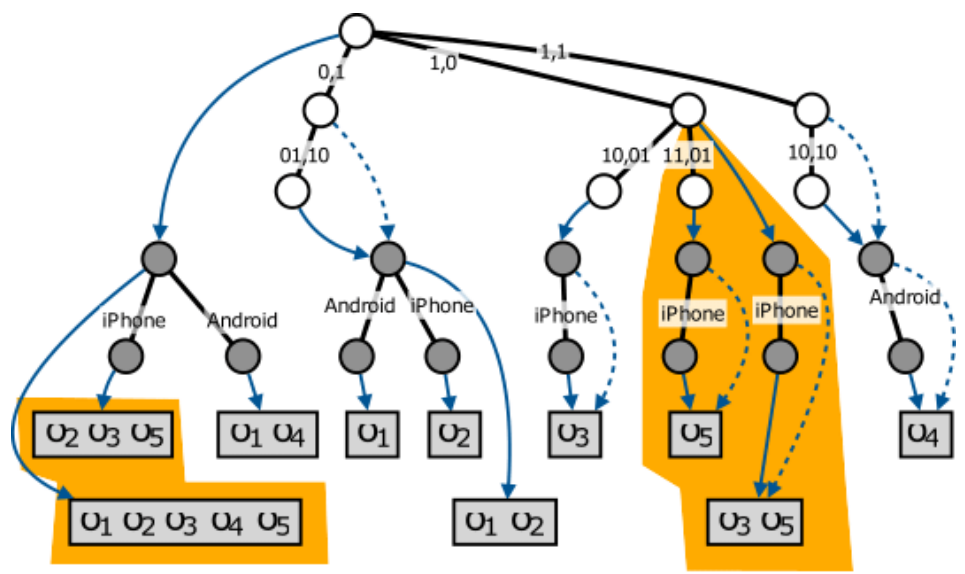

(b) Estrutura hierárquica de um nanocube.

Fonte: Adaptada de Lins, Klosowski e Scheidegger (2013).

Dado um esquema de indexação (Figura 16a) contendo os rótulos de espaço $\ell_{\text {spatial }} \mathrm{e}$ de atributos $\ell_{\text {attr }}$ (dado como $\ell_{\text {device }}$ no exemplo), e um arquivo de instâncias $O=o_{1}, \ldots, o_{k}$, o algoritmo constrói uma árvore dividida por níveis. O primeiro nível contém as informações espaciais, respeitando os rótulos $\ell_{\text {spatial }}$. Os níveis intermediários são formados respeitando os atributos $\ell_{\text {attr }}$, cada um pertencente a sua região do espaço. O último nível é formado pelos atributos de tempo. Cada nó nesse nível é representado por um vetor acumulativo (Figura 17) contendo os tempos no qual um determinado atributo de $\ell_{\text {attr }}$ ocorreu. Tal estrutura permite uma rápida consulta dos eventos que ocorreram entre determinados intervalos de tempo. Um exemplo da construção de um nanocube é ilustrado na Figura 16b. O objetivo é verificar, rapidamente, quais as instâncias que ocorreram em determinadas regiões do espaço e em determinados intervalos de tempo.

A rapidez dessa técnica é garantida pela presença de ponteiros que conectam não somente os nós filhos ao nó pai, mas também cada nó a sua dimensão inferior (próximo atributo). Essa abordagem compacta o espaço e otimiza o processo de busca. Dado um nanocube $m$-dimensional 
Figura 17 - Estrutura de indexação acumulativa de tempo.

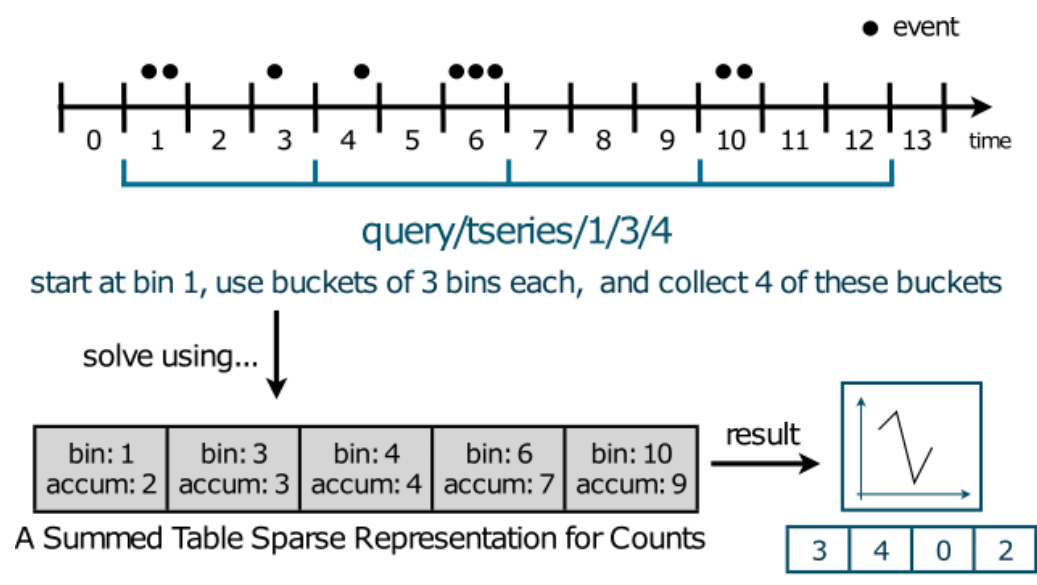

Fonte: Lins, Klosowski e Scheidegger (2013).

e uma consulta $q_{i}$ com $2 \leq i \leq m$ chaves, a busca que satisfaz $q_{1}$ começa por sua localização no espaço. Uma vez encontrada a região da consulta, a busca continua para a próxima chave $q_{2}$ no próximo nível, e assim sucessivamente.

Dentre outros trabalhos relacionados à visualização multidimensional na Web, um grande número possui o mesmo problema: existe a limitação imposta pelo número de dimensões do conjunto de dados. Se o número de dimensões de um conjunto de dados for muito grande, a representação destes dados se torna inviável, seja por cubos de dados na forma de matrizes ou árvores, seja por qualquer outra técnica. Além disso, a maioria das técnicas é baseada em instâncias cujos atributos espaciais ou espaço-temporais são presentes, tornando-se inválidas para conjunto de dados em que as coordenadas das instâncias são desconhecidas, seja por falta de informação ou por não fazerem sentido no cenário estudado.

\subsection{Análise por Atributo com Projeções Multidimensio- nais}

Uma boa visualização revela estruturas e padrões sobre os dados fornecidos, assim como proporciona uma interface para exploração de relações entre instâncias e dimensões. Tendo em vista estas necessidades, a projeção de dados multidimensionais é uma técnica que simplesmente por si só pode não atingir estes objetivos. Por maior que seja a influência e interatividade que o usuário possa ter na fase inicial da projeção, como por exemplo, na hora de determinar os pontos de controle utilizados nas técnicas PLP e LAMP, a principal fase de análise se dá após a projeção, uma vez que a detecção de grupos e padrões (estruturas típicas de projeções multidimensionais) podem ser informações insuficientes para o analista. Neste contexto, esta seção apresentada alguns trabalhos que permitem a análise de atributos pelo usuário sobre os dados projetados.

Kandogan (2012) desenvolveu Just-in-Time descriptive analytics, uma aplicação Web para ajudar o usuário a entender a estrutura e a semântica dos dados projetados a partir de 
técnicas estatísticas. Apesar da técnica ter sido desenvolvida na Web, esta (e as demais descritas nesta seção) difere das técnicas apresentadas na Seção 2.5 pelo fato de propor uma ferramenta para análise de atributos após a projeção, e não apenas uma visualização multidimensional dos dados na Internet.

Apesar da ferramenta utilizar todas as dimensões para explicar a semântica da projeção, Just-in-Time fornece um modelo de análise restrito ao espaço visual da projeção, obtendo características como grupos, tendências e ruídos em relação aos dados projetados, e não levando em conta informações do espaço original. Logo, o autor assume que a projeção reflita muito bem os dados originais para uma análise válida do espaço visual.

Projetados os dados, a detecção de grupos se dá através do uso de uma grade regular $G_{w \times h}$. Uma instância é atribuída a uma célula $G_{(i, j)} \in G, 1 \leq i \leq w, 1 \leq j \leq h$ se suas coordenadas foram projetadas dentro de $G_{(i, j)}$. A fim de simplificar notação, considere a célula $G_{(i, j)}$ como $G_{g=i w+j h}$. Sejam $\left|G_{g}\right|$ o número de pontos atribuídos à célula $G_{g}$ e $\mu$ a média de números de pontos de todas as células ocupadas. Uma célula da grade é considerada válida (ver células na cor cinza na Figura 18a) se $\left|G_{g}\right|>\mu \cdot f$, em que $f$ é um parâmetro determinado pelo usuário. Atravessando a grade de cima para baixo e da esquerda para a direita (Figura 18b), a atribuição de um grupo a uma célula acontece da seguinte maneira. Se um dos 4 vizinhos (acima, esquerda, direta, abaixo) de uma célula for de um grupo $c_{i}$, este também é atribuído para a célula (Figuras 18c e 18d). Caso contrário, um novo grupo $c_{j}$ é formado. Nota-se, porém, que esta abordagem só funciona na prática para grupos bem definidos e separados no espaço visual, o que comumente não acontece para conjunto de dados reais. O próprio autor justifica que o objetivo do método é analisar os grupos criados, e não criar uma ferramenta de agrupamento ótima.

A detecção de ruídos ocorre comparando o valor de cada dimensão $d^{k}$ de cada instância $\mathbf{p}_{i}$ com os valores médios das dimensões $\mu^{k}$ do respectivo grupo deste ponto. Se o valor estiver acima ou abaixo da média por um fator (por exemplo 3) do desvio padrão $\sigma$, isto é, $\left|d_{i}^{k}-\mu^{k}\right|>3 \sigma^{k}$, o ponto é marcado como um ruído.

A tendência de um grupo $c_{i}$ é dada analisando todas as médias de todas dimensões $(k)$ para todas as linhas $(i)$ e colunas $(j)$ de células deste grupo, ou seja, $\mu_{\text {linha }=i}^{k}, \mu_{\text {coluna }=j}^{k}, \forall G_{g} \in c_{i}$. Em seguida, uma regressão linear é realizada para estimar uma linha vertical $\left(\widehat{\mu_{\text {linha }=i}^{k}}\right)$ e horizontal $\left(\widehat{\mu_{\text {coluna }=j}^{k}}\right)$ que se ajuste a estas médias, para determinar se as médias estão crescendo ou diminuindo linha após linha ou coluna após coluna, conforme ilustrado na Figura 19. Se o erro entre o valor real e o valor estimado for considerado baixo e o declive da reta for menor que um parâmetro, então é admitido que o grupo apresenta um padrão direcional, ou uma tendência em pelo menos uma dimensão.

A partir destas três características, agrupamento, ruídos e tendência, processadas em função do espaço visual, medidas como densidade $\left(\operatorname{den}_{i}^{k}\right)$, sobreposição entre grupos, $\left(\operatorname{sob}_{i}^{k}\right)$ pontuação de ruídos $\left(\operatorname{rui}_{i}^{k}\right)$, pontuações de tendência de linha $\left(\operatorname{lin}_{i}^{k}\right)$ e coluna $\left(\operatorname{col}_{i}^{k}\right)$ de cada 
Figura 18 - Identificação de grupos em Just-in-Time.

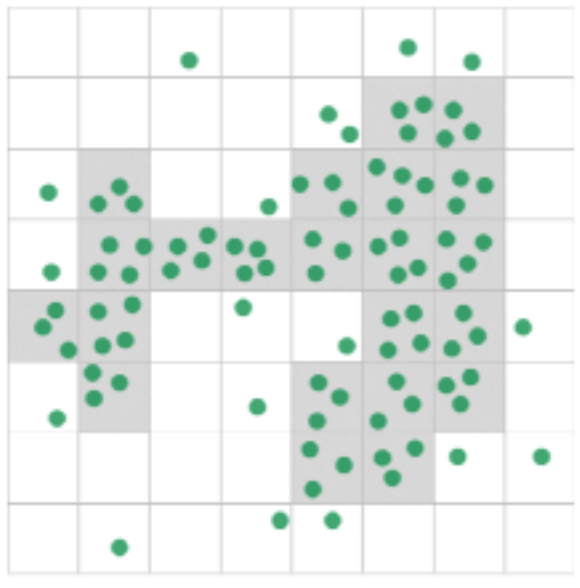

(a)

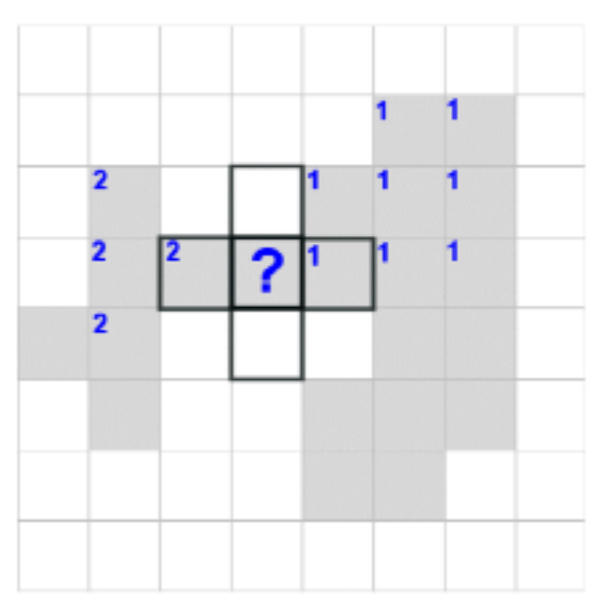

(c)

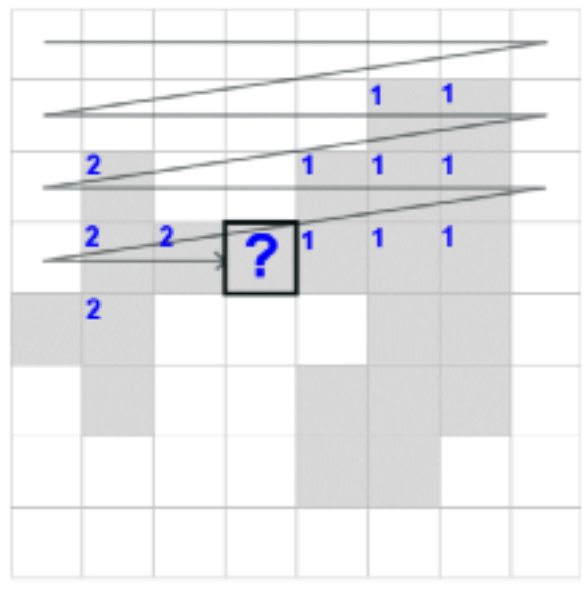

(b)

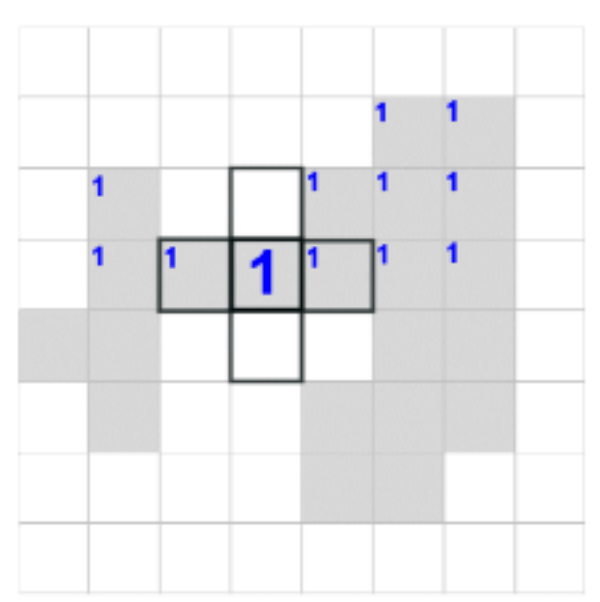

(d)

Fonte: Kandogan (2012).

dimensão $(k)$ para cada grupo $\left(c_{i}\right)$ são derivadas. Todas estas medidas são usadas no cálculo de um valor de ranqueamento (ou nota) de uma dimensão de um grupo, dada pela soma ponderada:

$$
\operatorname{nota}_{i}^{k}=w_{\text {den }} \cdot\left(\operatorname{den}_{i}^{k}\right)+w_{\text {sob }} \cdot\left(\operatorname{sob}_{i}^{k}\right)+w_{\text {rui }} \cdot\left(\operatorname{rui}_{i}^{k}\right)+w_{\text {lin }} \cdot\left(\operatorname{lin}_{i}^{k}\right)+w_{\text {col }} \cdot\left(\operatorname{col}_{i}^{k}\right),
$$

sendo $w_{\text {med }}$ o peso da medida "med". A soma de todas as notas dividida pelo número de grupos resulta na média de notas por dimensão $\left(\mu_{\text {nota }}^{k}\right)$. Por fim, um conjunto de dimensões acima da média por algum parâmetro é selecionado e utilizado para representar cada grupo. Dessa forma, suponha que um grupo $c_{i}$ tenha as dimensões 2,4,5 com notas acima da média $\mu_{\text {nota }}^{2}, \mu_{\text {nota }}^{4}, \mu_{\text {nota }}^{5}$, por exemplo. Estas dimensões serão tidas como as mais importantes para $c_{i}$, e anotações (informações) como intervalo de valores, valor nominal, ruídos e tendência destas dimensões podem ser mostradas ao usuário em cada grupo, conforme ilustrado na Figura 20. O usuário pode interativamente selecionar as anotações a serem visualizadas em cada dimensão.

Um fator não claro neste trabalho está no fato de que dimensões classificadas como importantes são baseadas na média das respectivas dimensões de todos os grupos da projeção. Mesmo assumindo um conjunto de dados onde todos os grupos sejam bem definidos e a projeção 
Figura 19 - Identificação de tendências de um grupo.

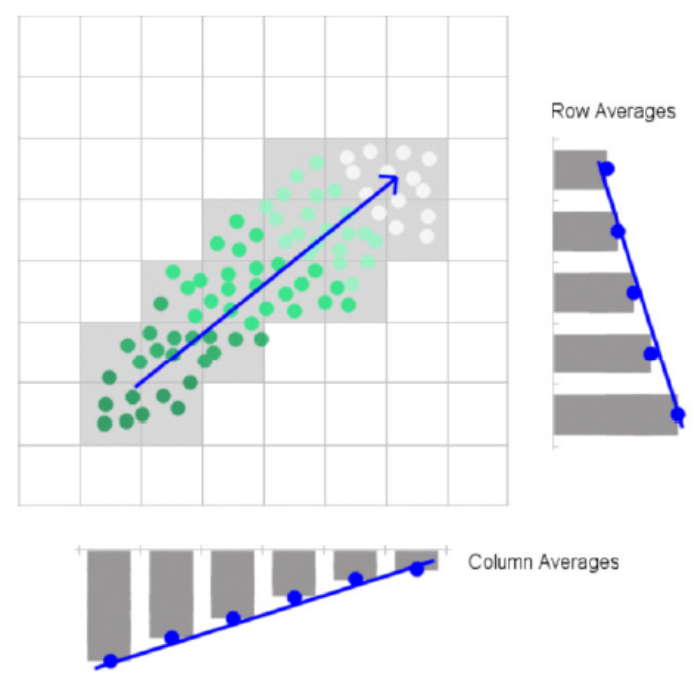

Fonte: Kandogan (2012).

separe instâncias adequadamente, não há nenhuma garantia de que comparar dimensões entre grupos seja uma maneira adequada para tirar conclusões sobre a dimensão específica de um grupo. Em outras palavras, a técnica propõe que uma dimensão seja mais importante em um grupo se sua nota for maior que a média dos demais, mas não há justificativa do porquê tal comparação deve ser feita, ou se é válida em primeiro lugar. Outro fator importante é o cálculo da nota dada a cada dimensão, dado pela Equação 2.21. Diferentes maneiras e medidas poderiam ser utilizadas, e uma análise de como outras notas influenciam na visualização e na busca por informações poderia ser interessante.

Figura 20 - Análise de dimensão (e. g. cilindros) de um grupo em Just-in-Time. Anotações de (a) valor nominal; (b) intervalo de valores e (c) tendência de valores.

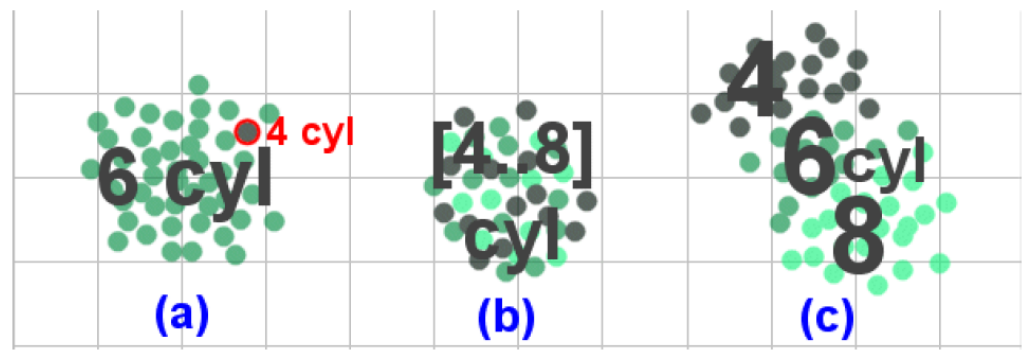

Fonte: Kandogan (2012).

Yuan et al. (2013) propuseram Dimension Projection Matrix/Tree, uma ferramenta cliente-servidor de análise hierárquica de dados multidimensionais através da exploração em conjunto do espaço visual e do espaço de dimensões dos dados através de uma árvore de projeções. Os dados são estruturados de tal forma que um nó filho contenha um subconjunto do espaço visual ou um subconjunto de dimensões do seu pai. Cada nó é representado por uma matriz de projeções (veja Figura 21), caracterizada por ser uma extensão de scatterplot matrix (BECKER; 
CLEVELAND, 1987), onde cada linha ou coluna representa um grupo de dimensões (indicados por uma faixa de dimensões), e cada célula um tipo de projeção. Células da triangulação superior da matriz mostram projeções dos dados utilizando somente um subconjunto de dimensões, enquanto células da triangulação inferior representam as projeções destas dimensões. Ao lado da matriz é mostrada a projeção de todos as dimensões simultaneamente.

Figura 21 - Nó como uma matriz de projeções.

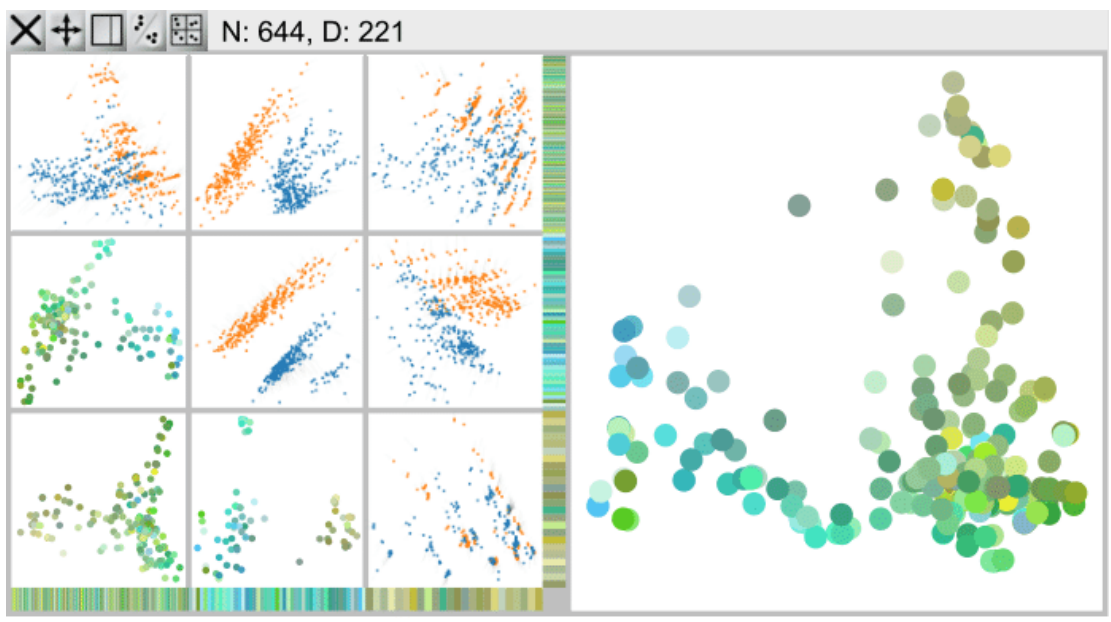

Fonte: Adaptada de Yuan et al. (2013).

A ferramenta possibilita uma série de funcionalidades disponíveis em um menu presente na matriz. Dentre as opções fornecidas, as mais interessantes são atribuídas a algoritmos de agrupamento automáticos do espaço de dimensão e do espaço de dados. Os grupos identificados são usados para a criação de novos nós na árvore.

Inicialmente a árvore possui apenas um nó que contém todos os pontos e dimensões projetados, representada por duas janelas. A primeira a esquerda contém uma matriz de projeção $1 \times 1$ e a segunda a projeção mostrando a correlação de todas dimensões. O usuário pode selecionar subespaços manualmente ou utilizar algum algoritmo de agrupamento para detectar grupos e criar novos nós na árvore. Da mesma forma, é possível unir dois nós para estudar a correlação das suas dimensões (Figura 22).

A Figura 23 ilustra o processo de criação de novos nós e a representação hierárquica da árvore. A criação de nós através da exploração de dimensões cria um novo nível na árvore tal que cada filho contém o mesmo espaço de dados do nó pai, mas cuja projeção envolve somente as dimensões selecionadas. O parentesco de cada nó filho criado desta forma é caracterizado por linhas através da árvore. Por outro lado, filhos criados através da seleção de um subconjunto de dados do espaço visual mostram a projeção destes dados com todas as dimensões do pai; esta relação é representada por setas na visualização.

A principal contribuição dessa ferramenta consiste no fato do usuário poder explorar hierarquicamente os dados e analisar como as dimensões influenciam na relação entre instâncias. No entanto, apesar da ferramenta conter algoritmos de agrupamento e possibilitar a seleção 
Figura 22 - Exploração de subespaços de dimensões. Dimensões A a E (esquerda) foram separadas em três grupos (centro) e depois reagrupadas em dois grupos (direita).

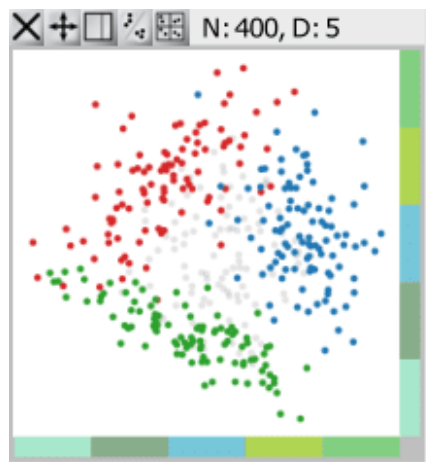

$(A, B, C, D, E)$

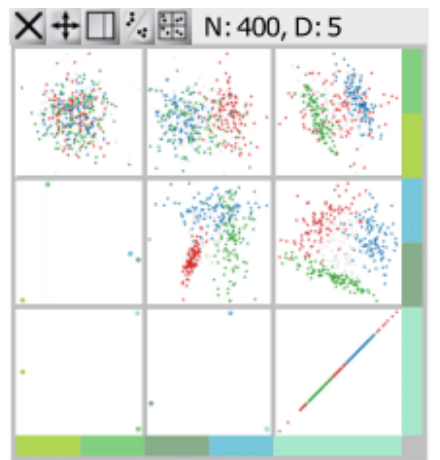

$(A, B) \quad(D, E) \quad(C)$

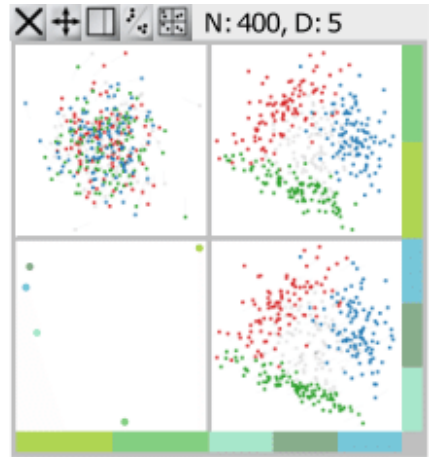

$(A, B) \quad(C, D, E)$

Fonte: Yuan et al. (2013).

manual de grupos, esta não apresenta medidas ou metáforas para explicar as características observadas e/ou porquê um grupo se difere do outro.

Brushing Dimensions é uma ferramenta semelhante a Dimension Projection proposta por Turkay, Filzmoser e Hauser (2011) para exploração de dimensões. Apesar de não possuir uma estrutura hierárquica de visualização, esta dispõe de maior variedade de métricas e medidas estatísticas para análise dos dados. O usuário dispõe de uma série de transformações $f$ e $s$ para explorar tanto o espaço de dados quanto o espaço de dimensões, respectivamente. Tais transformações reduzem o espaço visual em um scatterplot contendo a projeção dos dados sobre duas das medidas selecionadas. Na teoria, quaisquer transformações podem ser utilizadas, sujeitas a necessidade do usuário e aos tipos de dados analisados. Sugestões de transformações são propostas na Tabela 2.

Tabela 2 - Transformações de dados $f$ e dimensões $s$.

\begin{tabular}{|c|c|c|}
\hline Análise & $f$ & $S$ \\
\hline $\begin{array}{l}\text { Redução de dimensionalidade } \\
\text { não-supervisionado }\end{array}$ & $\begin{array}{l}\text { Principal Component Analy- } \\
\text { sis (PCA) (JOLLIFFE, 1986), } \\
\text { MDS (COX; COX, 2000) }\end{array}$ & $\begin{array}{l}\text { Média, variância, obliquidade, } \\
\text { curtose, IQR (FUKUNAGA, } \\
\text { 1990) }\end{array}$ \\
\hline $\begin{array}{l}\text { Redução de dimensionalidade } \\
\text { supervisionado }\end{array}$ & SVM (BURGES, 1998) & $\begin{array}{l}\text { Variância, teoria da informa- } \\
\text { ção (GUYON; ELISSEEFF, } \\
\text { 2003) }\end{array}$ \\
\hline Agrupamento & $\begin{array}{l}\text { DBSCAN (ESTER et al., } \\
\text { 1996), K-means (HARTI- } \\
\text { GAN; WONG, 1979) }\end{array}$ & $\begin{array}{l}\text { Média, variância, mediana, } \\
\text { IQR }\end{array}$ \\
\hline
\end{tabular}

Fonte: Adaptada de Turkay, Filzmoser e Hauser (2011).

Dessa maneira, é possível a criação de diversas projeções com diferentes relações para análise dos dados. Todos os scatterplots são conectados de modo que seleções e alterações em 
Figura 23 - Criação de nós de dados (acima) e de dimensão (abaixo) na árvore.
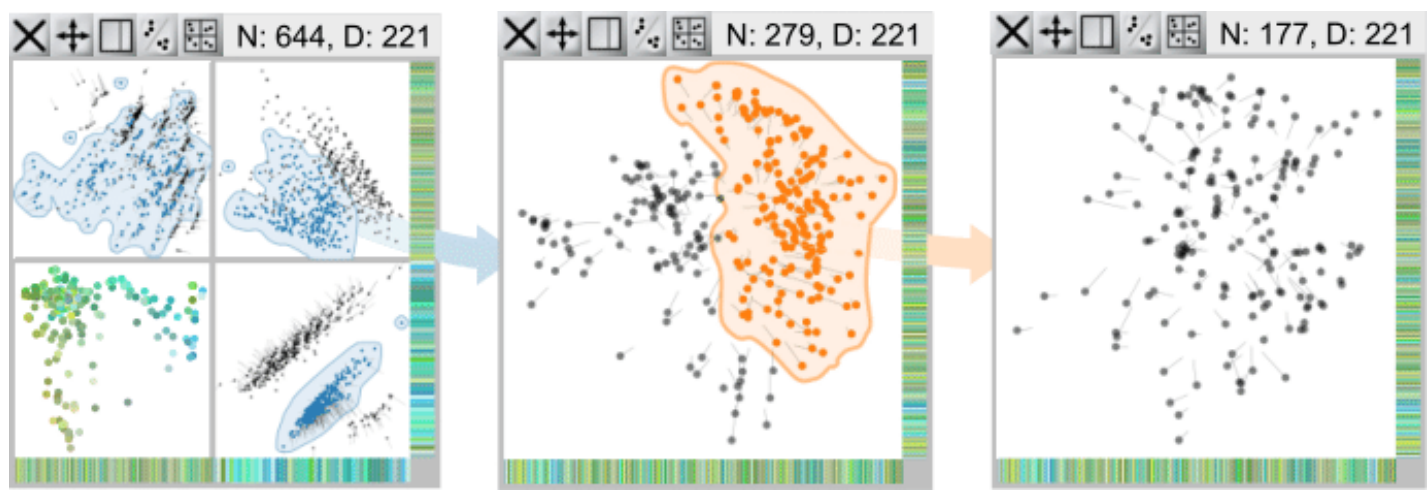

(a) Subgrupo de dados.
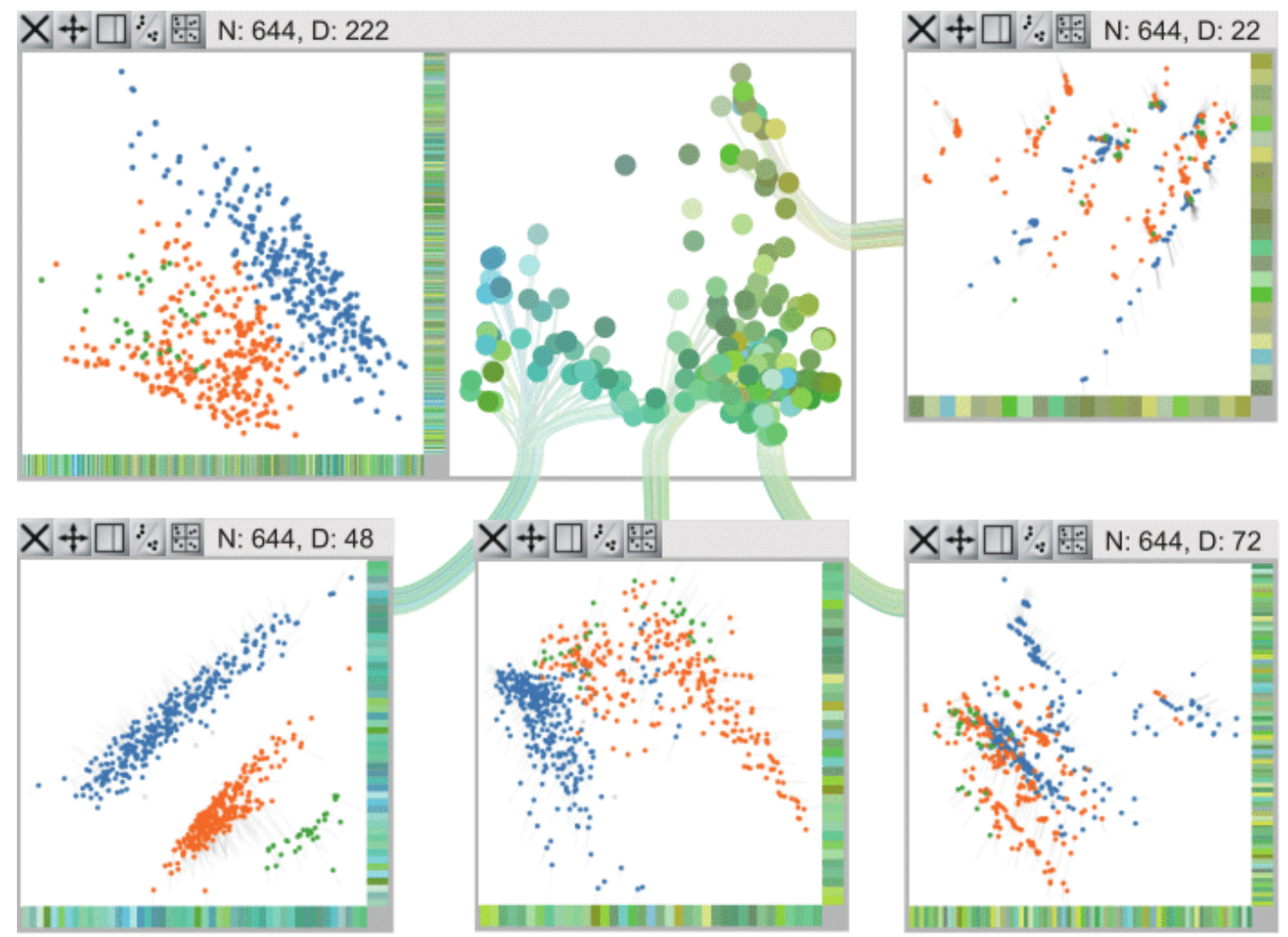

(b) Subgrupo de dimensões.

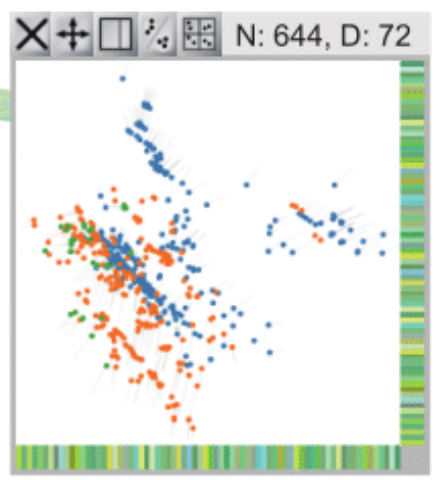

Fonte: Yuan et al. (2013).

um são visíveis e aplicadas as demais. Um exemplo de aplicação desta técnica está ilustrada na Figura 24, cujo foco é o estudo das dimensões CR e MV de um conjunto de dados. Três scatterplots $\mathrm{S}_{1}, \mathrm{~S}_{2}, \mathrm{~S}_{3}$ são visualizados nas Figuras 24(a), 24(b), 24(c), respectivamente, mostrando a relação entre as duas dimensões (CR vs. $\mathrm{MV})$, as duas componentes principais $\left(\mathrm{PC}_{1}\right.$ vs. $\mathrm{PC}_{2}$ ) e a relação entre média e desvio padrão ( $\mu$ vs. $\sigma$ ) de todas as dimensões do conjunto de dados, respectivamente. A análise começa com o usuário selecionando uma região de interesse em $S_{1}$ (Figura 24(d)). Valores aplicados a dimensões como média e desvio padrão são atualizados para os pontos selecionados (Figura 24(e)). Tais valores decorrentes da seleção são mostrados em laranja, enquanto que valores antigos referentes a todo o conjunto de dados permanecem na 
projeção como referência. Uma linha conecta as dimensões para identificar como o conjunto de dados selecionados influenciou na projeção. Na Figura 24(d) é possível observar que algumas dimensões não sofreram tanta variação após a seleção, e uma justificativa pode se dar ao fato destas dimensões serem menos sensíveis a valores fora da média de MV e CR. O usuário pode explorar tal comportamento selecionando tais dimensões (Figura 24(f)). Da mesma forma que as dimensões são atualizadas quando uma seleção acontece no espaço de dados, PCA é aplicada para as instâncias utilizando somente as dimensões selecionadas em $\mathrm{S}_{2}$. O impacto da análise pode ser visto na Figura 24(g), que mostra a projeção das dimensões selecionadas (em laranja) e de todas as dimensões (em cinza), além da identificação de dois grupos em relação a PC $_{1}$.

Figura 24 - Exemplo de análise proposta em Brushing Dimensions

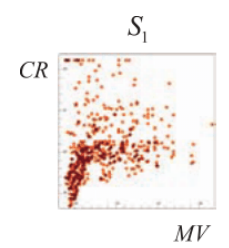

(a)

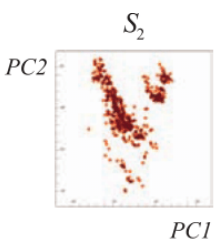

(b)

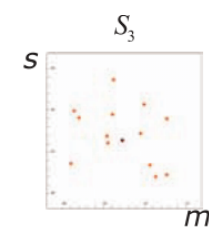

(c)

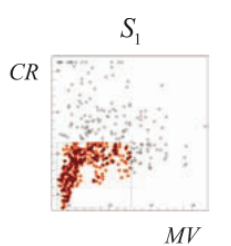

(d)

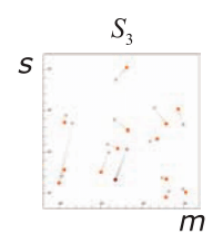

(e)

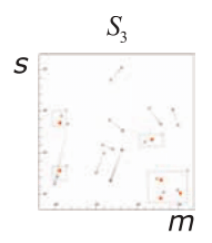

(f)

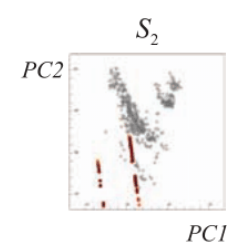

(g)

Fonte: Turkay, Filzmoser e Hauser (2011).

Apesar dessa ferramenta possuir alto nível de exploração estatística e ser um dos trabalhos cujos paradigmas apresentam maior similaridade com este projeto, Brushing Dimensions dispõe de metáforas visuais e análises diferentes as propostas neste trabalho de mestrado, uma vez que temos por meta explorar os dados em função da projeção multidimensional de todas as dimensões simultaneamente em uma única visualização principal. Uma desvantagem de Brushing Dimensions consiste no fato de que a ferramenta foi proposta para interação do usuário e o estudo de dimensões específicas, de modo que a análise é feita observando duas dimensões e as suas influências sobre as demais. Logo, são necessário diversos scatterplots para uma análise geral dos dados e de todas dimensões. A ideia da análise dual entre dados e dimensões, no entanto, pode ser aplicada e estendida para outras técnicas de visualização, como coordenadas paralelas e séries temporais, conforme ilustrado na Figura 25.

\subsection{Considerações Finais}

Neste capítulo foram apresentados alguns dos principais trabalhos relacionados às áreas de visualização multidimensional na Web e projeções multidimensionais, assim como alguns conceitos e ferramentas de programação Web que foram utilizados neste projeto de mestrado. Também foram expostos alguns trabalhos que propõem métricas e metáforas para análise de atributos, a fim de auxiliar na exploração das dimensões em conjunto com os dados projetados.

O número de trabalhos e serviços voltados à Internet tem aumentado com o avanço da capacidade de transferência de dados e de processamento dos navegadores Web. Neste cenário, a 
Figura 25 - Estensões de análise de atributos para coordenadas paralelas (a) e séries temporais (b).

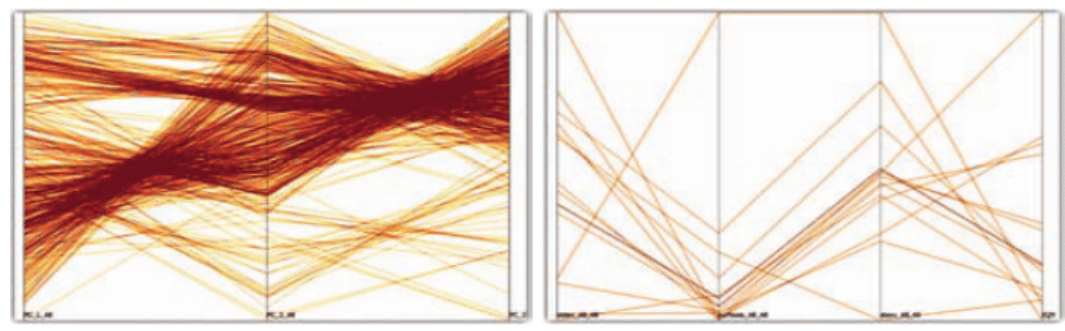

(a) As três coordenadas principais são mostradas para o espaço de dados, enquanto que medidas como $\sigma$, obliquidade, curtose e IQR são mostradas em cada eixo para o espaço de dimensões.
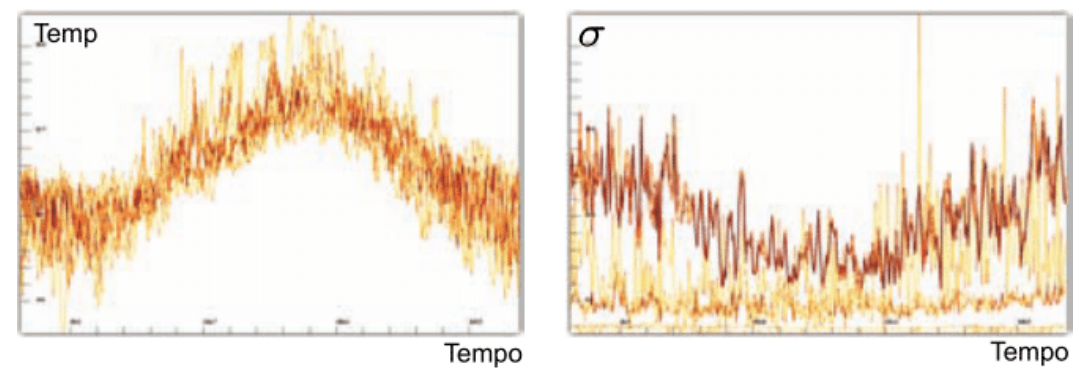

(b) Serie temporal do dado Temp (esq.). Variações de medidas podem ser mostradas ao longo do tempo para cada dimensão (dir.).

Fonte: Turkay, Filzmoser e Hauser (2011).

visualização de dados evoluiu proporcionalmente, uma vez que foram disponibilizadas novas ferramentas para depuração e criação de gráficos. Com a programação Web como uma alternativa, muitos trabalhos propondo novas técnicas de visualização foram disponibilizados ou até mesmo exclusivamente implementados para Web, devido à facilidade de divulgação, estudo e uso da nova técnica.

A importância e demanda de análise de arquivos de muitas dimensões têm proporcionado maior interesse em mostrar estas dimensões e como elas se relacionam entre si. No entanto, apesar da parcela de trabalhos relacionados a projetos de visualização multidimensional ter ganhado espaço, esta área ainda não possui tanto destaque quando comparado a trabalhos de visualização relacionados a grafos, fluidos, análise de documentos e processamento de imagem.

Apesar de ajudar a relacionar instâncias similares e na identificação de grupos e padrões, técnicas de projeção multidimensional podem não ser suficientes para uma análise mais profunda dos dados, dependendo do objetivo da visualização e dos dados coletados. Trabalhos recentes criaram ferramentas que auxiliam na análise de dados projetados, através da visualização de informações como distribuição e variância, assim como métodos para detecção de ruídos, tendências e grupos dos dados. 


\section{3}

\section{ANÁLISE DE DADOS BASEADA EM ATRIBUTOS}

\subsection{Considerações Iniciais}

No Capítulo 2 foram apresentados alguns trabalhos do estado da arte envolvendo análise de dimensões e projeções na exploração de dados multidimensionais. No entanto, apesar de tais trabalhos proporem diferentes métodos de exploração, perguntas como "por que tais grupos foram formados?" ou “como determinado atributo se comporta na projeção?" não são diretamente respondidas. Além disso, o fluxo de explorações de alguns casos de testes mostrados nestes trabalhos não se mostraram diretos nem óbvios, sugerindo que as conclusões obtidas pelas respectivas ferramentas podem não ser tão triviais de serem obtidas como apresentado.

Dentro deste contexto, neste capítulo são apresentadas as metáforas visuais propostas neste trabalho de mestrado, desenvolvidas para responder as perguntas citadas acima, assim como outras ferramentas implementadas para ajudar o usuário a explorar os dados de diferentes maneiras em diferentes cenários. A Seção 3.2 introduz as definições e nomenclaturas utilizadas ao longo de todo capítulo. Em seguida, as metáforas para auxiliar na análise dos dados projetados são apresentadas com maiores detalhes na Seção 3.3. A primeira delas consiste na detecção dos atributos mais relevantes para a proximidade dos pontos em cada região da projeção. Dessa maneira, é possível detectar os principais atributos responsáveis pela similaridade e dissimilaridade de certos pontos no espaço. A segunda métrica, derivada da primeira, ajuda a compreender qual o impacto de cada atributo em toda a projeção, mostrando sua relevância pela opacidade de cada região. A última métrica consiste da visualização de artefatos para análise estatística de uma determinada região, com informações como distribuição, média e variância de cada dimensão. Um algoritmo de agrupamento, proposto para auxiliar na identificação de estruturas com similaridade de variância, é proposto na Seção 3.4. Por fim, a Seção 3.5 contém a descrição das demais ferramentas disponíveis ao usuário. 


\subsection{Definições e Notação}

Nesta seção são apresentadas algumas definições sobre os pontos no espaço original e visual, para padronizar o uso de certos termos no decorrer do capítulo. Seja $\mathbf{x}_{i}=\left[x_{i, 1}, x_{i, 2}, \cdots, x_{i, m}\right]$ um ponto $m$-dimensional no espaço Euclidiano $\mathbb{E}^{m}$. O conjunto de dados formado por $n$ pontos $U=\left\{\mathbf{x}_{1}, \mathbf{x}_{2}, \cdots, \mathbf{x}_{n}\right\}$ pode ser representado por uma matriz $\mathbf{U}_{n \times m}$ tal que cada linha caracteriza uma instância $\mathbf{x}_{i}, 1 \leq i \leq m$. Denotando cada coluna $\mathbf{C}(\mathbf{U}, \mathbf{d})$ como o valor do atributo $d \in[1, n]$ observada em todos os elementos de $\mathbf{U}$, isto é

$$
\mathbf{C}(\mathbf{U}, \mathbf{d})=\left[x_{1, d}, x_{2, d}, \cdots, x_{n, d}\right],
$$

tem-se que

$$
\mathbf{U}=\left[\begin{array}{llll}
{[\mathbf{C}(\mathbf{U}, \mathbf{1})]} & {[\mathbf{C}(\mathbf{U}, \mathbf{2})]} & \cdots & {[\mathbf{C}(\mathbf{U}, \mathbf{m})]}
\end{array}\right]=\left[\begin{array}{cccc}
x_{1,1} & x_{1,2} & \cdots & x_{1, m} \\
x_{2,1} & x_{2,2} & \cdots & x_{2, m} \\
\vdots & \vdots & \ddots & \vdots \\
x_{n, 1} & x_{n, 2} & \cdots & x_{n, m}
\end{array}\right]
$$

A transformação ou função $T(U): U \rightarrow V$, aplicada por uma técnica de projeção multidimensional, tem como princípio reduzir os dados para o espaço visual $V \subseteq \mathbb{E}^{2}$ tal que cada ponto $\mathbf{x}_{\mathbf{i}}$ seja representado por um ponto $\mathbf{p}_{\mathbf{i}} \in V$ preservando a relação de vizinhança original. $\mathrm{O}$ conjunto $V$ pode ser representado por uma matriz $\mathbf{V}_{n \times 2}$ :

$$
\mathbf{V}=\left[\begin{array}{cc}
p_{1,1} & p_{1,2} \\
p_{2,1} & p_{2,2} \\
\vdots & \vdots \\
p_{n, 1} & p_{n, 2}
\end{array}\right]
$$

Seja $R_{i} \subseteq V$ um conjunto de pontos projetados no espaço visual. Este conjunto pode ser definido através da seleção individual destes pontos ou de regiões da projeção, conforme ilustrado na Figura 26. Mais precisamente, uma região $R_{i} \subseteq V$, tal que $\bigcup_{i} R_{i}=V$, é qualquer particionamento ou subespaço da projeção sobre a qual serão aplicadas análises visuais e estatísticas. Uma região pode ser definida, por exemplo, por meio de algoritmos de particionamento ou pela seleção manual de subespaços da projeção pelo usuário. No entanto, a aplicação implementada neste trabalho se baseia, inicialmente, em regiões formadas por uma grade regular $G_{w \times h}$ (Figura 27), semelhante à proposta por Kandogan (2012). Esta abordagem se justifica devido à necessidade de analisar o por quê de pontos serem projetados próximos uns aos outros em situações em que grupos não são claramente estabelecidos na projeção. Logo, uma região mínima de vizinhança foi implementada na forma de regiões uniformes na projeção. Neste caso, cada célula $C_{i, j} \in G$ de tamanho $r$ é um grupo individual $c_{i, j}$ (ou simplesmente $c_{i}$ ), fornecendo diferentes informações sobre as instâncias $\mathbf{p}_{j} \in c_{i}$ contidas em cada célula. Um ponto $\mathbf{p}_{j}$ pertence a uma célula $c_{i}$ se as coordenadas $p_{j, 1}, p_{j, 2}$ no espaço visual foram projetadas dentro de $c_{i}$ no espaço visual. 
Figura 26 - Regiões da projeção.

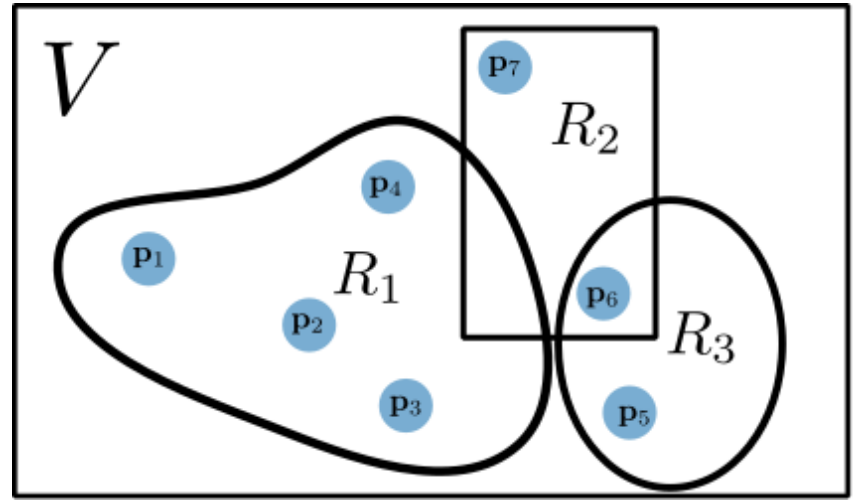

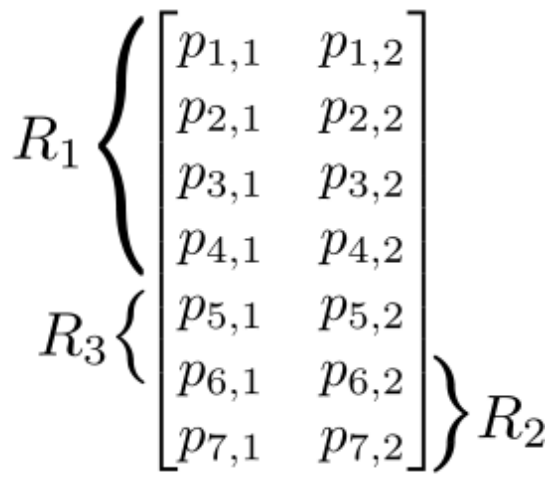

Fonte: Elaborada pelo autor.

A cardinalidade $\left|c_{i}\right|$ de uma célula é determinada pelo número de pontos contidos na célula. Uma célula $c_{i}$ é considerada não significativa se $\left|c_{i}\right|<\varepsilon$, sendo $\varepsilon$ um parâmetro especificado pelo usuário para descartar células com poucas informações ou com possíveis ruídos. Para os conjuntos de dados utilizados como experimentos de teste e validação (ver Capítulo 4), o autor achou suficiente (de forma empírica), utilizar $\varepsilon=3$ para descrever as células com ruídos. $O$ número de células não significativas define a cardinalidade efetiva $|G|$ da grade.

Figura 27 - Grade construída sobre o retângulo envolvente da projeção. Cada célula $c_{i}$ é uma região de análise da projeção.

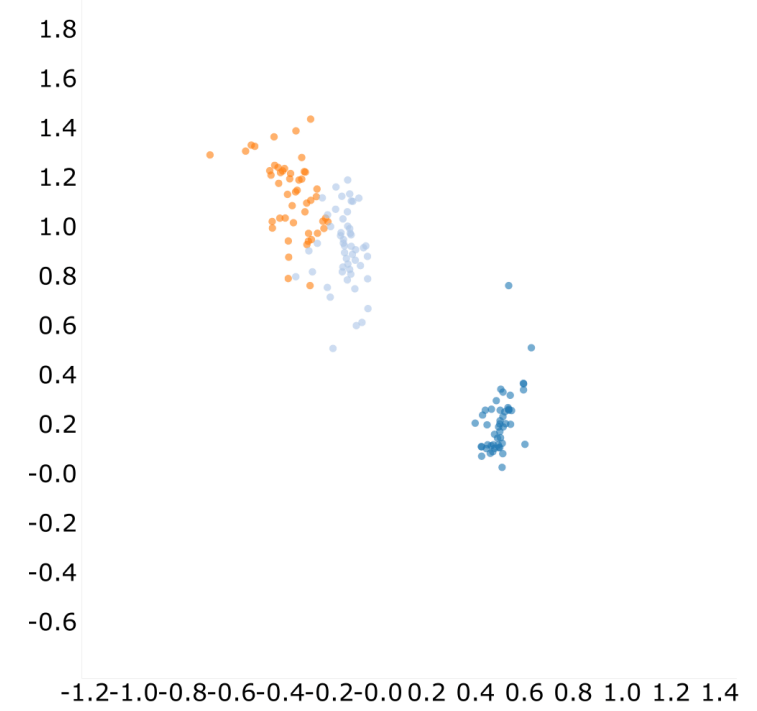

(a) Projeção dos pontos.

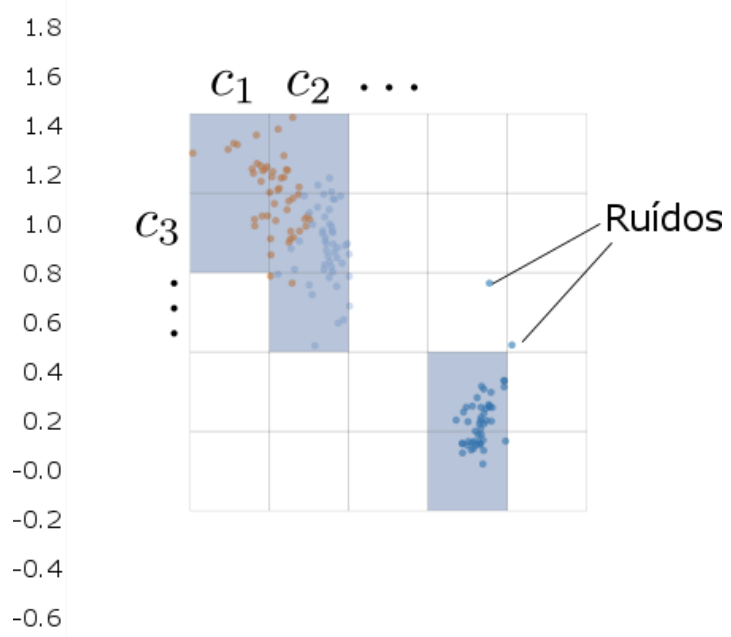

-1.2-1.0-0.8-0.6-0.4-0.2-0.00.2 0.40 .60 .81 .01 .21 .4 (b) Grade uniforme.

Fonte: Elaborada pelo autor. 


\subsection{Metáforas Baseadas em Atributos}

Dados a distribuição dos pontos no espaço 2D determinados por uma projeção multidimensional e a identificação de grupos e ruídos por algoritmos específicos ou pela percepção humana, perguntas importantes que podem surgir no decorrer do processo de análise destas estruturas são: quais são os principais atributos responsáveis pela similaridade dos pontos em uma região? Quais são os atributos que mais influenciam para a formação de um grupo? Qual o impacto de um atributo em toda a projeção? Pensando nisso, três metáforas visuais foram propostas para auxiliar na respostas a essas perguntas.

Sejam duas instâncias $\mathbf{x}_{i}, \mathbf{x}_{j} \in \mathbb{E}^{m}$ projetadas próximas uma das outras nos pontos $\mathbf{p}_{i}, \mathbf{p}_{j}$ no espaço visual $V$, respectivamente. Como a similaridade entre eles é comumente representada por alguma medida de distância, $\mathbf{x}_{i}$ e $\mathbf{x}_{j}$ devem possuir um ou mais atributos semelhantes, cujas similaridades influenciaram para a proximidade em $V$. Definimos o módulo da diferença entre os atributos $i \in[1, m]$ de dois pontos como a relevância (contribuição) de $i$ para a proximidade dos mesmos. Logo, quanto menor tal diferença, mais relevante o atributo. Vale a pena comentar que outras medidas poderiam ser atribuídas como relevância, como por exemplo o quadrado da diferença dos atributos. No entanto, como queria se estabelecer uma conexão entre os atributos de um ponto e a similaridade deste com seus vizinhos, o módulo da diferença se mostrou uma medida mais simples, porém suficiente para mostrar essa relação. Considere, por exemplo, os pontos $\mathbf{x}_{i}=[3.5,4.0,5.6,7.3], \mathbf{x}_{j}=[3.2,4.0,3.6,2.3]$ e $\mathbf{x}_{l}=[3.3,4.5,3.3,7.6]$. Logo, os vetores de relevância entre estes pontos são definidos por $\mathbf{R}_{i, j}=[0.3,0.0,2.0,5.0]$, $\mathbf{R}_{i, l}=[0.2,0.5,2.3,0.3]$ e $\mathbf{R}_{j, l}=[0.1,0.5,0.3,5.3]$. Pode-se concluir, portanto, que na média, a segunda e a primeira dimensão são as mais relevantes para a similaridade entre os pontos $\mathbf{x}_{j}, \mathbf{x}_{i} \mathrm{e}$ $\mathbf{x}_{l}$, respectivamente.

Para cada célula significativa de $G$ é atribuída uma cor, representando a dimensão mais relevante desta região. Logo, para dados $m$-dimensionais, existem $m$ diferentes cores disponíveis tomadas de uma determinada paleta $t$, de tal modo que cada cor $t_{i}$ represente a $i$-ésima dimensão. No entanto, para dados de dimensões consideradas altas ( $m \geq 12$, de acordo com Ware (2004)), $t$ pode não ter cores visualmente distintas para representar todas as dimensões adequadamente, dificultando a identificação de atributos na visualização.

O processo de identificação da dimensão mais relevante (DMR) de cada célula $c_{i}$ é realizado como se segue. Para cada ponto $\mathbf{p}_{j} \in c_{i}$ é computado o conjunto $K_{\mathbf{p}_{j}}$ dos seus $k$ pontos vizinhos originais mais próximos, dentro de um raio de influência $f r, f \in \mathbb{R}^{+}$, dado em função do tamanho da célula. Esse processo pode ser otimizado aplicando o algoritmo $k$ NN (CUNNINGHAM; DELANY, 2007) apenas nas células vizinhas de $c_{i}$. Uma vez calculados, as relevâncias de cada um dos $k$ vizinhos de $\mathbf{p}_{\mathbf{j}}$ são somadas atributo a atributo, gerando apenas um vetor de relevâncias $\mathbf{P}_{j}$ (Figura 28), conforme a Equação 3.2.

$$
\mathbf{P}_{j}=\sum_{\mathbf{p}_{k} \in K_{p_{j}}} \mathbf{R}_{j, k}
$$


Figura 28 - Relevância de uma célula.

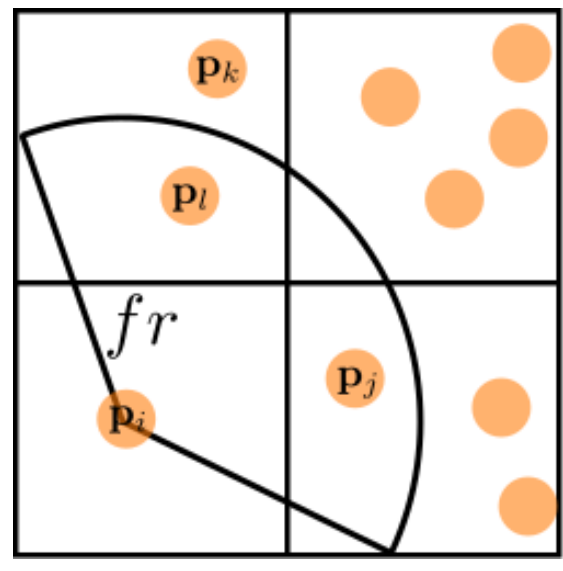

$$
\begin{aligned}
& \mathbf{R}_{i, j}=[0.3,0.0,2.0,5.0] \\
& \mathbf{R}_{i, l}=[0.2,0.5,2.3,0.3] \\
& \mathbf{P}_{i}=[0.5,0.5,4.3,5.3]
\end{aligned}
$$

Fonte: Elaborada pelo autor.

O processo se passa para todos os pontos da célula. No final, o vetor $\mathbf{C}_{i}$ com a média da soma das relevâncias de todos os pontos é atribuído à célula $c_{i}$ :

$$
\mathbf{C}_{i}=\sum_{\mathbf{p}_{j} \in c_{i}} \mathbf{P}_{j} /\left|c_{i}\right|
$$

A primeira metáfora proposta utiliza o vetor de relevâncias de cada célula para classificar os atributos mais importantes para a similaridade dos seus pontos. Dessa forma, é possível observar qual o impacto de cada atributo na projeção, e como estes influenciam ou não a formação de grupos, tendências e ruídos.

Todos os atributos foram classificados por ordem de relevância, de modo que o usuário possa verificar, por exemplo, qual o segundo ou terceiro atributo mais relevante em cada região. A análise das últimas posições do ranking mostra qual são os atributos que mais ajudaram na separação dos pontos. Uma observação importante consiste no fato de que a relevância de uma região, como proposta neste trabalho, está diretamente relacionada com a distância Euclidiana dos atributos em cada ponto. Caso alguma técnica de projeção utilize outra medida de similaridade, a relevância pode não representar corretamente as estruturas observadas na projeção. No entanto, outras métricas podem ser formuladas, sem perda de generalidade.

A Figura 29 ilustra um exemplo da relevância em um conjunto de dados com três dimensões, identificadas em ordem pelas cores vermelho, verde e azul. Analisando cada região (representadas, por simplicidade, por células da grade), o usuário pode entender como os atributos se comportam na projeção. As Figuras 29a, 29b, 29c mostram o primeiro, segundo e terceiro principal atributo responsável pela similaridade dos pontos em cada região, respectivamente. $\mathrm{O}$ segundo atributo (verde) é o mais relevante em toda a projeção, seguido pelo primeiro atributo (vermelho). A dimensão identificada pela cor azul é importante para classificar apenas duas regiões da projeção.

A segunda metáfora proposta, decorrente da primeira, consiste em visualizar, selecionada uma dimensão pelo usuário, qual a relevância desta dimensão em toda projeção. De fato, esta 
Figura 29 - Primeira métrica visual para relevância de regiões da projeção.

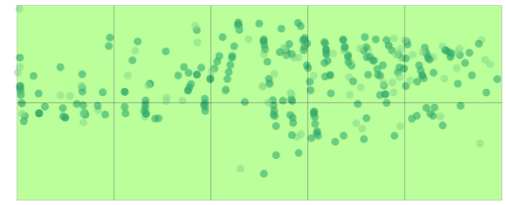

(a) Atributo mais relevante.

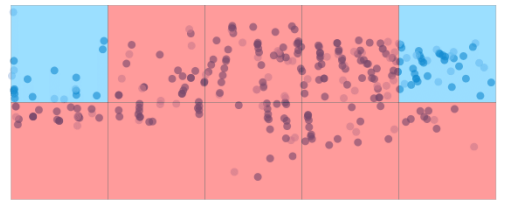

(b) Segundo atributo mais relevante.

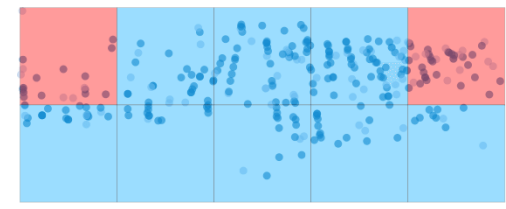

(c) Atributo menos relevante.

Fonte: Elaborada pelo autor.

é apenas outra forma de mostrar a relevância em cada célula, mas propõe expressamente uma forma de observar regiões onde um atributo tem maior ou menor impacto para a correlação dos pontos. Selecionada a $i$-ésima dimensão, todas células são desenhadas com a $i$-ésima cor, sendo a opacidade de cada célula $c_{i}$ proporcional à importância do atributo $i$ para $c_{i}$, conforme mostrado na Figura 30. Quanto mais transparente a célula, menor a contribuição da dimensão $n$ para a similaridade das instâncias naquele espaço, e quanto mais nítida a cor, maior a importância do atributo $n$ para a relevância dos pontos em $c_{i}$.

Figura 30 - Segunda métrica visual mostra a relevância de um atributo em toda a projeção.

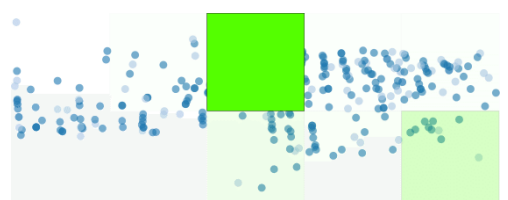

(a) Relevância do segundo atributo (verde) na projeção.

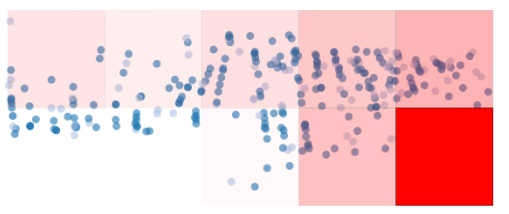

(b) Relevância do primeiro atributo (vermelho) na projeção.

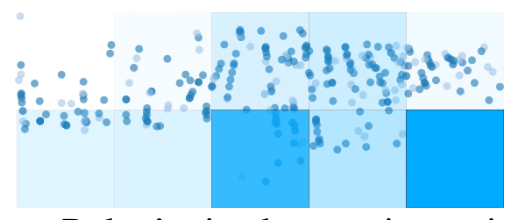

(c) Relevância do terceiro atributo (azul) na projeção.

Fonte: Elaborada pelo autor.

Uma aplicação direta dessas técnicas é exemplificada a seguir. Considerando um conjunto de dados contendo a descrição de carros produzidos por uma concessionária, o empresário ou cliente pode querer observar quais são os fatores que melhor descrevem cada tipo de carro. Uma vez projetados e identificados os grupos e estruturas formadas, o usuário poderia querer saber qual o atributo (por exemplo "preço") mais semelhante entre dois grupos distintos, ou em qual região o atributo "motor" foi mais relevante na projeção. Resultados envolvendo essas técnicas são descritos no Capítulo 4.

A terceira métrica proposta envolve a criação de artefatos visuais para a análise estatística de regiões e grupos na projeção, com o objetivo de ajudar o usuário a compreender como os pontos se comportam em cada dimensão em cada grupo. Seja $X=\left\{x_{1}, x_{2}, \cdots, x_{n}\right\}$ um conjunto finito de $|X|=n$ números reais. Supondo que $x_{i}$ sejam os valores de uma variável aleatória qualquer, a variância (populacional) de $X$ é:

$$
\operatorname{var}(X)=\frac{1}{|X|} \sum_{i=1}^{|X|}\left(x_{i}-M_{X}\right)^{2}
$$


em que $M_{X}=S_{X} /|X|$ é a média e $S_{X}=\sum_{i=1}^{|X|} x_{i}$ é a soma dos elementos de $X$. Desenvolvendo-se o lado direito da Equação 3.4, tem-se:

$$
\begin{gathered}
\frac{x_{1}^{2}-2 x_{1} M_{X}+M_{X}^{2}}{|X|}+ \\
\frac{x_{2}^{2}-2 x_{2} M_{X}+M_{X}^{2}}{|X|}+ \\
\vdots \\
\frac{x_{n}^{2}-2 x_{n} M_{X}+M_{X}^{2}}{|X|}= \\
\frac{x_{1}^{2}+x_{2}^{2}+\cdots+x_{n}^{2}}{|X|}-\frac{2 M_{X}\left(x_{1}+x_{2}+\cdots+x_{n}\right)}{|X|}+\frac{|X| M_{X}^{2}}{|X|}= \\
\left.\frac{1}{n} \sum_{i=1}^{|X|} x_{i}^{2}\right)-2 M_{X}^{2}+M_{X}^{2}= \\
\therefore \operatorname{var}(X)=\frac{Q_{X}}{|X|}-M_{X}^{2}=\frac{Q_{X}}{|X|}-\left(\frac{S_{X}}{|X|}\right)^{2}=\frac{|X| Q_{X}^{2}-S_{X}^{2}}{|X|^{2}},+M_{X}^{2} .
\end{gathered}
$$

em que $Q_{X}=\sum_{i=1}^{|X|} x_{i}^{2}$.

Para dois conjuntos disjuntos $X_{1}$ e $X_{2}$ da mesma variável aleatória, a variância da união dos conjuntos é:

$$
\operatorname{var}\left(X_{1} \cup X_{2}\right)=\frac{\left(\left|X_{1}\right|+\left|X_{2}\right|\right)\left(Q_{X_{1}}+Q_{X_{2}}\right)-\left(S_{X_{1}}+S_{X_{2}}\right)^{2}}{\left(\left|X_{1}\right|+\left|X_{2}\right|\right)^{2}}
$$

Generalizando-se a Equação 3.6 para $n$ conjuntos disjuntos, tem-se:

$$
\operatorname{var}\left(\bigcup_{i=1}^{n} X_{i}\right)=\frac{\sum_{i=1}^{n} \sum_{j=1}^{n}\left|X_{j}\right| Q_{X_{i}}-\left(\sum_{i=1}^{n} S_{X_{i}}\right)^{2}}{\left(\sum_{i=1}^{n}\left|X_{i}\right|\right)^{2}}
$$

Logo, assumindo $X_{d}=\mathbf{C}(\mathbf{U}, \mathbf{d})$ como o conjunto formado pelos valores de cada dimensão de uma região, valores estatísticos baseados em média e variância de cada atributo de uma região são rapidamente computados através da união dos respectivos valores de subregiões menores.

Neste contexto, o primeiro artefato consiste na representação das variâncias de um grupo por meio de um histograma, em que cada coluna do gráfico corresponde a uma dimensão dos dados, conforme ilustrado na Figura 31a. Neste exemplo, uma região está representada por uma célula da grade $G$. O usuário pode analisar a variância dos atributos localmente, em cada célula, ou globalmente, em função da união de uma ou mais células. A variância pode ser mostrada, ainda, em função da própria escala ou normalizada pela maior variância observada na projeção, como mostrado na Figura 31b. Dessa maneira, é possível analisar, distintivamente das métricas 
anteriores, diretamente quais são os conjuntos de atributos que mais caracterizam uma região ou grupo, e quais são os mais responsáveis pela dissimilaridade dos seus pontos. De fato, usando a distância Euclidiana utilizada na maioria das projeções, temos que a soma das distâncias $D$, no espaço original, entre os $k$ pontos $\mathbf{p}_{i} \in c$ de uma célula $c$ e seus respectivos vizinhos $K_{\mathbf{p}_{i}}$ é:

$$
\begin{aligned}
D & =\sum_{i=1}^{k} \sum_{j=1}^{\left|K_{\mathbf{p}_{i}}\right|} \sqrt{\left(x_{i 1}-x_{j 1}\right)^{2}+\left(x_{i 2}-x_{j 2}\right)^{2}+\cdots+\left(x_{i n}-x_{j n}\right)^{2}} \\
& \propto \sum_{i=1}^{k} \sum_{j=1}^{\left|K_{\mathbf{p}_{i}}\right|}\left|\left(x_{i 1}-x_{j 1}\right)\right|+\left|\left(x_{i 2}-x_{j 2}\right)\right|+\cdots+\left|\left(x_{i n}-x_{j n}\right)\right| \\
& \propto \sum_{i=1}^{k} \underbrace{\mid\left(x_{i 1}-\left(x_{11}+x_{21}+\cdots+x_{\left|K_{p_{i}}\right|} n\right) \mid\right.}_{\text {média } \bar{o}_{1}}+\cdots+\underbrace{\mid\left(x_{i n}-\left(x_{1 n}+x_{2 n}+\cdots+x_{\left.\left|K_{p_{i}}\right| n\right)}\right)\right.}_{\text {média } \bar{o}_{n}} \\
& \propto \sum_{i=1}^{k} \sum_{l=1}^{n} \underbrace{\mid\left(x_{i l}-\bar{o}_{l} \mid\right.}_{\propto \sigma_{l}} .
\end{aligned}
$$

Logo, a distância entre os pontos em uma projeção é diretamente proporcional à variância das dimensões destes pontos (MARTINS et al., 2012), de forma que quanto menor a variância entre seus atributos, maior a similaridade entre estas instâncias, e vice-versa.

O segundo artefato consiste na visualização da distribuição dos pontos de uma região por box-plots ou diagrama de caixa (Figura 32), ferramenta estatística que fornece informações como valor mínimo, médio, máximo, quartis e possíveis ruídos dos dados (WICKHAM; STRYJEWSKI, 2012). Um quartil é qualquer um dos três valores, nomeados inferior (Q1), mediana (Q2) e superior (Q3), que divide o conjunto ordenado de dados em quatro partes iguais. A diferença

Figura 31 - Variância das dimensões em diferentes regiões da projeção. Cada histograma contém um ponteiro, ilustrado por um pequeno retângulo preto, para que o usuário possa manipular e escolher o melhor posicionamento do histograma no espaço visual.

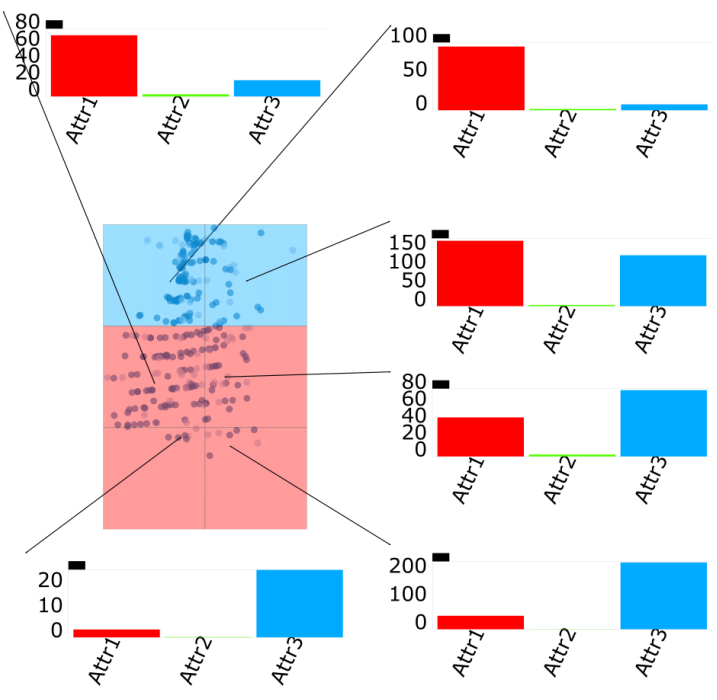

(a) Variância individual.

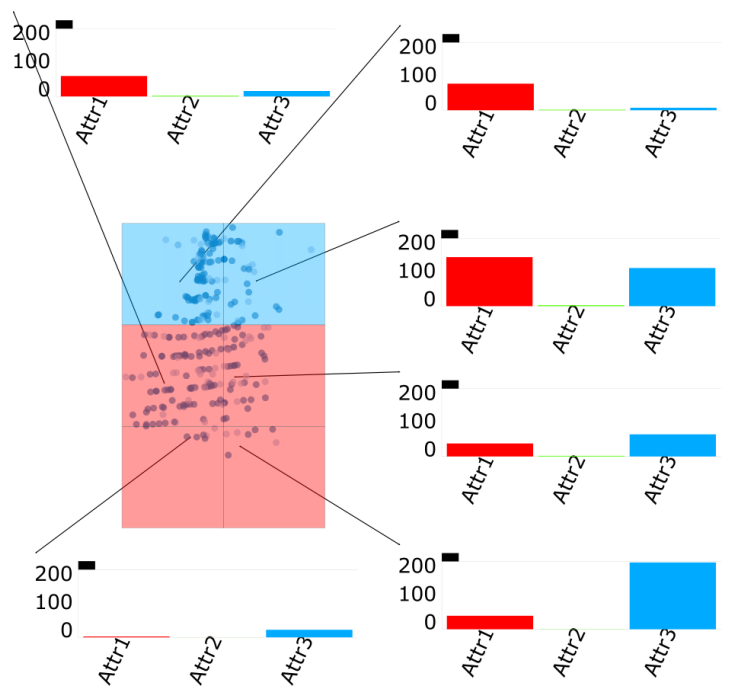

(b) Variância normalizada.

Fonte: Elaborada pelo autor. 
entre o terceiro e primeiro quartil chama-se amplitude interquartil ou Interquartile Range (IQR), e representa um intervalo esperado dos dados, abrangendo $50 \%$ do conjunto. Valores abaixo ou acima de $1.5 \times$ IQR do quartil inferior ou superior, respectivamente, são considerados ruídos, uma vez que estão muito esparsos em relação a maior concentração dos pontos e caracterizam instâncias atípicas do conjunto.

Figura 32 - Detalhes da distribuição de um conjunto de dados são mostrados.
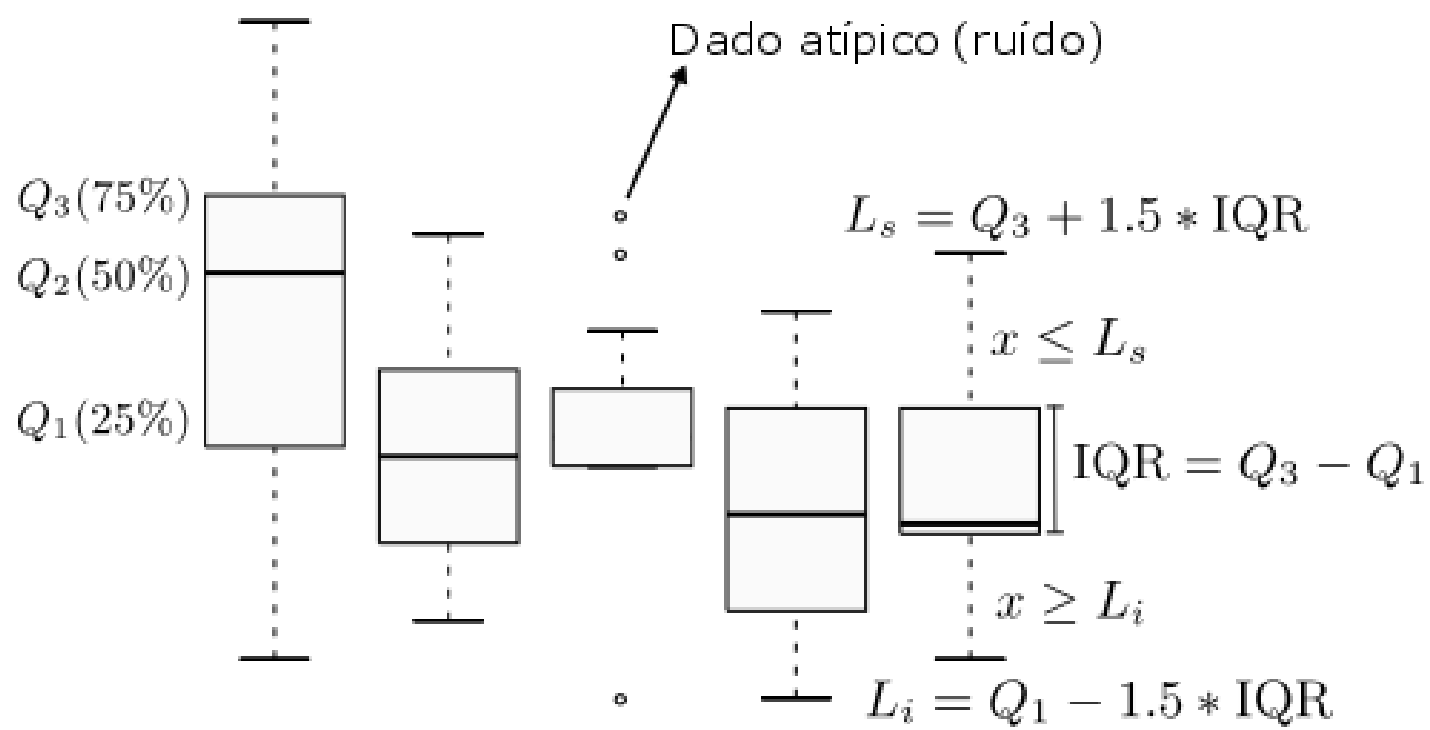

Fonte: Elaborada pelo autor.

Para cada dimensão é criado um diagrama de caixa descrevendo como cada atributo se comporta em uma região. Essa visualização possibilita uma rápida compreensão da distribuição de cada dimensão em cada grupo, além de facilitar a comparação de dimensões intra e entre grupos e a detecção de possíveis ruídos nos dados.

Foi implementada uma conexão entre ambas visualizações, conforme mostrado pela Figura 33, de modo que ao passar o mouse encima de uma dimensão no histograma, abre-se o artefato visual contendo os diagramas de caixas, mostrando os detalhes estatísticos de todas dimensões, e ao lado outras informações sobre o atributo selecionado, como por exemplo a linha da instância e o respectivo valor da dimensão de um ruído no arquivo de dados original, assim como valores detalhados de distribuição. $\mathrm{O}$ usuário também pode utilizar essas e as outras metáforas em diferentes tipos de regiões, como por exemplo, aquelas formadas por uma coleção de células ou por outros algoritmos de particionamento, para um estudo mais amplo ou detalhado da projeção.

\subsection{Agrupamento por Similaridade de Variância}

Como as metáforas visuais propostas baseadas na distribuição dos atributos de cada região mostraram-se úteis para analisar como os pontos se comportam na projeção (mais detalhes sobre 
Figura 33 - Detalhes da distribuição de uma dimensão. A análise foi feita sobre a região formada por todas as células da projeção.
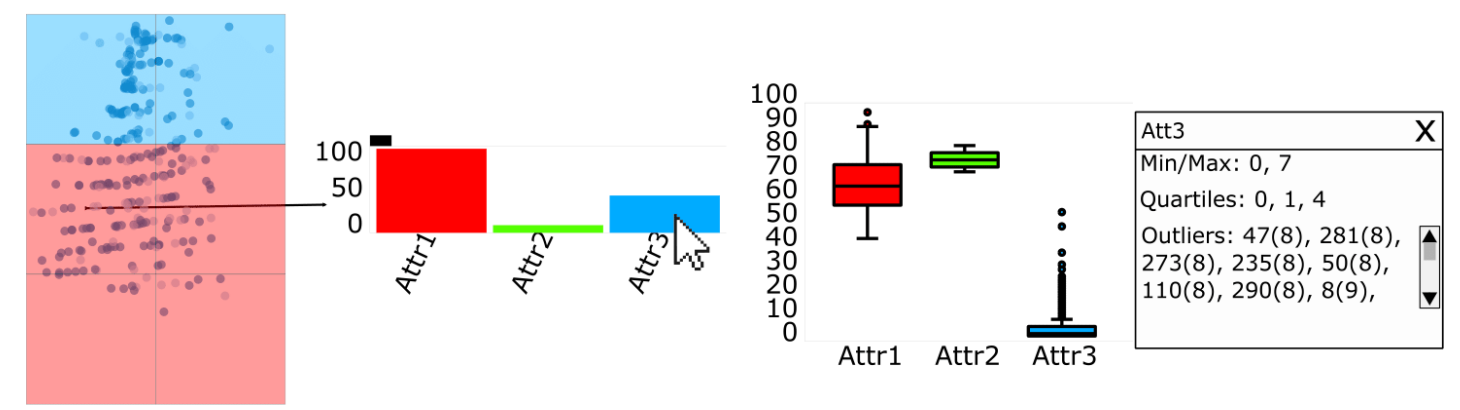

Fonte: Elaborada pelo autor.

os resultados no Capítulo 4), surgiu o interesse em desenvolver uma técnica de agrupamento com o mesmo estilo, baseado na variância dos atributos de uma região. A ideia consistia, inicialmente, em detectar a maior região de pontos com variância normalizada menor ou igual a $v \in[0,1]$, sendo $v$ uma parâmetro estipulado pelo usuário, conforme ilustrado na Figura 34. Dessa forma, o usuário poderia observar quais são os pontos mais similares na projeção, uma vez que quanto menor a variância de uma região, maior a relevância dos seus atributos. No entanto, essa abordagem possuía alguns problemas que dificultaram a sua implementação, comentados a seguir. Primeiro, a definição de $v$ como variância multidimensional de uma região teria que ser especificada. Dentre as possibilidades, incluindo a média das variâncias, autocorrelação, covariância, entre outras medidas, foi definida que a variância multidimensional de um conjunto de $m$ dimensões fosse dada pela maior variância da respectiva região. Segundo, a visualização deveria mostrar, intuitivamente, regiões contínuas com maiores e menores detalhes à medida que o usuário modificasse $v$, variando entre a região formada por todo o espaço visual até a menor região de tamanho mínimo aceitável na projeção.

Figura 34 - Ideia inicial de agrupamento por variância. A maior região consistia de toda projeção com variância máxima (esquerda). Regiões com instâncias mais similares eram formadas à medida que o usuário especificasse menores valores de variância (centro e direita).
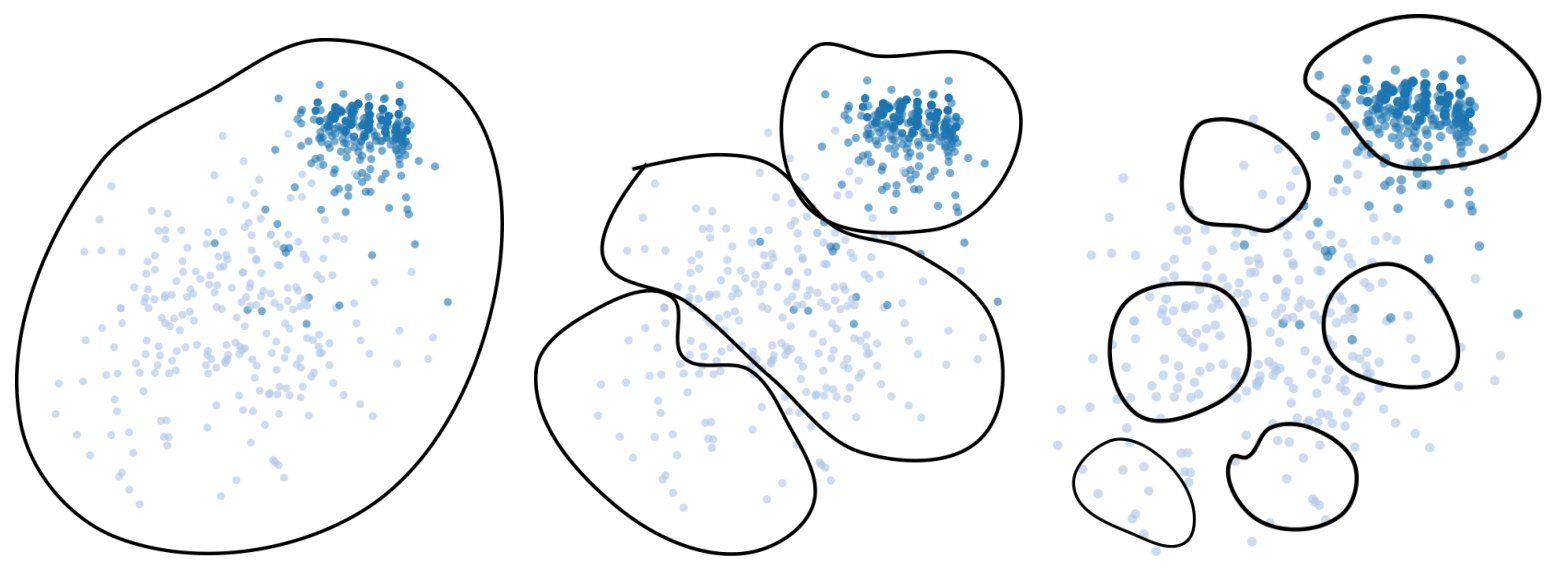

Fonte: Elaborada pelo autor. 
Contudo, a variância de um conjunto de pontos não reflete a área do conjunto analisado, e sim como um conjunto de pontos se afasta em relação à media dos pontos. A Figura 35 mostra um exemplo, em que a variância de uma região menor (A) pode ser maior ou igual à variância de uma região maior (B), dificultando o controle de variância global e local e a normalização do intervalo de valores de $v$. Por último, pelo fato da variância ser uma função não é crescente, isto é, a variância da união de dois conjuntos não ser necessariamente maior que a soma da variância destes conjuntos, o procedimento para encontrar a maior região cuja variância fosse menor ou igual a $v$ foi identificado como um problema de otimização NP-difícil (GAREY; JOHNSON, 1990), uma vez que seria necessário o cálculo de todas as combinações possíveis entre regiões. No decorrer desta abordagem, provou-se (apesar de não demonstrado neste texto) que este problema seria uma redução do problema da mochila 0-1 (PISINGER, 1995).

Figura 35 - A variância de um subconjunto de pontos pode ser maior que a variância de todo o conjunto.

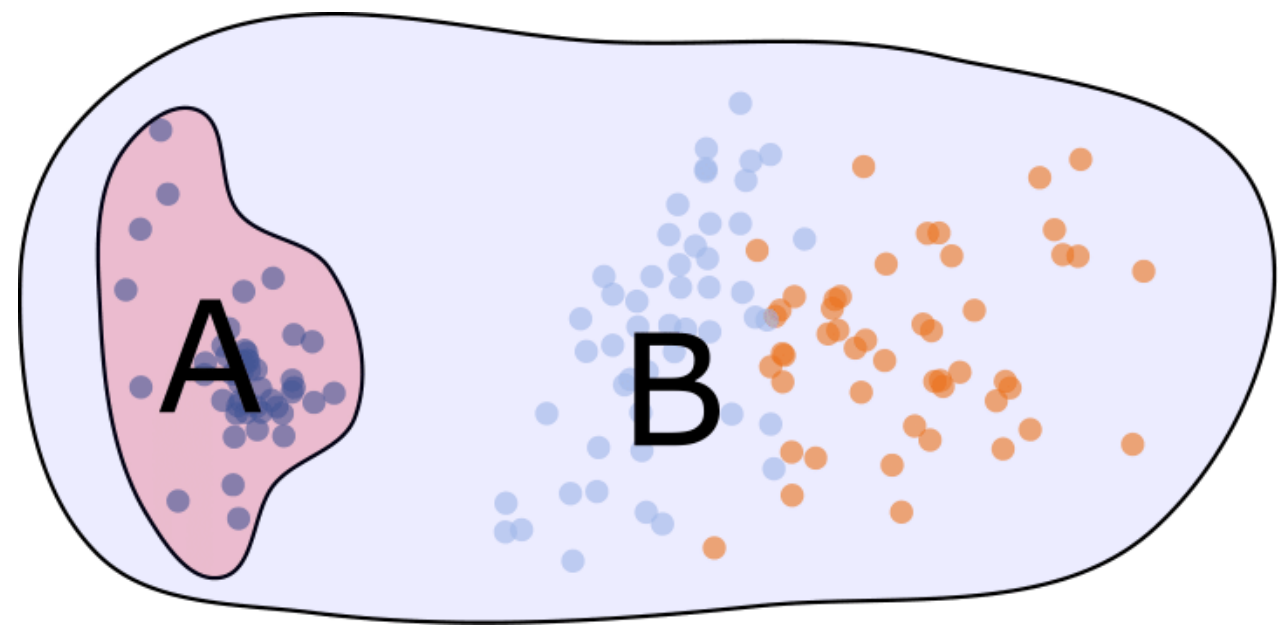

Fonte: Elaborada pelo autor.

Diferentes versões do modelo inicial foram analisadas e propostas, com novas medidas de variância, criação de algoritmos genéticos (GOLDBERG, 1989) para contornar a NP-completude do algoritmo, outras definições para $v$, não como um valor entre um intervalo mas como um fator de variedade de variância, entre outras. À medida que experimentos foram feitos, descobriram-se alguns problemas que dificultaram o avanço da técnica, como por exemplo, que a maior variância entre as dimensões poderia não representar pontos similares adequadamente, uma vez que as demais dimensões poderiam ser completamente diferentes entre duas instâncias, ou que não havia uma justificativa do por que duas células conexas representassem instâncias do mesmo grupo, caso a variância da união das mesmas não variasse muito em relação às variâncias individuais das células. $\mathrm{O}$ autor desse texto achou importante descrever tais tentativas de visualização, uma vez que podem representar alguma abordagem de pesquisa semelhante de algum leitor.

Logo, uma nova interpretação foi considerada. Definindo-se a variância multidimensional de uma célula $c_{i}$ como o vetor de variâncias de todas as $m$ dimensões dos seus pontos, isto é:

$$
\mathbf{v}_{\mathbf{i}}=\left[\sigma_{i, 1}, \sigma_{i, 2}, \cdots, \sigma_{i, m}\right]
$$


em que $\sigma_{i, d}=\operatorname{var}\left(\mathbf{C}\left(\mathbf{c}_{\mathbf{i}}, \mathbf{d}\right)\right)$, o algoritmo de agrupamento por similaridade de variância encontra regiões, não necessariamente conexas, cujas diferenças entre todas as variâncias não são maiores que uma distância máxima dada pelo usuário. Essa abordagem se mostrou mais adequada para comparação entre regiões, uma vez que todas as dimensões são utilizadas no cálculo de similaridade, conforme ilustrado na Figura 36. O algoritmo Density-Based Spatial Clustering of Applications with Noise (DBSCAN) (ESTER et al., 1996) foi utilizado para agrupar células cujas variâncias multidimensionais são consideradas similares pelo usuário. Assumindo cada vetor $\mathbf{v}_{\mathbf{i}}$ como um ponto no espaço $\mathbb{E}^{m}$, o DBSCAN agrupa subconjuntos de instâncias que estão próximas uma das outras até uma distância estipulada. Mais detalhes do algoritmo são descritos na Subseção 3.5.1. Utilizando a distância do cosseno como similaridade entre duas instâncias $\mathbf{v}_{\mathbf{i}}, \mathbf{v}_{\mathbf{j}}$, dada pela expressão $1-\mathbf{v}_{i} \cdot \mathbf{v}_{j} /\left(\left|\mathbf{v}_{i}\right|\left|\mathbf{v}_{j}\right|\right)$, o algoritmo se mostrou capaz de classificar, adequadamente, regiões com a mesma distribuição de variância, como descrito e exemplificado no Capítulo 4.

Figura 36 - Cada célula é representada por um vetor $m$-dimensional de variâncias. Cada vetor é visto como um ponto no espaço para o DBSCAN. Neste exemplo, $m=2$.
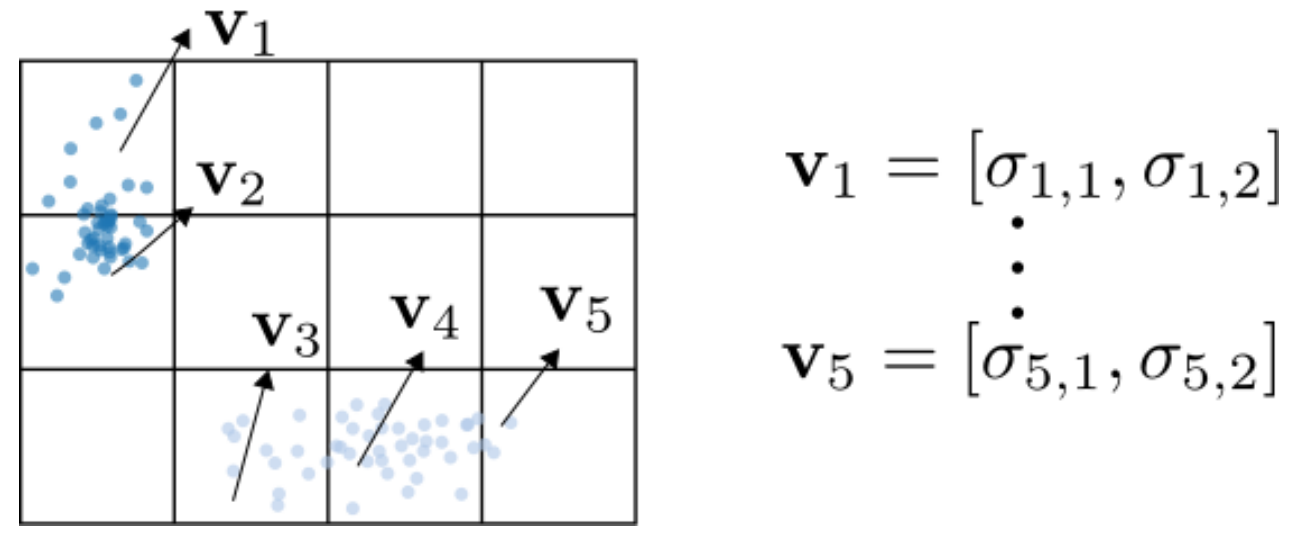

Fonte: Elaborada pelo autor.

O motivo pelo qual foi escolhido o DBSCAN dentre as técnicas de agrupamento foi porque este algoritmo não requer um parâmetro que indica o número de grupos a serem formados pelo usuário, como técnicas como k-means (HARTIGAN; WONG, 1979) e $k$-medoids (BERKHIN, 2006). Neste caso, foi proposto que o número de grupos a serem formados se dá em função do parâmetro $v$ (ou DBSCAN $\varepsilon$ ), pertencente ao intervalo definido pela maior e menor distância de células que definem $[|G|, 1]$ grupos na visualização, respectivamente. A Figura 37 ilustra a formação de grupos mais similares entre si, à medida que o usuário informa ao algoritmo uma nova distância do cosseno (no exemplo, uma distância menor) necessária para o agrupamento de regiões consideradas "próximas" uma das outras. Cada grupo é representado por uma cor aleatória. No caso daqueles formados por regiões de células, um grupo é caracterizado por células da mesma cor. A distância do cosseno foi utilizada pelo fato de melhor representar a similaridade entre vetores de variâncias (quando comparado à distância Euclidiana) de duas células diferentes, como mostrado na Figura 38. Deste modo, duas células são idênticas se seus 
Figura 37 - Formação de grupos com maior similaridade de variância. A maior distância encontrada agrupa todas células em um único grupo (a). À medida que o usuário diminui a distância de corte (b)-(c), instâncias mais similares são agrupadas, até o caso onde $|G|$ são formados (d).

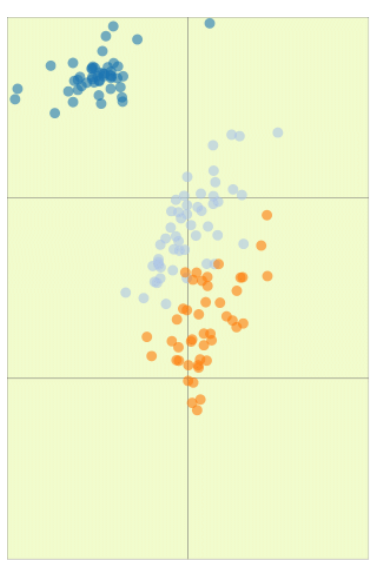

(a) 0.3617 .

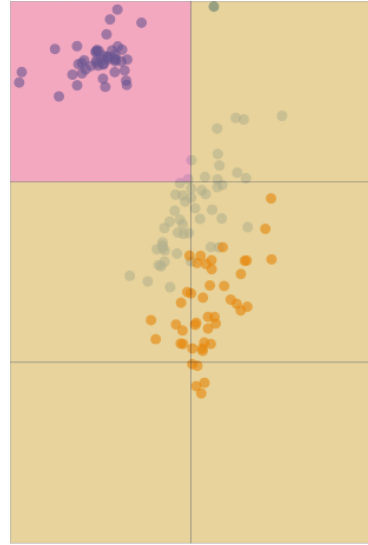

(b) 0.1196 .

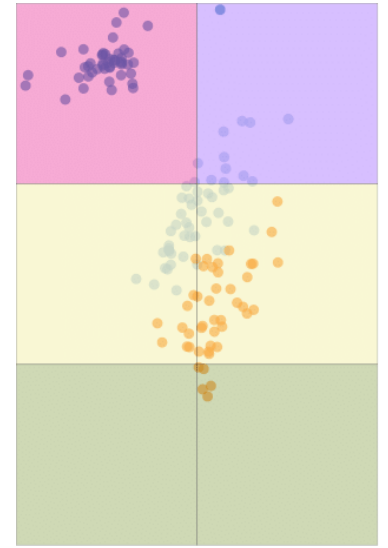

(c) 0.0127 .

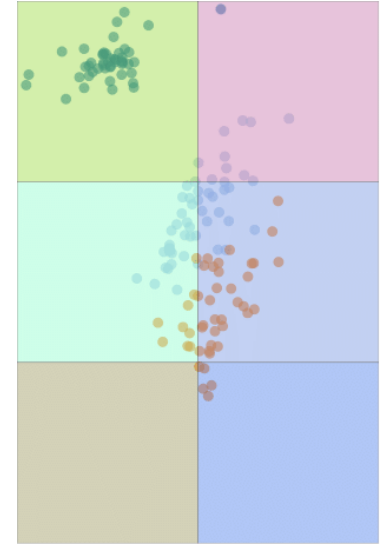

(d) 0.0056 .

Fonte: Elaborada pelo autor.

respectivos vetores de variância são paralelos com mesma direção e sentido entre si. O processo de agrupamento é descrito pelo Algoritmo 2, que recorre à função descrita pelo Algoritmo 1. Os grupos são formados agrupando-se todos os pontos com o mesmo id (ver algoritmo), de modo que dois pontos $\mathbf{v}_{i}, \mathbf{v}_{j}$ pertencem ao mesmo grupo se a função $\operatorname{Procurar}\left(Y_{i}\right)$ e $\operatorname{Procurar}\left(Y_{j}\right)$ retornarem o mesmo valor.

Figura 38 - Exemplo bidimensional da distância do cosseno para medir a similaridade entre o vetor de variância de células da grade.

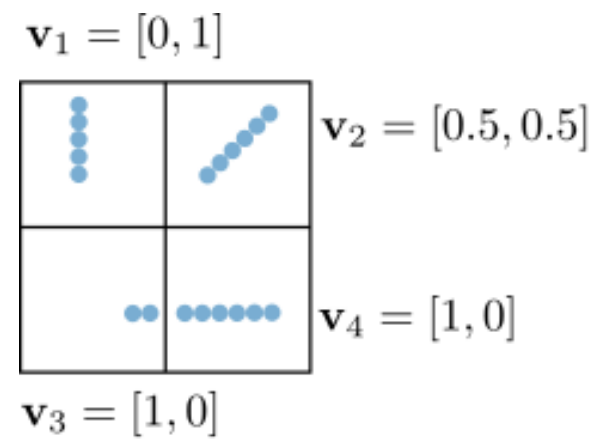

$$
\begin{aligned}
& d_{3,4}=0 \\
& d_{1,3}=d_{1,4}=1 \\
& d_{1,2}=d_{2,3}=d_{2,4}=0.2928
\end{aligned}
$$

Fonte: Elaborada pelo autor.

A técnica de agrupamento por similaridade de variância tem dois propósitos diretos. Primeiro, ela identifica regiões na projeção cujas variâncias entre atributos são consideradas similares pelo usuário, indicando um comportamento parecido de distribuição de pontos nas respectivas regiões (Figura 39a). Segundo, por existir uma relação entre a variância das dimensões e a como os pontos são projetados, esta métrica serve como um indicador para determinar possíveis estruturas que de fato são grupos na projeção (Figura 39b). Para auxilar na busca por grupos e não restringir o algoritmo à dependência entre o tamanho de cada célula e como os 


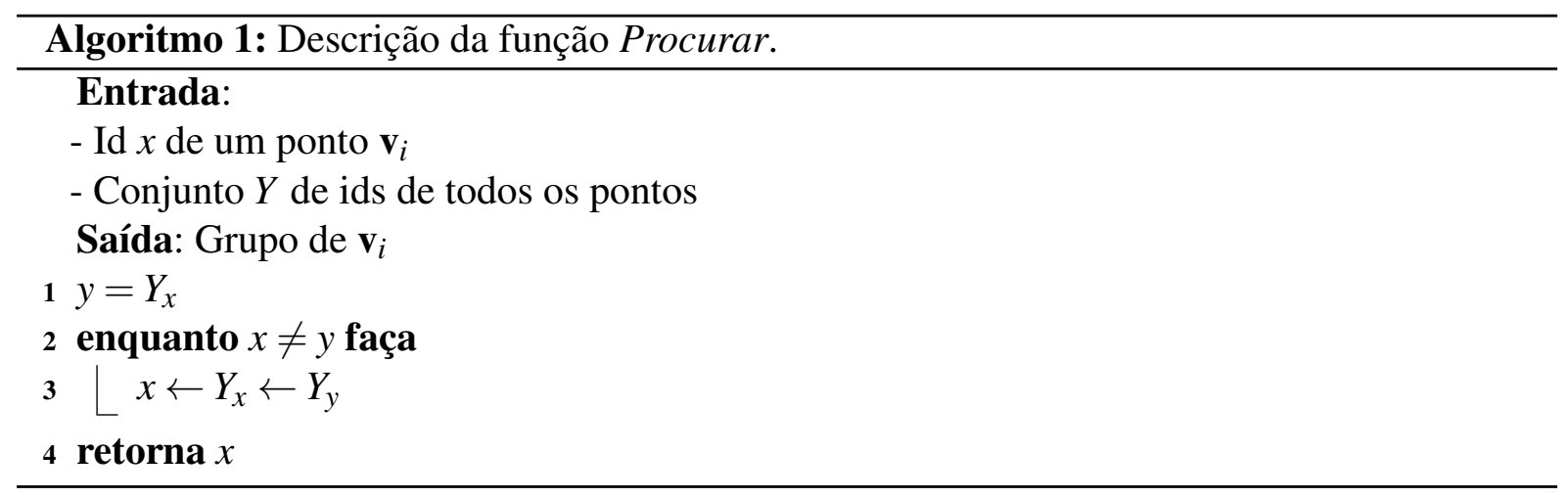

pontos foram atribuídos a cada região, o vetor de variância de uma célula $c_{i}$ é dado sobre a união dos $k$ vizinhos de todos os pontos de $c_{i}$.

Figura 39 - Diferentes aplicações da ASV.

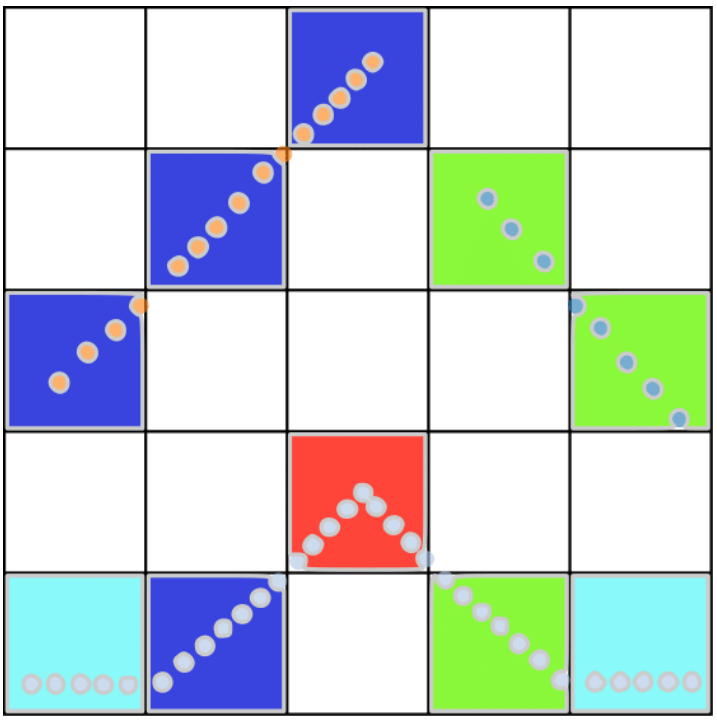

(a) Identificação de regiões com variância mutidimensional parecidas.

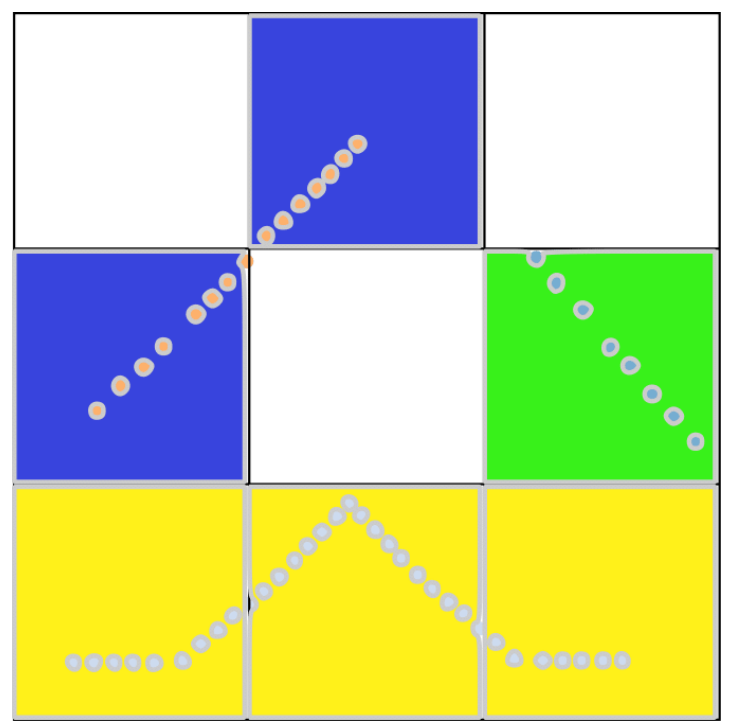

(b) Os grupos foram adequadamente identificados, aumentando o tamanho da célula da grade.

Fonte: Elaborada pelo autor.

\subsection{Técnicas e Ferramentas Auxiliares}

Nesta seção são apresentadas as demais técnicas e ferramentas implementadas no decorrer deste projeto para auxiliar na exploração e análise dos dados projetados.

\subsubsection{DBSCAN}

Ao contrário da técnica ASV, responsável por agrupar regiões pela variância dos seus pontos em relação ao espaço original dos dados, o DBSCAN é utilizado neste projeto para detecção de grupos de pontos geometricamente próximos no espaço visual. Esse tipo de agrupamento 


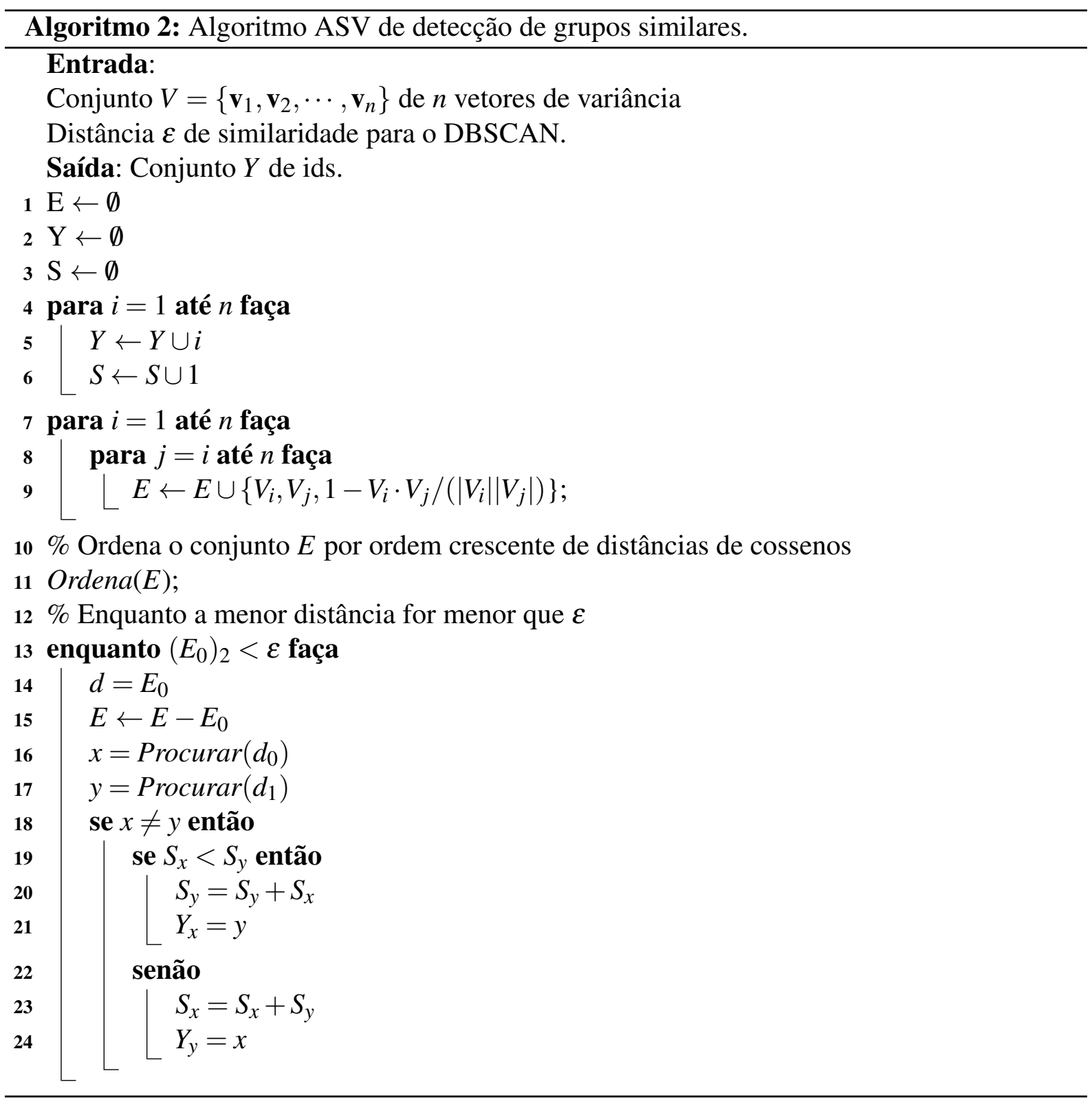

se mostrou interessante de se disponibilizar como uma alternativa ao usuário, uma vez que a técnica ASV, assim como outras técnicas de agrupamento, pode não ser adequada para separar corretamente certos conjuntos de dados, ou quando a variância não for um fator importante de agrupamento.

Dado um conjunto de $n$ pontos em algum espaço Euclidiano $\mathbb{E}^{m}$, o DBSCAN agrupa instâncias que estejam próximas uma das outras (com muitos vizinhos em comum), rotulando aquelas que permanecem distantes em regiões de baixa densidade como ruídos.

Duas versões deste algoritmo foram implementadas. A primeira consiste em agrupar um ponto $\mathbf{p}_{i}$ aos seus minPts pontos vizinhos dentro de um raio de influência $\varepsilon$. Todos estes pontos são ditos alcançáveis por $\mathbf{p}_{i}$. Por sua vez, todos os pontos alcançáveis pelos vizinhos de $\mathbf{p}_{i}$ também fazem parte do mesmo grupo de $\mathbf{p}_{i}$. Logo, um grupo é formado por todos os pontos próximos uns aos outros por uma distância até $\varepsilon$ no espaço, conforme ilustrado na Figura 40. 
Figura 40 - Exemplo do agrupamento dado pelo DBSCAN com $\operatorname{minPts}=3$.

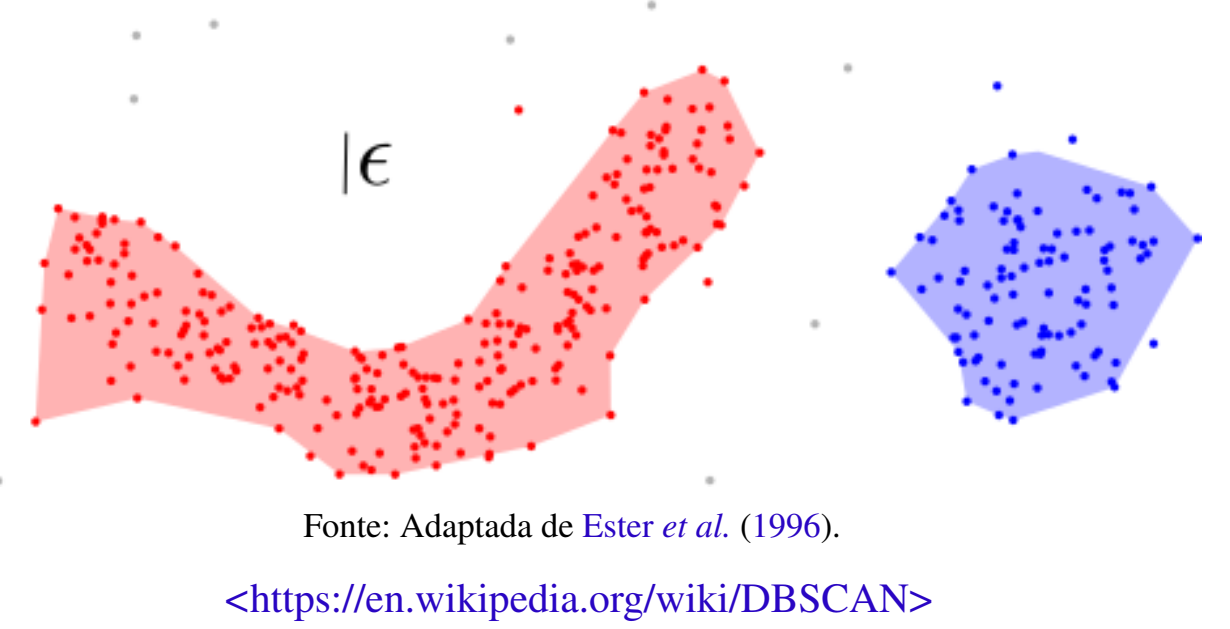

A segunda abordagem estabelece um número $k \leq n$ de grupos desejados. Para o DBSCAN, esta versão pode ser implementada assumindo o conjunto de pontos como um grafo $G_{r}\left(V^{\prime}, E\right)$, sendo cada vértice $v \in V^{\prime}$ um ponto $\mathbf{p}_{i}$ e $e \in E$ uma aresta conectando dois vértices, cujo comprimento representa a distância entre os mesmos (ver Figura 41), e agrupando os pontos formados pela remoção das $k-1$ maiores arestas (em vermelho) da árvore geradora mínima (WILSON, 1986) de $G_{r}$.

Figura 41 - O agrupamento de $k$ grupos pelo DBSCAN equivale à remoção das $k-1$ maiores arestas (em vermelho) da árvore. No exemplo, $k=4$.

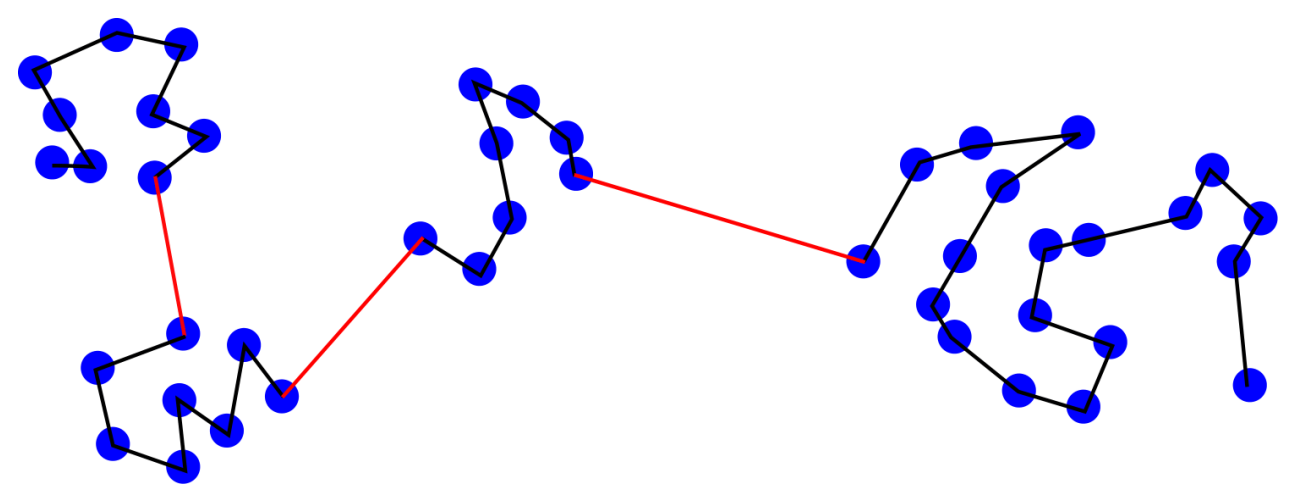

Fonte: Elaborada pelo autor.

Ambas as formas de execução do DBSCAN foram implementadas no projeto, sendo a segunda para detecção de $k$ grupos na projeção, utilizando a distância Euclidiana como medida de similaridade. Neste caso, cada região é identificada pelo fecho convexo (BARBER; DOBKIN; HUHDANPAA, 1996) dos seus pontos, conforme ilustrado na Figura 42. A Figura 43 mostra alguns exemplos.

No entanto, admitindo que os pontos não formem um padrão de grupo esperado pelo usuário, isto é, estruturas formadas por pontos próximos no espaço, o DBSCAN também foi implementado na técnica de agrupamento por similaridade de variância, descrita na Seção 3.4, 
Figura 42 - Da esquerda pra direita: diferentes grupos dado pelo DBSCAN, com $k=1,2,3$ e 4 .
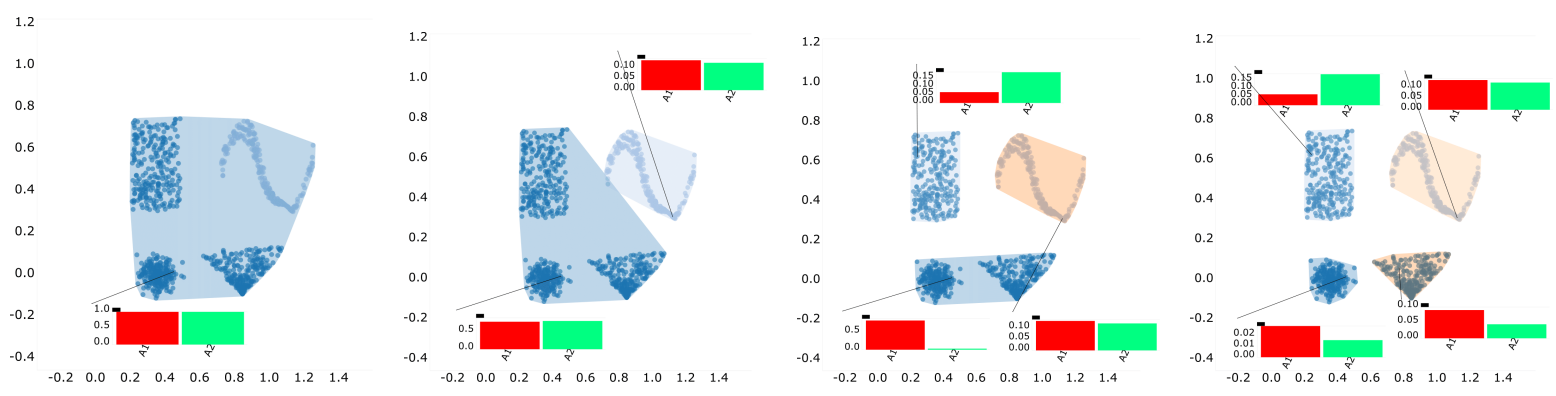

Fonte: Elaborada pelo autor.

Figura 43 - Exemplos de grupos formados pelo DBSCAN.

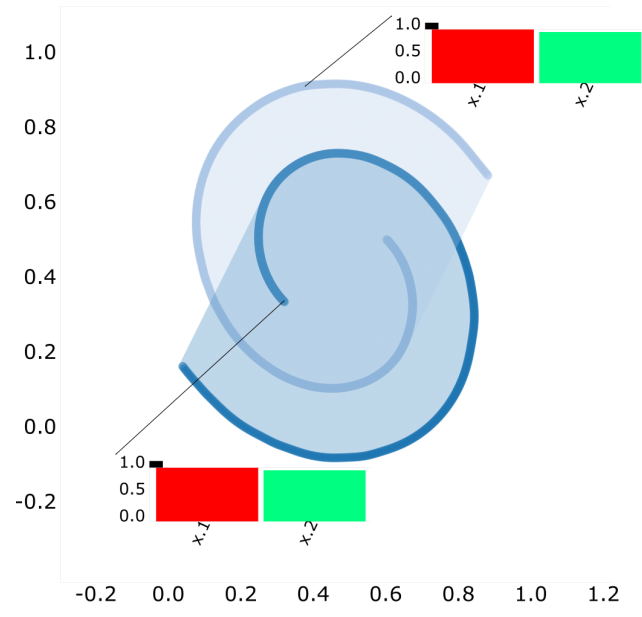

(a)

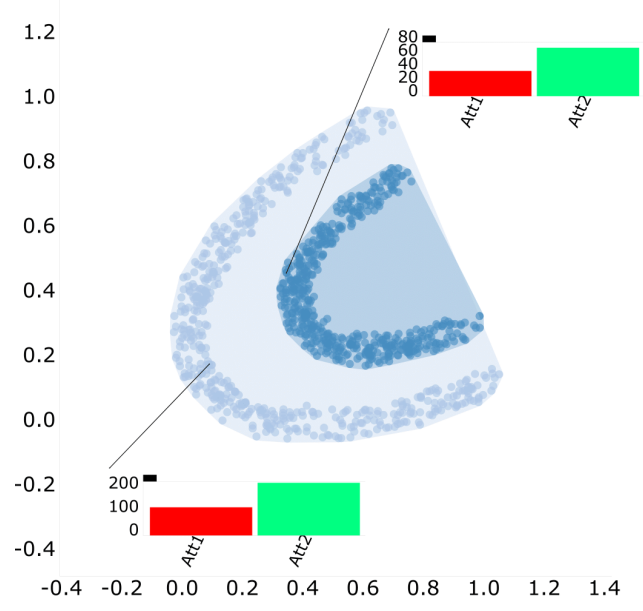

(b)

Fonte: Elaborada pelo autor.

em que diferentes parâmetros de distância $(\varepsilon)$ determinam diferentes grupos similares na projeção. Para tanto, a distância do cosseno entre vetores de variância foi utilizada para medir a similaridade entre regiões.

\subsubsection{GMap}

GMap é uma técnica de geração de mapas para auxiliar na visualização de grafos densos, proposta por Gansner, Hu e Kobourov (2009). Dado um conjunto de pontos $U$ projetados em um espaço bidimensional e uma relação de similaridade e agrupamento entre esses pontos, o algoritmo cria um mapa desse conjunto tal que cada grupo é representado por um "país" identificado pelos limites do contorno dos seus pontos. Em uma primeira abordagem, GMap cria um diagrama de Voronoi (AURENHAMMER, 1991) sobre os pontos de $U$ e classifica cada célula de Voronoi com a cor do grupo do respectivo ponto (Figura 44a). Para criar mapas mais suaves e naturais são adicionados $k$ pontos artificiais aleatórios no espaço visual (Figura 44b), de modo que uma maior quantidade de células menores sejam criadas. Uma célula de um ponto 
artificial pertence a um grupo somente se esta está a uma distância máxima $r$ de um ponto original. Dependendo do valor de $r$, grupos podem apresentar buracos (ou lagos) em áreas onde os vértices reais estão muito longe entre si, conforme mostrado na Figura 45d. Por fim, o último passo do algoritmo (Figura 44c) consiste em deixar que os países ou grupos assumam algum forma homogênea e/ou que suas áreas sejam proporcionais a importância dos seus pontos. Essa etapa é feita adicionando mais pontos artificias na projeção obedecendo algum padrão ou estrutura desejada.

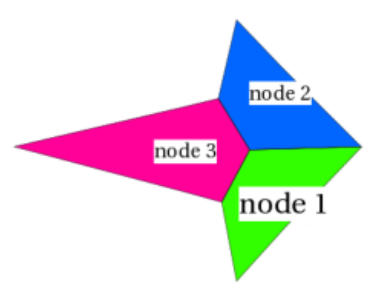

(a) Voronoi sobre os pontos.
Figura 44 - Algoritmo de geração de mapas GMap.

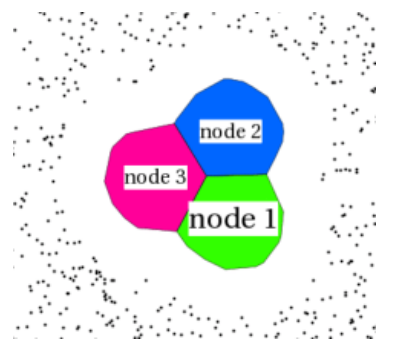

(b) Voronoi após a adição de pontos artificiais.

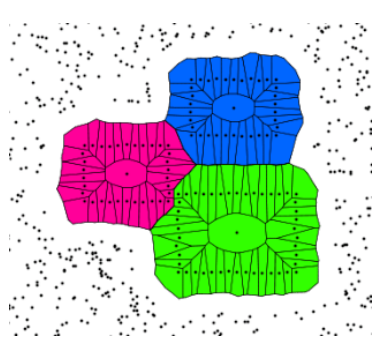

(c) Grupos são modelados pela forma dos seus rótulos.

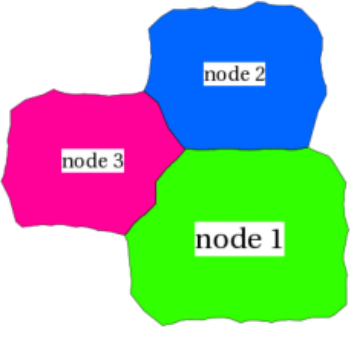

(d) Visualização final.
Fonte: Gansner, Hu e Kobourov (2009).

Neste projeto de mestrado o GMap foi adaptado para ajudar na visualização das regiões da projeção, uma vez que estas podem ser descontínuas ou estarem fragmentadas no espaço visual. Foram adicionados dez por cento da área da projeção em número de pontos artificiais para suavizar o mapa, sendo o parâmetro $r$ ajustável em tempo real pelo usuário (Figura 45). Apesar de não ser necessária, a terceira etapa de construção do GMap foi implementada em função das células da grade, de modo que os grupos formados tendam a seguir o formato das células de $G$.

\subsubsection{Preservação de Vizinhaça Suave}

Para validar a qualidade da projeção e o visualizar o impacto de erros causados pelo processo de perda de dimensionalidade, foi implementada a métrica de preservação de vizinhança suave ou Smooth Neighborhood Preservation (SNP) (PAGLIOSA et al., 2015), descrita a seguir. Seja $N_{i}^{F N}$ um conjunto formado pelos $k$ vizinhos mais próximos (CUNNINGHAM; DELANY, 2007) do elemento $i$ no espaço original que não estão entre os $k$ vizinhos de $i$ no espaço visual (vizinhos falso negativos), e $N_{i}^{F P}$ o conjunto de elementos que não fazem parte dos $k$ vizinhos de $i$ no espaço original mas foram mapeados entre os $k$ vizinhos de $i$ no espaço visual (vizinhos 
Figura 45 - Diferentes raios de influência sobre pontos artificiais do GMap geram diferentes formas de visualizar os mesmos grupos na projeção.

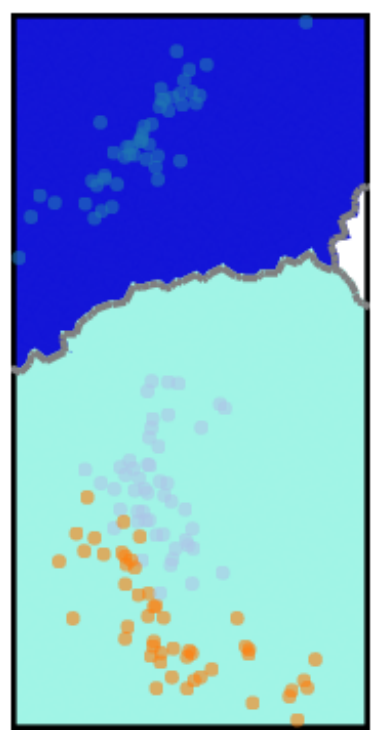

(a) 1 .

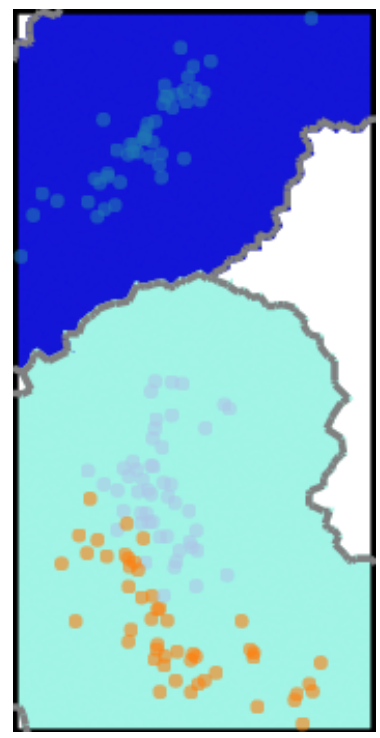

(b) 0.7 .

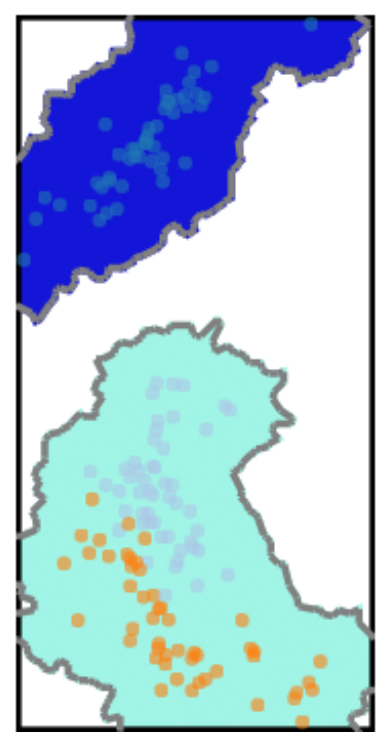

(c) 0.4 .

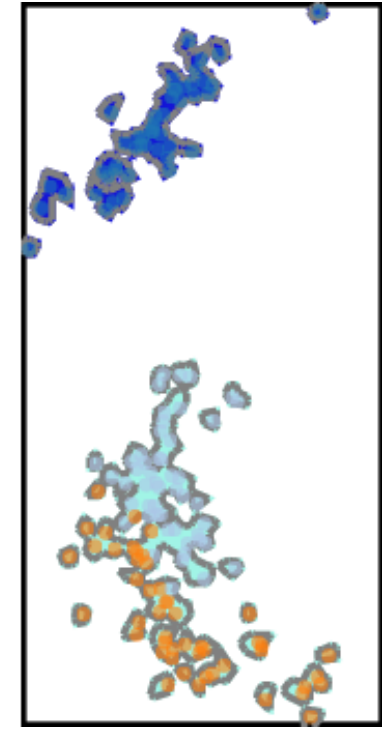

(d) 0.2 .

Fonte: Elaborada pelo autor.

falso positivos). As métricas locais de má colocação são dadas por:

$$
\begin{aligned}
& W_{i}^{F N}=\left\{\begin{array}{cc}
\frac{1}{\left|N_{i}^{F N}\right|} \sum_{j \in N_{i}^{F N}} w\left(\bar{r}_{i}, \bar{d}_{i, j}\right) & N_{i}^{F N} \neq \emptyset, \\
0 & \text { caso contrário, }
\end{array}\right. \\
& W_{i}^{F P}=\left\{\begin{array}{cc}
\frac{1}{\left|N_{i}^{F P}\right|} \sum_{j \in N_{i}^{F P}} w\left(r_{i}, d_{i, j}\right) & N_{i}^{F P} \neq \emptyset, \\
0 & \text { caso contrário, }
\end{array}\right.
\end{aligned}
$$

sendo $\left|N_{i}^{*}\right|, *=\mathrm{FN}$, FP o número de elementos no conjunto, $d$ e $\bar{d}$ as distâncias no espaço original e visual, respectivamente, e $w$ uma função de peso que mede quanto o elemento $j$ está longe da sua real vizinhança. Os parâmetros $\overline{r_{i}}$ e $r_{i}$ correspondem à maior distância de $i$ para seus $k$ vizinhos no espaço visual e original, respectivamente. A função $w$ é uma função radial na forma

$$
w(r, t)=\left\{\begin{array}{cc}
\frac{28}{5}\left(\frac{t-r}{r}\right)^{5}-14\left(\frac{t-r}{r}\right)^{4}+\frac{4}{5}\left(\frac{t-r}{r}\right)^{3}+\frac{1}{5}\left(\frac{t-r}{r}\right)^{2} & r \leq t \leq 2 r \\
1 & \text { caso contrário. }
\end{array}\right.
$$

A métrica que calcula a preservação de vizinhança global, derivada da Equação 3.9 e da Equação 3.10 , é dada por

$$
E_{N b}=\frac{1}{2|S|} \sum_{i \in S}\left(W_{i}^{F N}+W_{i}^{F P}\right),
$$

sendo $S$ o conjunto de dados analisado. Esta métrica, criada originalmente para comparar a qualidade entre duas projeções, foi utilizada neste projeto para identificar instâncias mal projetadas e o impacto delas na análise dos grupos. Como a qualidade final da projeção é dada 
pela média da qualidade individual de cada instância, o usuário pode detectar quais pontos foram corretamente projetados no espaço visual por uma margem de qualidade $q \in[0,1]$, variando entre pontos perfeitamente projetados $(q=0)$ ou aqueles projetados sem preservar nenhuma relação de vizinhança original $(q=1)$, conforme ilustrado na Figura 46. Uma vez determinado um intervalo aceitável de qualidade, o usuário pode aplicar as metáforas visuais propostas apenas sobre os pontos confiáveis, desconsiderando os pontos que não foram projetados corretamente, de acordo com a métrica de qualidade adotada.

Figura 46 - A métrica de qualidade SNP identifica e descarta das metáforas visuais os pontos mal projetados (em vermelho) na visualização.

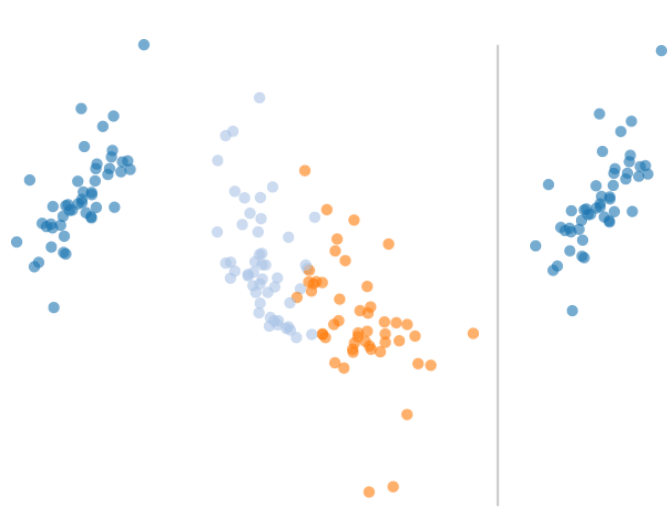

(a) 1 .

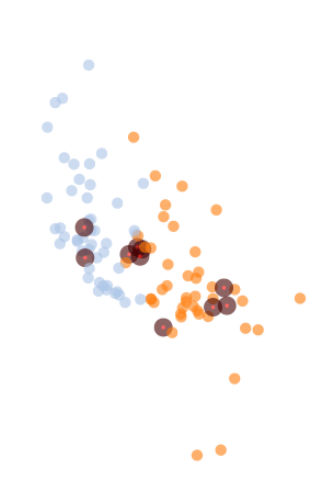

(b) 0.5

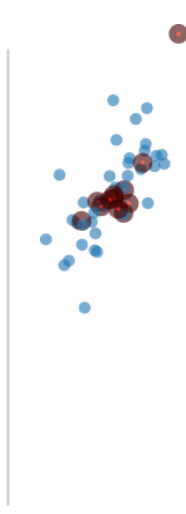

(c) 0.25

Fonte: Elaborada pelo autor.

\subsection{Interface com o Usuário}

As páginas Web criadas neste projeto foram implementadas em CSS3 e HTML5. A parte lógica computacional do projeto foi implementada em JavaScript no cliente e em JSP/Java na parte do servidor. O programa começa com o usuário informando o arquivo a ser analisado. Uma vez selecionado, o próximo passo consiste na aplicação de uma técnica de projeção para projeção destes pontos no espaço bidimensional. Tal como implementado, o programa dispõe da técnica de projeção LAMP (Seção 2.3) para a redução de dimensionalidade, implementada em conjunto com a técnica Force Scheme para projeção da amostra de pontos de controle aleatoriamente selecionados. O processo de projeção dos pontos pode ser realizado localmente na máquina do usuário ou pelo servidor, cujo protocolo de comunicação se dá através de WebSockets (Subseção 2.4.6). O modo de execução de todas estas etapas e outras informações ficam registradas em um arquivo chamado Status (Figura 47), responsável por informar ao usuário as características dos dados analisados e o estágio atual de processamento.

Uma vez projetados, a aplicação pode proceder de diversas formas, de modo que o usuário possa especificar um pipeline de execução ajustada à necessidade de análise. O usuário pode (i) criar regiões de interesse manualmente, (ii) criar regiões geometricamente próximas 
Figura 47 - O status apresenta o registro de todas as operações realizadas pelo programa.

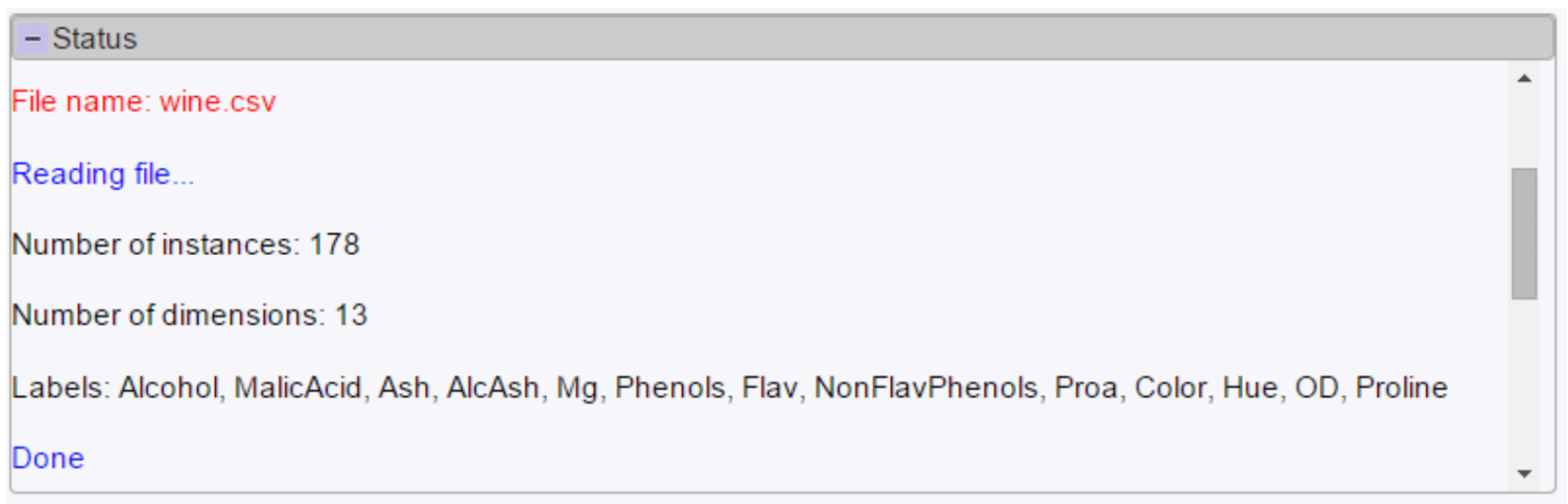

Fonte: Elaborada pelo autor.

com o DBSCAN (iii) ou utilizar da métrica ASV para identificar regiões com similaridade de variância. Dentre as possibilidades, (ii) é a única que não utiliza a grade regular criada sobre o retângulo envolvente dos pontos da projeção. Para os casos (i) e (iii), as regiões são dadas pela união de células uniformes do espaço visual. Determinadas as regiões, a análise acontece por meio das metáforas visuais baseadas em atributos propostas neste projeto.

Todas as opções de interatividade e ajuste de parâmetros são mantidas em menus na aba de visualização da projeção. O menu rotulado Data (Figura 48) é responsável por ler o arquivo de dados a ser analisado, com opções de normalização dos arquivos por coluna e a escolha da métrica de dissimilaridade a ser utilizada pela técnica de projeção. O menu rotulado Histogram contém o histograma das classes dos dados. O usuário pode visualizar e interagir somente com instâncias das classes selecionadas, conforme ilustrado na Figura 49. A agregação de combinações de instâncias foi feita com o auxílio do Crossfilter (Subseção 2.4.5).

Figura 48 - Leitura de arquivo, escolha do método de projeção e função distância utilizada.

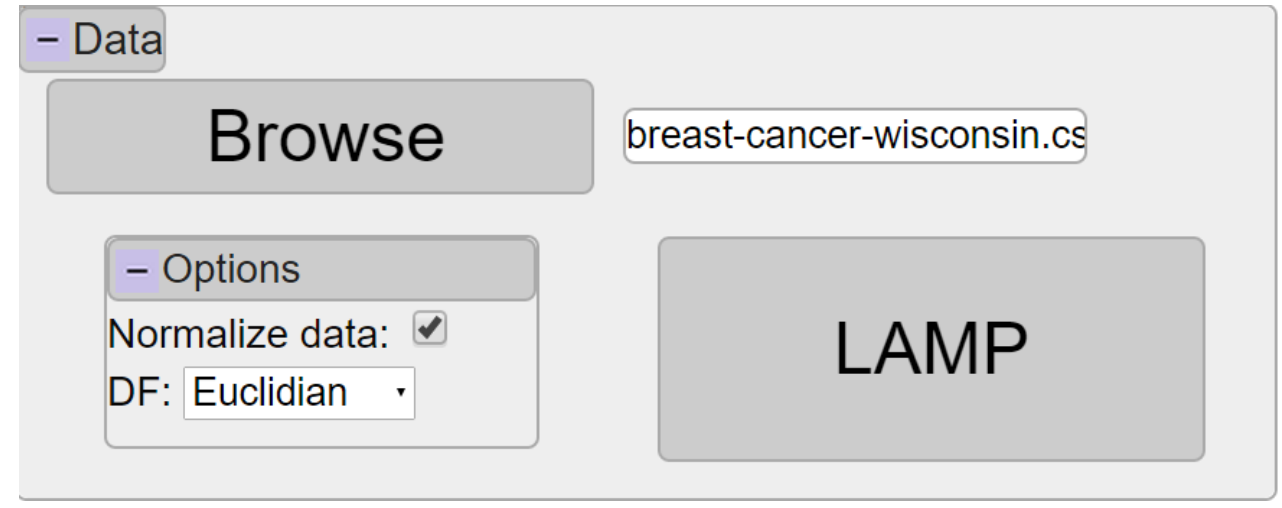

Fonte: Elaborada pelo autor.

O menu rotulado Attributes (Figura 50) contém os parâmetros de entrada para a primeira e segunda metáfora visual. O usuário pode escolher visualizar qual o atributo mais relevante em uma região ou analisar como uma dimensão se comporta em toda a projeção. A aba Attribute Relevance \# indica qual a relevância mostrada nas regiões da projeção, de modo que a \#-ésima 
relevância mostra o \#+1 atributo mais relevante. Na frente de cada atributo existe um checkbox que, quando selecionado, mostra a relevância da respectiva cor em toda a projeção. As cores atribuídas a cada atributo podem ser mudadas a qualquer momento pelo usuário.

Figura 49 - Relação entre classes e instâncias da projeção. (b) e (d) refletem as classes selecionadas pelo histograma em (a) e (c), respectivamente.

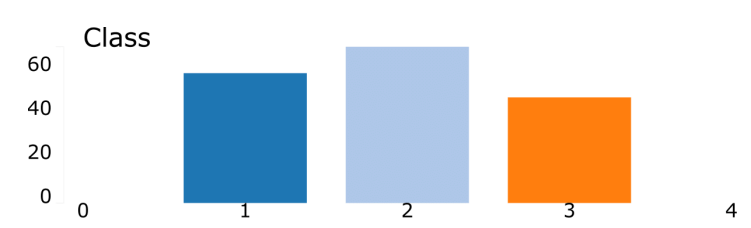

(a) Relação entre instâncias e classes de um conjunto de dados $U$.

(b) Projeção de $U$.

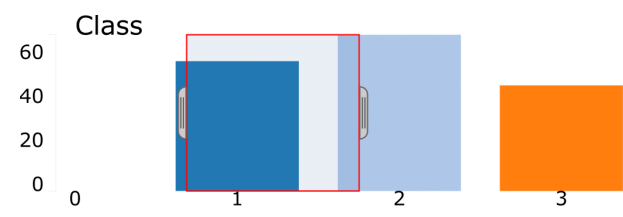

(c) Seleção das classes 1 e 2.

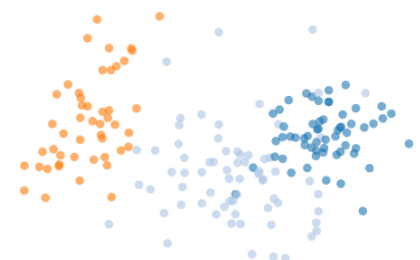

Fonte: Elaborada pelo autor.

Figura 50 - Menu contendo os parâmetros da primeira e segunda métrica visual de análise de atributos.

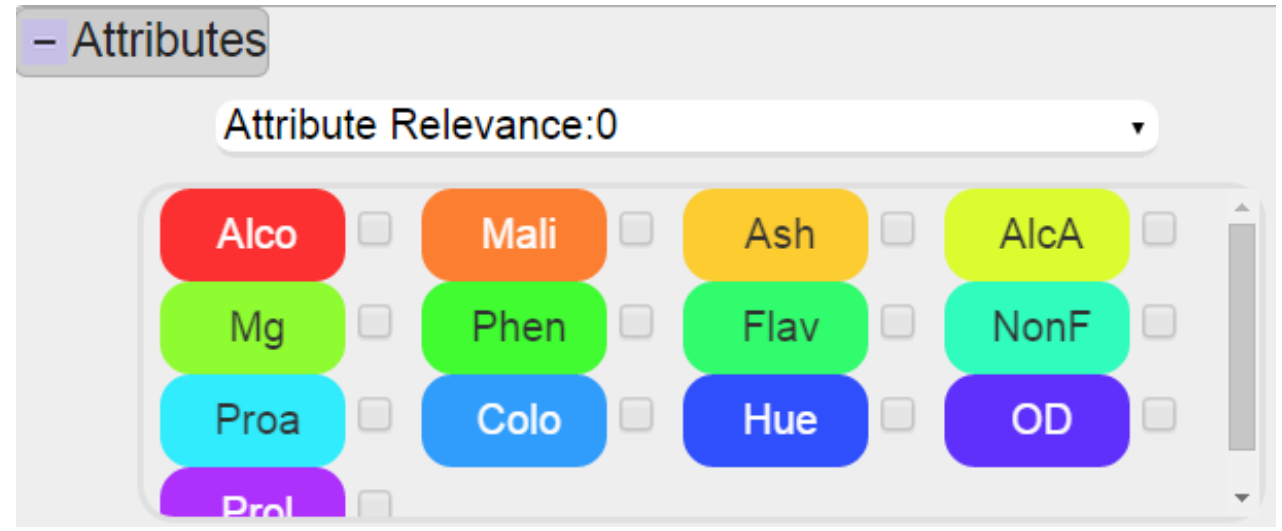

Fonte: Elaborada pelo autor.

A aba rotulada Menu (Figura 51) contém os demais parâmetros do programa, como tamanho de cada célula, distância e número de grupos do DBSCAN, raio de influência do GMap, número de vizinhos $(k \mathrm{NN})$ utilizado no cálculo da variância do ASV, normalização dos valores estatísticos por região, entre outros.

Por fim, o menu rotulado Create own, mostrado na Figura 52, permite a criação de grupos manuais pelo usuário. Tal como implementado, grupos são criados pela seleção e união de células 
Figura 51 - Escolha de parâmetros.

\begin{tabular}{|c|c|c|}
\hline - Menu & Show bar chart path $\downarrow$ & DBScan eps: 0.1158 \\
\hline Show points $\downarrow$ & Show data per cell & $\square$ \\
\hline Show back grid $\square$ & Normalize y scale $\square$ & $\begin{array}{l}\text { DBScan \# of clusters: } 1 \\
0 \square \quad 10\end{array}$ \\
\hline Show box plots $\square$ & SNP: $\quad 0.5$ & GMap radius: 50 \\
\hline Fill GMap clusters $\square$ & $\begin{array}{ll}0 & 1\end{array}$ & $0 \quad \equiv 50$ \\
\hline $\begin{array}{l}\text { Show convex clusters } \\
\text { Remove bad projected points }\end{array}$ & $\begin{array}{ll} & \text { Grid cell size: } 50 \\
5 & 100\end{array}$ & $\begin{array}{ll}\text { Knn: } 171 \\
0 & 341\end{array}$ \\
\hline
\end{tabular}

Fonte: Elaborada pelo autor.

da grade $G$. Além da identificação dos grupos por células da mesma cor, grupos também são representados pelo fecho convexo dos seus pontos. Para casos em que há sobreposição de grupos, cada fecho convexo é restrito sobre os limites das células de cada grupo.

Figura 52 - Seleção manual de regiões por células da grade.

\section{- Create own}

\section{Create own clusters}

\section{Add cell}

\section{Remove cell}

New cluster

\section{Create}

Fonte: Elaborada pelo autor.

Além das funcionalidades interativas já mencionadas, o programa permite ações do tipo zoom in, zoom out, pan, assim como seleção e arrasto de instâncias projetadas e regiões da projeção.

\subsection{Considerações Finais}

Neste capítulo foram apresentadas três metáforas visuais para análise de atributos de uma projeção multidimensional e um algoritmo de detecção de regiões com similaridade de variância. Tais métodos foram propostos para auxiliar na compreensão dos dados e na visualização dos atributos mais importantes para a proximidade de pontos em determinadas regiões. O objetivo 
destas técnicas consiste em identificar como as dimensões influenciam na classificação de cada grupo e como e quanto estes são semelhantes entre si. Outros algoritmos como DBSCAN, GMap e SNP foram implementados como ferramentas auxiliares para proporcionar maior interatividade e opções de análise ao usuário. 


\subsection{Considerações Iniciais}

Neste capítulo são apresentados os experimentos realizados com as metáforas visuais propostas neste trabalho. A expectativa é que tais visualizações consigam, em um primeiro momento, ajudar o usuário a entender a projeção com o auxílio de informações estatísticas sobre as instâncias e suas dimensões. O segundo objetivo consiste em fornecer ao usuário ferramentas de exploração e análise, como por exemplo, diferentes formas de agrupamento e detecção de ruídos, para que este consiga, de forma interativa, definir regiões de interesse e escolher metáforas visuais conforme sua necessidade. Os experimentos foram selecionados em casos de testes que exemplificam as possíveis formas de uso da ferramenta, dando ênfase à técnica de agrupamento por similaridade de variância (ASV) e às diferentes utilidades do programa, respectivamente.

Apesar de ser uma métrica de detecção de grupos, a ASV não foi comparada com nenhuma técnica de agrupamento, uma vez que o foco do trabalho não é propor um algoritmo de agrupamento robusto e melhor que os presentes na literatura, mas proporcionar um novo método para detecção de regiões similares de variância. De fato, a ferramenta dispõe de outras técnicas de agrupamento à disposição do usuário, sendo outras facilmente integráveis, sem perda de generalidade. A conclusão final obtida pela análise de cada experimento em cada um dos casos de teste foi comparada, para conjuntos de testes conhecidos, com as características esperadas de cada conjunto, a fim de verificar se a ferramenta foi útil para extração de informações relevantes. Para conjuntos sem conhecimento prévio dos dados, estudos foram realizados para simular o uso real da ferramenta por usuários, utilizando desde informações estatísticas à detecção de ruídos em dimensões de cada grupo. No entanto, as conclusões obtidas a partir destes conjuntos de dados se deram de forma empírica, principalmente pela análise do autor, uma vez que não haviam usuários especializados realizando tal análise. Logo, testes com o usuário poderiam ser aplicados em trabalhos futuros relacionados ao contexto de pesquisa deste trabalho de mestrado, 
a fim de comprovar de fato a eficácia da ferramenta proposta.

Para ilustrar o uso da métrica de detecção de grupos por similaridade de variância (ASV) e as demais metáforas do projeto, descritas nas Seções 3.4 e 3.5, respectivamente, foram selecionados sete conjuntos de dados (para ilustração de resultados, uma vez que foram utilizados mais arquivos para teste e validação), cujas características como número de instâncias, número de dimensões e quantidade de classes são descritas na Tabela 3. Foram realizados experimentos tanto com arquivos sintéticos para validação, como os conjuntos Cluster2D, Cluster3D, Circles e Spirals, descritos na Seção 4.2, quanto com dados de teste para análise, como os arquivos de dados Cancer (Seção 4.3), Iris (Seção 4.4) e Wine (Seção 4.5), obtidios do repositório de aprendizado de máquina UCI (LICHMAN, 2013). Todas as imagens deste capítulo foram geradas pela ferramenta e capturadas diretamente do navegador, acessível pela página Web $<$ http://stroggos.facom.ufms.br/varclustering/>.

Tabela 3 - Características dos conjuntos de dados utilizados como casos de teste nos experimentos realizados neste capítulo.

\begin{tabular}{|c|c|c|c|}
\hline Conjunto de dados & Instâncias & Dimensões & Classes \\
\hline Cluster2D & 450 & 2 & 1 \\
Cluster3D & 1050 & 3 & 1 \\
Circles & 1000 & 2 & 2 \\
Spirals & 1000 & 2 & 2 \\
Cancer & 683 & 9 & 2 \\
Iris & 150 & 4 & 3 \\
Wine & 178 & 13 & 3 \\
\hline
\end{tabular}

Fonte: Dados da pesquisa.

O restante do capítulo contém a descrição dos arquivos sintéticos e os experimentos realizados com arquivos reais, analisados separadamente em cada caso de teste, aplicando diferentes análises sobre o conjunto através das diferentes metáforas visuais propostas.

\subsection{Conjuntos Sintéticos}

Para validar a ferramenta foi desenvolvido um programa que, dado o número de dimensões desejadas, cria-se um arquivo com $|C|=2^{n}-1$ grupos, onde cada grupo $c \in C$ é gerado por uma distribuição Gaussiana $p \sim N\left(\mu_{c}, \sum_{c}\right)$ centrada em $\mu_{c}$ e com covariância $\sum_{c}$. Apesar de cada ponto $\mathbf{x}_{i} \in c$ conter $m$ atributos $\left(\mathbf{x}_{i} \in \mathbb{R}^{m}\right)$, apenas um subconjunto $k<m$ de dimensões tem valores não nulos para cada grupo. Por exemplo, para as dimensões $\{x, y, z\}(m=3)$ são obtidos sete grupos $C=\{\{x\},\{y\},\{z\},\{x, y\},\{x, z\},\{y, z\},\{x, y, z\}\}$ em cada subespaço de $\mathbb{R}^{3}$, conforme ilustrado na Figura 53.

Aplicando a técnica ASV é possível observar que os sete grupos do conjunto $C$ foram identificados de forma correta, isto é, para cada conjunto de pontos gerados por uma distribuição 
Figura 53 - Projeção de diferentes distribuições Gaussianas para $n=3$.
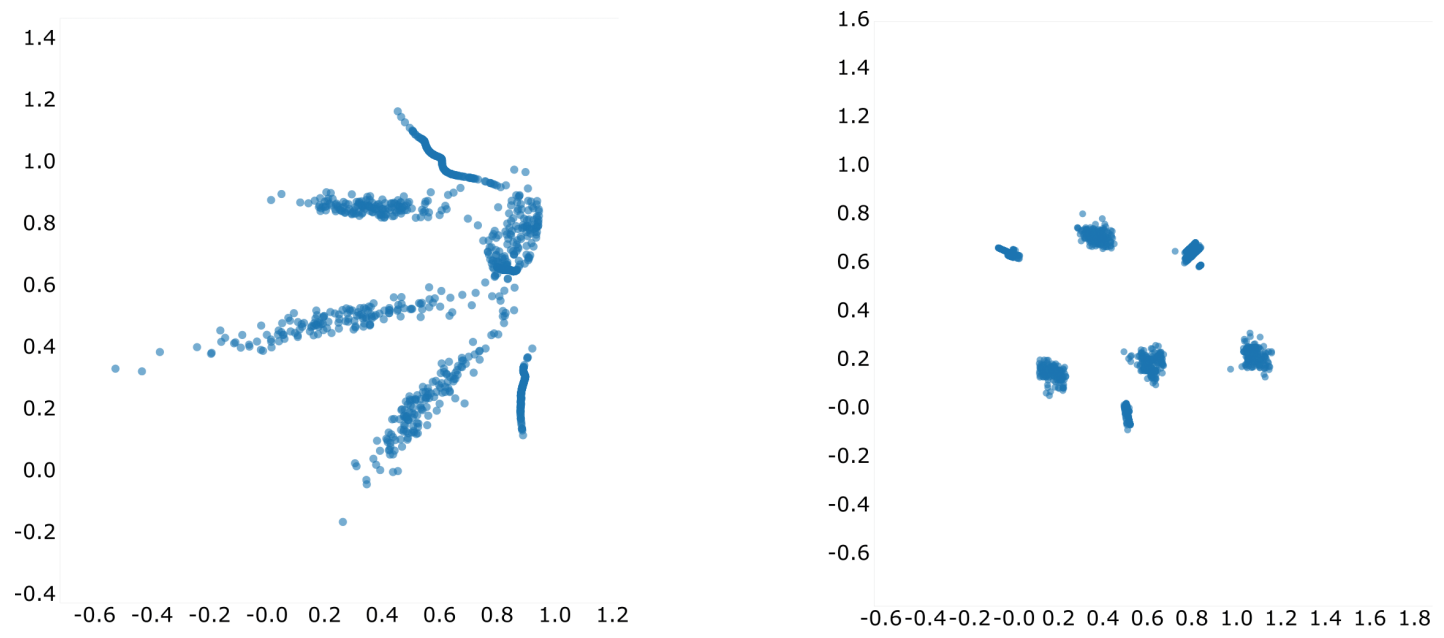

Fonte: Elaborada pelo autor.

Gaussiana, estes foram classificados como um único grupo, conforme ilustrado na Figura 54. No entanto, devido a erros de projeção ou ao modo como cada instância é atribuída a cada célula da grade, alguns pontos foram mal classificados em outros grupos, formando inclusive novos grupos na projeção. No entanto, como tais grupos são formados por poucas células e a estrutura dos grupos "reais" de $C$ não foi abalada, ou seja, o usuário consegue observar que existe uma divisão clara de sete grupos na visualização, tais erros foram considerados aceitáveis, visualmente, e dentro do esperado pela metáfora.

Figura 54 - Análise dos grupos pela ASV.

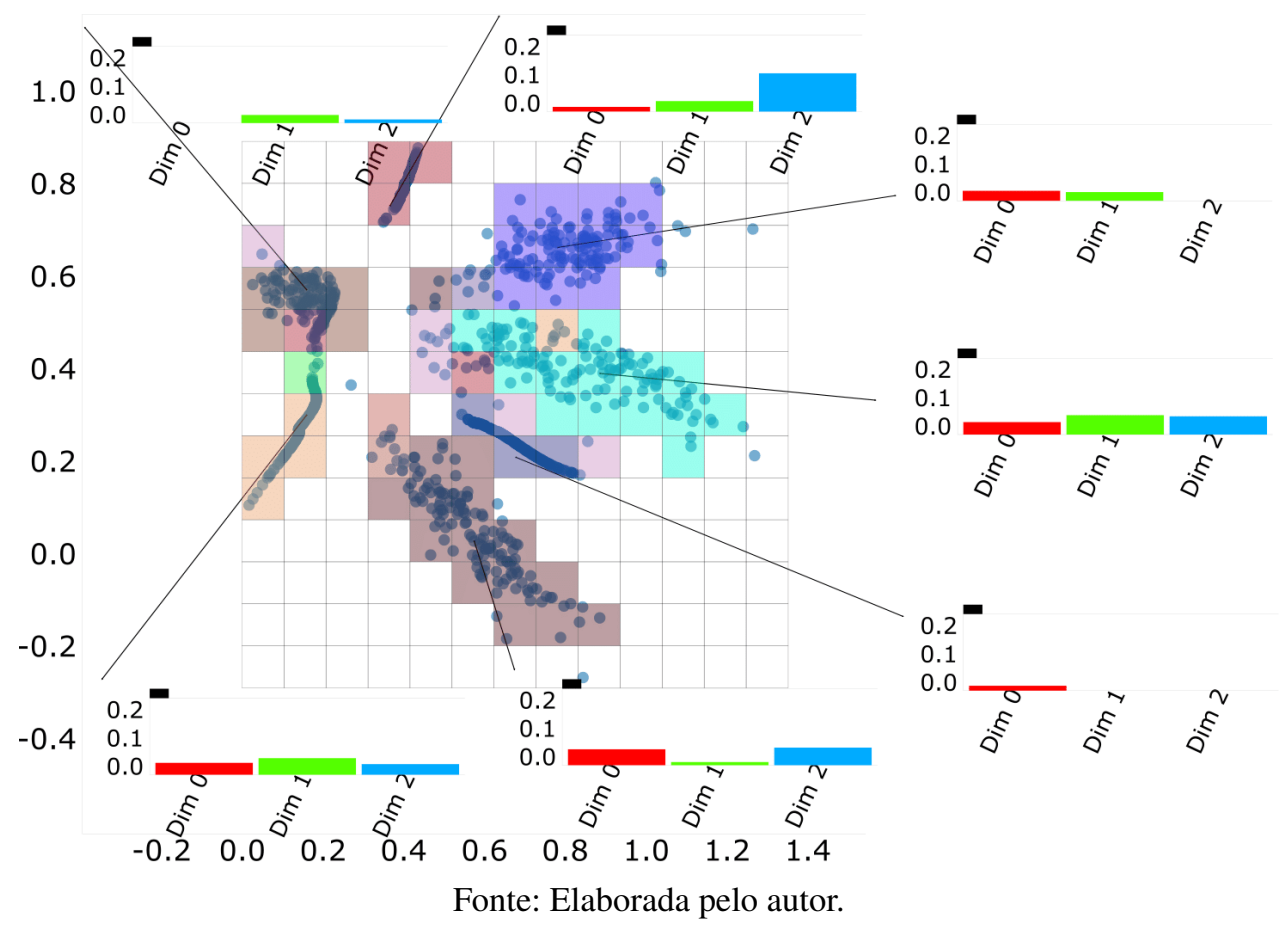

Apesar de sugerir grupos na projeção, é a análise desses grupos a principal contribuição 
deste trabalho, sendo possível observar quais as dimensões mais importantes e como estas se comportam na classificação de cada grupo. A visualização com bar-charts explica a diferença de atributos em cada grupo, e quais dimensões mais influenciam para a proximidade ou dispersão dos seus pontos. A partir disso, o usuário pode continuar a análise, por exemplo, em grupos onde existe maior relevância sobre um atributo de interesse.

Outro exemplo foi feito com um arquivo mais simples contendo apenas três grupos de Gaussianas (Figura 55a). O processo de identificação dos grupos é ilustrado na Figura 55b. Novos grupos com maior similaridade de variância são formados à medida que o limiar de distância do DBSCAN diminui (Figuras 55c e 55d). Por fim, a diferença da distribuição de cada atributo mostra como os pontos se comportam em cada grupo (Figura 55d).

Figura 55 - Interação e exploração para identificação de grupos. (a), (b), (c), (d) mostram, em ordem, o processo de exploração do usuário.
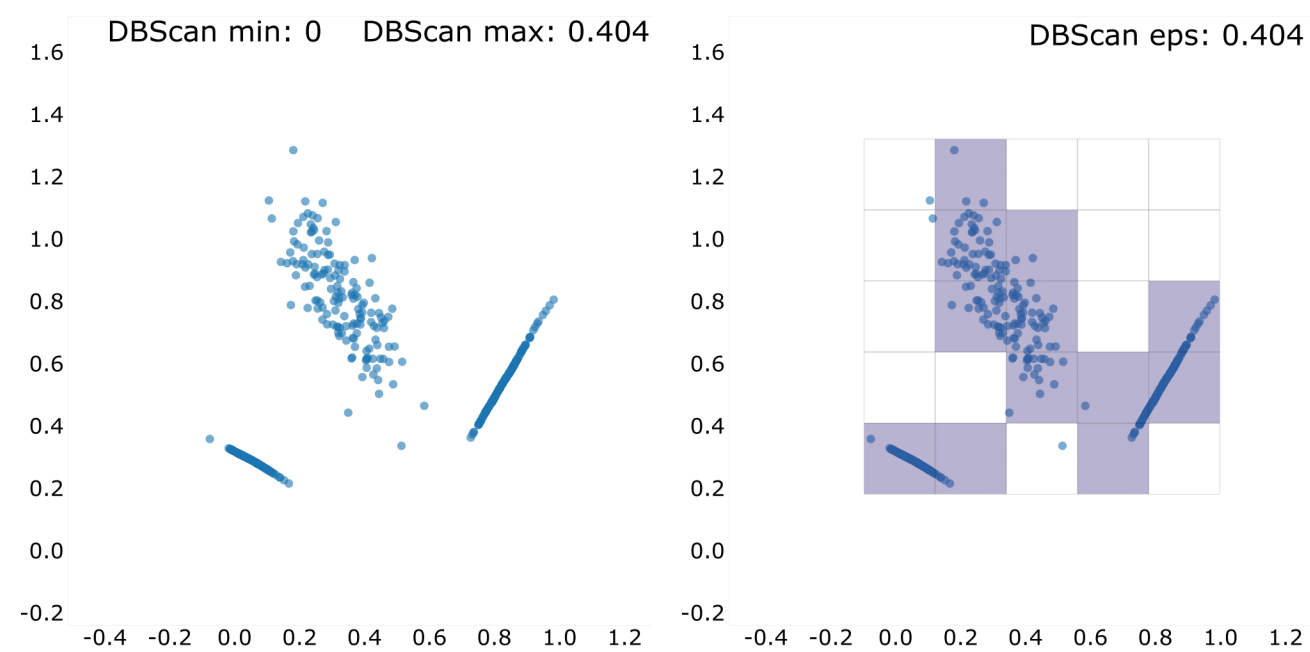

(a) Projeção de três Gaussianas.

(b) DBSCAN começa agrupando todos os pontos.
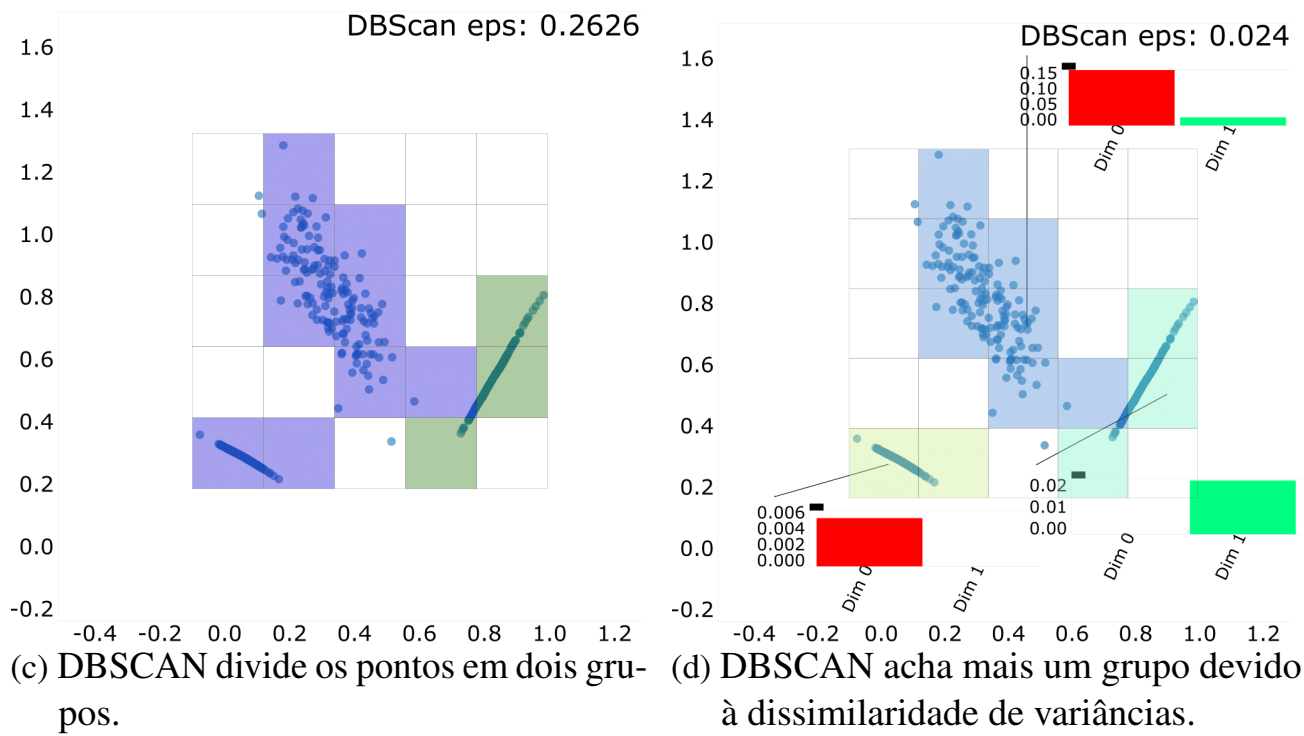

(d) DBSCAN acha mais um grupo devido à dissimilaridade de variâncias.

Fonte: Elaborada pelo autor. 
Também foi utilizado o arquivo sintético Spirals para validação da métrica. Este arquivo bidimensional contém duas classes de espirais com 500 instâncias cada, em que os atributos são as próprias coordenadas de cada ponto. Neste exemplo, é possível verificar que a ASV agrupa as células onde os pontos mais variam no espaço, conforme ilustrado na Figura 56. Diferentes tamanhos de células foram utilizados a fim de entender o impacto de diferentes regiões na análise dos dados. Foi observado, então, que diferentes regiões podem representar a mesma informação, se os demais parâmetros envolvidos nas metáforas visuais (como DBSCAN $\varepsilon$ e $k N N$ ) forem adequados para cada configuração.

Figura 56 - Diferentes tamanhos de células podem influenciar na análise dos dados. Células maiores tendem a conter mais pontos, e portanto mais informação sobre aquela região do espaço visual (Figura 56a). No entanto, células menores captam maiores detalhes sobre os dados projetados (Figura 56b).

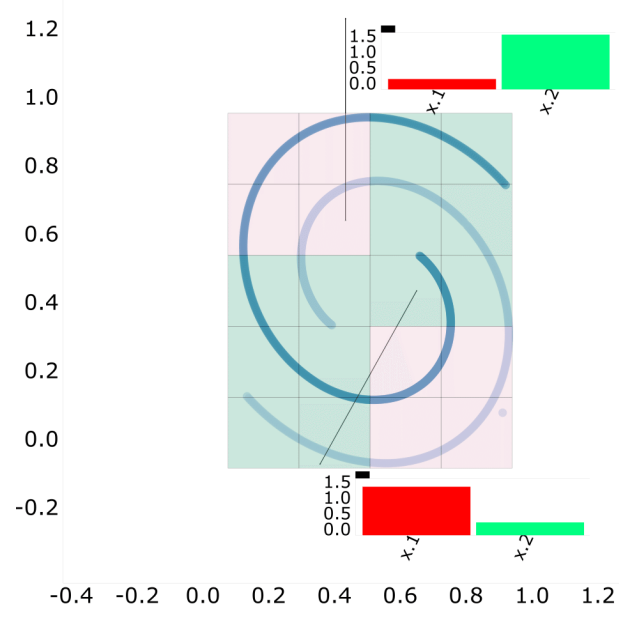

(a)

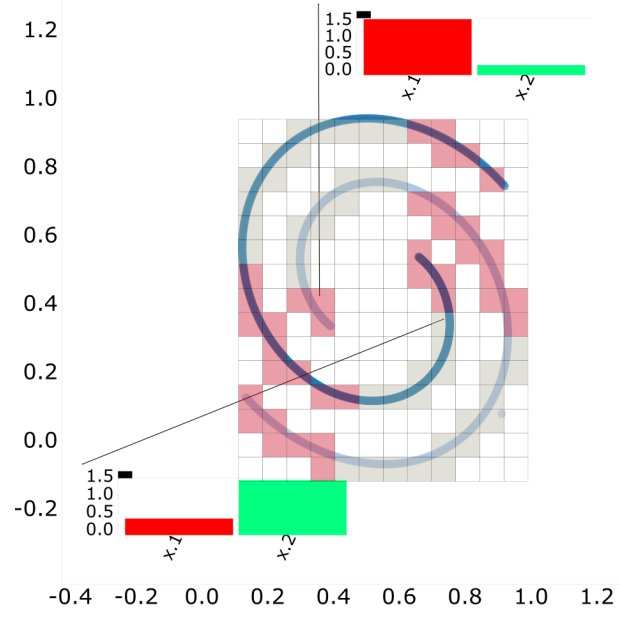

(b)

Fonte: Elaborada pelo autor.

O último arquivo de dados sintéticos foi o Circles, conjunto de dados bidimensional que contém um círculo inscrito em um quadrado. Esse arquivo possui uma característica importante comum em diversos tipos de dados, em que grupos podem estar misturados ou estruturados de forma hierárquica, com um grupo dentro do outro. Para esses dados, a ASV captou três grupos (Figura 57), mostrando que existem pontos em um grupo com alto nível de dissimilaridade (representando o círculo), e dois grupos cuja similaridade dos seus pontos se dá principalmente por um único atributo, representando os pontos nos lados horizontais e verticais do quadrado. Nestes casos, onde os grupos achados não são geometricamente unidos, a visualização dos grupos por um esquema de mapas como o Gmap é interessante e ajuda na visualização de dados mais complexos.

\subsection{Caso de Teste 1}

O primeiro caso de teste real foi aplicado sobre o arquivo Winconsin Breast Cancer (Original). Este arquivo contém 699 instâncias de células de câncer malignas (cancerígenas) e 
Figura 57 - Detecção de grupos agregados.

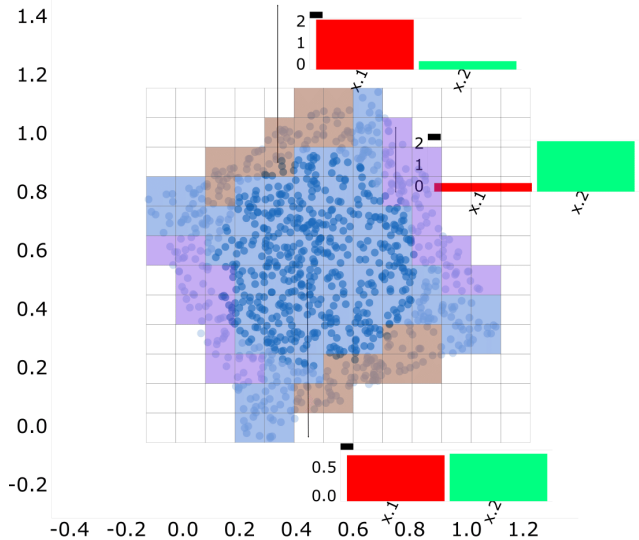

(a) Visualização dos grupos pela grade.

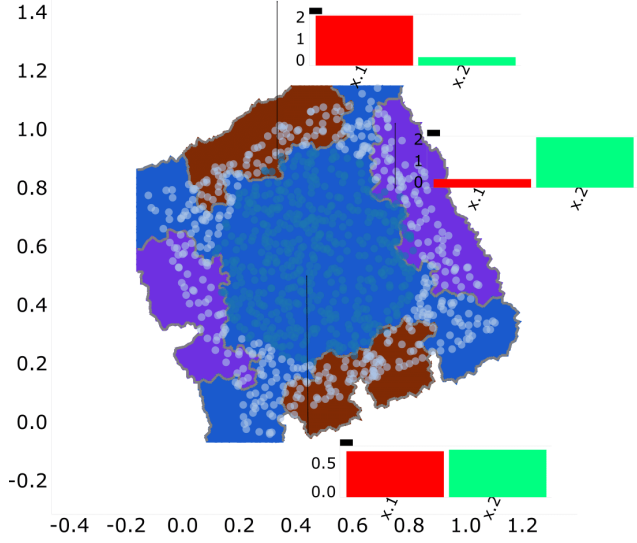

(b) Visualização dos grupos por Gmap.

Fonte: Elaborada pelo autor.

benignas (não cancerígenas) com 9 atributos (não contando id e classe). Esse conjunto de dados possui 16 instâncias com valores faltantes que foram removidos, deixando 683 para testes. As características esperadas de cada atributo em cada classe foram resumidas na Tabela 4, em que $\sigma$ corresponde à variância de um determinado atributo. A descrição desse arquivo foi baseada em (SALAMA; ABDELHALIM; ZEID, 2012):

Em células benignas o atributo clump thickness tende a ser agrupado em monocamadas, enquanto que em células cancerígenas este é geralmente agrupado multicamada. Por monocamada e multicamada entende-se que estes valores tendem a apresentar menor e maior variância, respectivamente. Uniformty of cell size/shape são valores que tendem a variar mais em células com câncer, influenciando no atributo single epithelial cell size, de modo que células epiteliais grandes podem sugerir câncer. A adesão marginal (marginal adhesion) faz com que células normais permaneçam unidas, de modo que perda de adesão pode ser um sinal de malignidade. Bare nucleio é um termo usado para núcleos que não estão completamente envolvidos pelo citoplasma (resto da célula), e são tipicamente vistos em células benignas. Bland chromatin é um atributo que descreve uma uniforme textura observada em células benignas. A cromatina costuma ser mais grossa em células com câncer. Normal nucleoli são pequenas estruturas vistas perto do núcleo, e geralmente aparecem em pouca quantidade em células normais. Em células com câncer existe maior chance de existirem tais estruturas. Finalmente, a mitose (mitoses) é uma divisão nuclear seguida de citocinese que produz duas células idênticas durante a prófase. É o processo pelo qual a célula se divide e multiplica. Patologistas podem determinar o grau de um câncer pelo número de mitoses realizadas.

Vale a pena ressaltar que pela descrição acima, o comportamento do atributo mitoses não é claramente especificado. Segundo a descrição do texto: "Patologistas podem determinar o grau de um câncer pelo número de mitoses realizadas", achou-se aceitável considerar que células com câncer se proliferam mais rapidamente do que as normais, e que por isso células deste tipo devem realizar um número maior de mitoses. 
Tabela 4 - Características dos atributos (em ordem) do arquivo Winconsin Breast Cancer (Original).

\begin{tabular}{|c|c|c|}
\hline Atributo & Maligna & Benigna \\
\hline Clump thickness & $\sigma$ alta & $\sigma$ baixa \\
Uniformty of cell size & $\sigma$ alta & $\sigma$ baixa \\
Uniformty of cell shape & $\sigma$ alta & $\sigma$ baixa \\
Single epithelial cell size & valor alto & valor baixo \\
Marginal adhesion & valor alto & valor baixo \\
Bare nucleio & valor alto & valor baixo \\
Bland chromatin & valor alto & valor/ $\sigma$ baixo \\
Normal nucleoli & valor alto & valor baixo \\
Mitoses & valor alto & valor baixo \\
\hline
\end{tabular}

Fonte: Elaborada pelo autor.

Nota-se que as células benignas e malignas apresentam padrões diferentes entre si, formando duas classes com atributos bem característicos. É possível esperar que tais células formem, portanto, dois grupos não necessariamente isolados, mas bem definidos na projeção. Células malignas são projetadas no espaço visual apresentando maior dispersividade entre seus pontos, enquanto que células normais formam um grupo menor, mais compacto em relação às células com câncer. Este estudo de caso, em que os atributos influenciam grupos com variâncias diferentes mostrou-se adequado para a técnica ASV proposta. A Figura 58 mostra que os grupos foram adequadamente identificados pela métrica. A análise continua analisando-se tanto o histograma de variância quanto o gráfico de box-plots de cada dimensão, onde é possível observar que tanto os valores de variância quanto de distribuição (mínimo, máximo, média) de cada atributo estão conforme os esperados pela descrição dos dados.

\section{Figura 58 - Análise dos grupos pela ASV.}

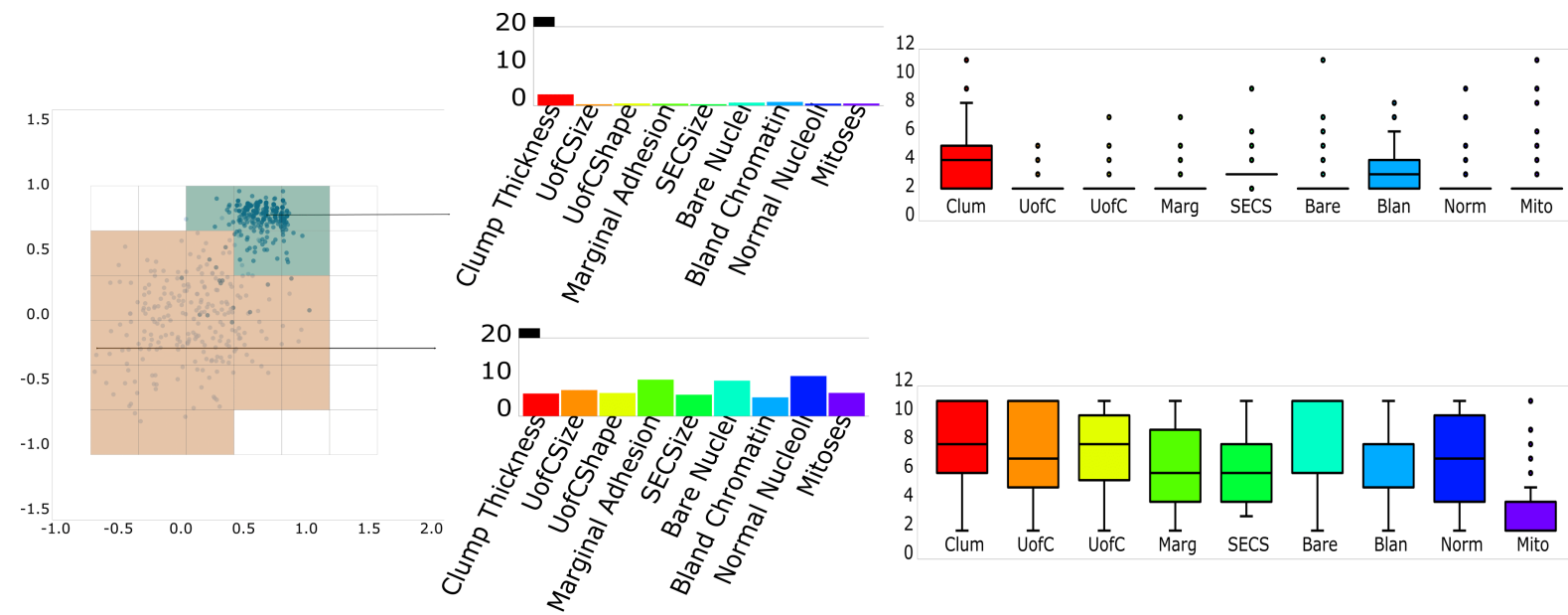

Fonte: Elaborada pelo autor.

É possível observar a qualidade da projeção utilizando a métrica SNP (Subseção 3.5.3) nos pontos deste conjunto, como mostrado na Figura 59. Apesar de alguns pontos serem mal projetados em relação a essa métrica, a ASV conseguiu identificar as mesmas estruturas. $\mathrm{O}$ 
usuário pode então escolher outra projeção mais adequada para os seus dados ou realizar a análise somente com os pontos que ele considera, dentro do aceitável para sua aplicação, bem preservados. No exemplo, como os pontos removidos não representaram grande variação na distribuição de cada grupo, o usuário poderia assumir que a projeção foi adequada na preservação dos pontos originais, e continuar a análise somente nestes pontos (Figura 59d).

Figura 59 - Remoção de pontos mal projetados pela métrica SNP.

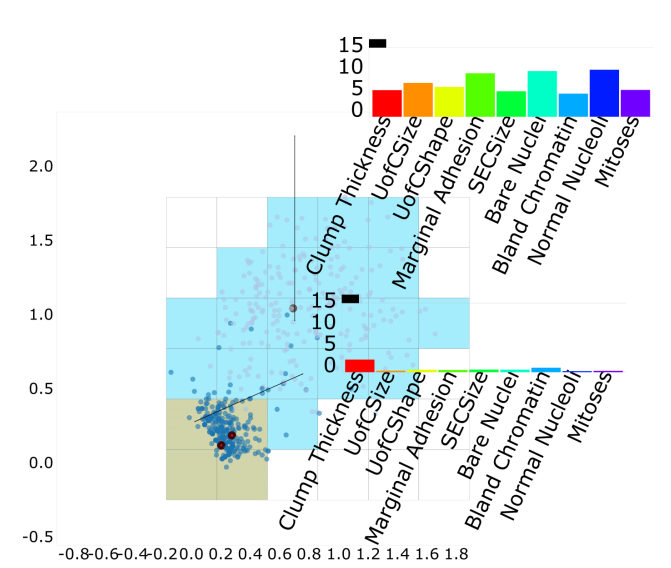

(a) SNP eps: 1.

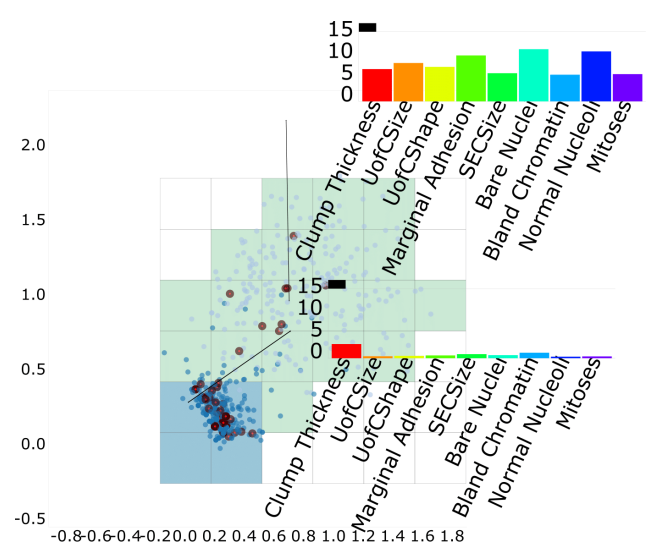

(c) SNP eps: 0.8 .

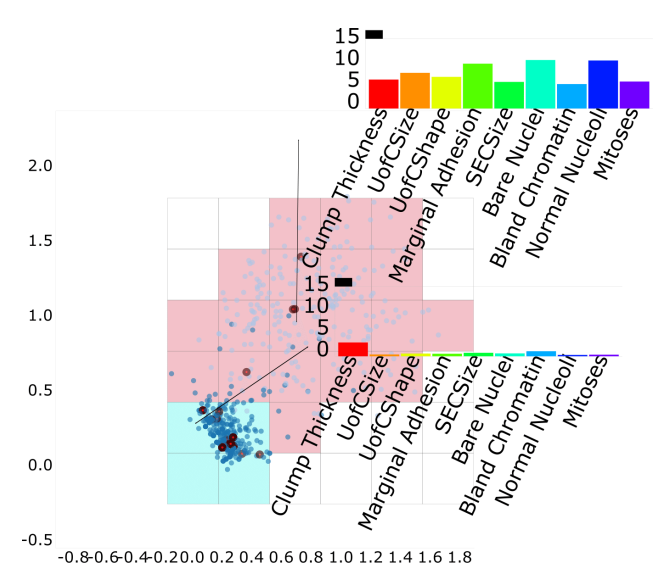

(b) SNP eps: 0.9.

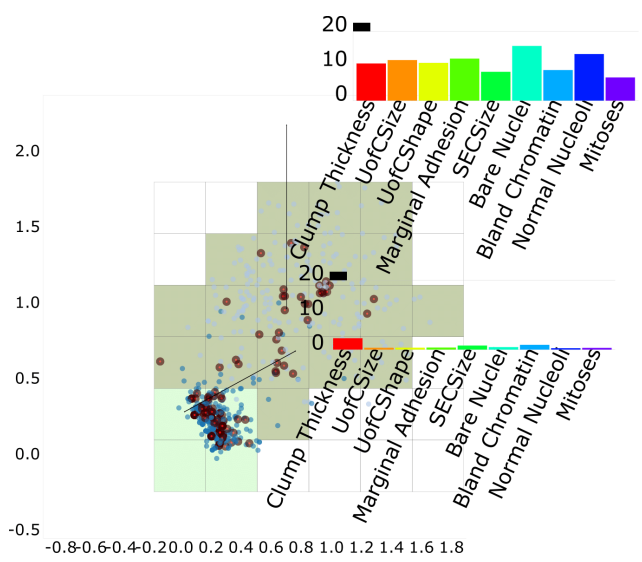

(d) SNP eps: 0.7.

\subsection{Caso de Teste 2}

Mesmo que os grupos não sejam exatamente identificados pela $\mathrm{ASV}$, este metáfora serve como uma ferramenta para sugerir possíveis relações de similaridade na projeção. Um exemplo disto pode ser observado pelo conjunto de dados Iris. Este arquivo contém três tipos de flores setosa, versicolor e virgínica (mostradas em ordem, de cima para baixo nos exemplos a seguir) — e quatro atributos - as medidas de comprimento e largura das suas pétalas e sépalas. As características esperadas de cada atributo são descritas na Tabela 5.

Duas destas flores, versicolor e viginica, possuem alto nível de correlação, de modo que pontos dessas classes não são facilmente separáveis por algumas projeções, prejudicando certos classificadores, inclusive a métrica ASV. A análise de células individuais de ambas as classes 
Tabela 5 - Características dos atributos (em ordem) do arquivo Iris.

\begin{tabular}{|c|c|c|c|}
\hline Atributo & Setosa & Versicolor & Virgínica \\
\hline Comprimento da sépala & $\sigma$ baixo & $\sigma$ médio & $\sigma$ alto \\
Largura da sépala & $\sigma$ alto & $\sigma$ baixo & $\sigma$ baixo \\
Comprimento da pétala & $\sigma$ baixo & $\sigma$ alto & $\sigma$ alto \\
Largura da pétala & $\sigma$ baixo & $\sigma$ alto & $\sigma$ médio \\
\hline
\end{tabular}

Fonte: Elaborada pelo autor.

justifica a união em um único grupo, mostrando ainda que o principal motivo responsável pela dissimilaridade dos respectivos pontos acontece devido à diferença entre a largura da sépala e do comprimento da pétala destas classes, conforme ilustrado na Figura 60a. A análise estatística de cada grupo (Figura 60b) mostra, por sua vez, que os dois grupos formados diferem em quase todos os atributos, sendo a largura e comprimento da pétala o atributo mais similar em flores do tipo setosa.

Figura 60 - Identificação de grupos e análise do conjunto Iris.

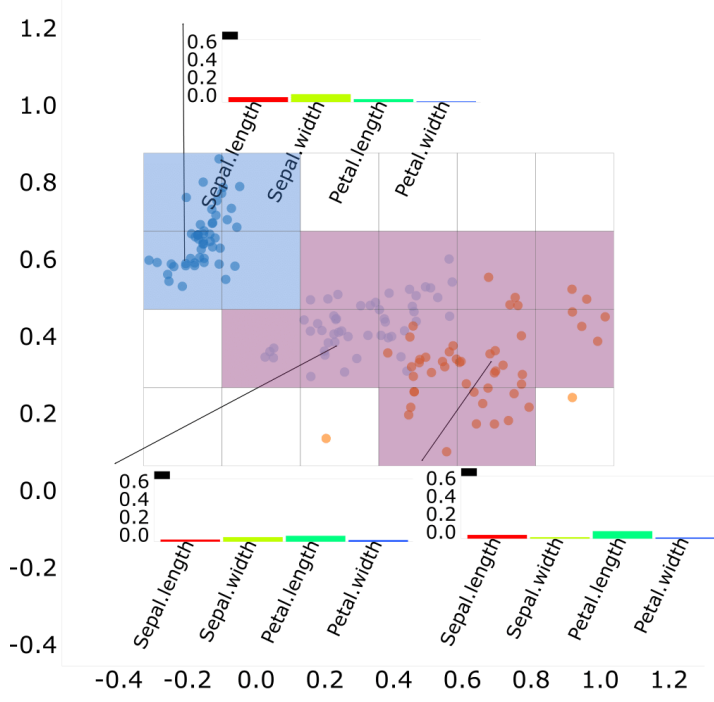

(a) Análise individual das células.

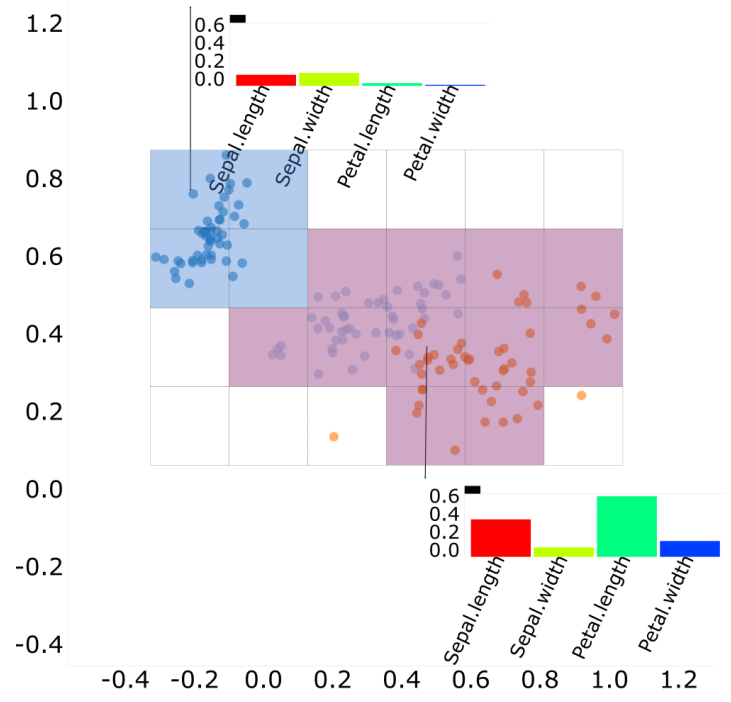

(b) Análise de cada grupo.

Fonte: Elaborada pelo autor.

Para conjuntos em que haja certa dificuldade de classificação pela ASV, como o conjunto Iris, o usuário pode especificar regiões manualmente, conforme ilustrado na Figura 61. De fato, não é incomum existirem usuários com certo conhecimento sobre os dados ou que queiram explorar apenas regiões específicas de pontos. Logo, a interatividade da ferramenta de exploração de dados é fundamental. Neste projeto, o usuário pode definir qualquer região de interesse, e anexar (caso necessário), qualquer nova metáfora visual, ajustada a sua necessidade. 
Figura 61 - Seleção de células para criação manual de grupos (a). Cada grupo é representado pelo feixo convexo dos seus pontos (b),(c). Análise dos grupos (d).

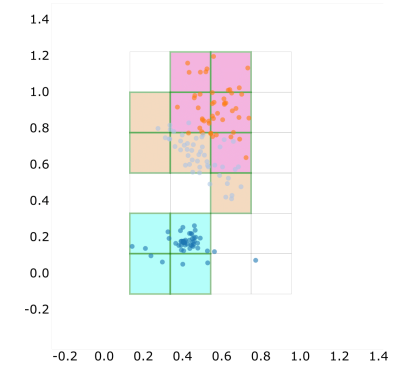

(a)

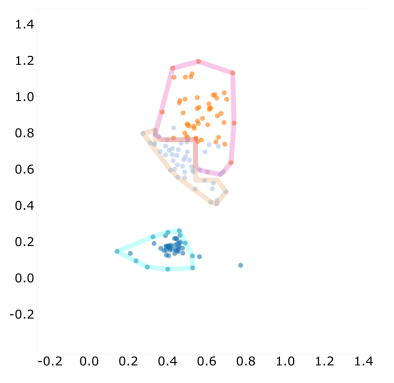

(b)

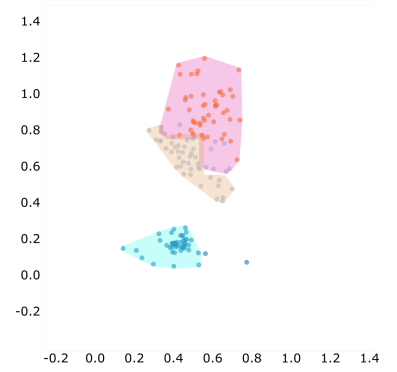

(c)

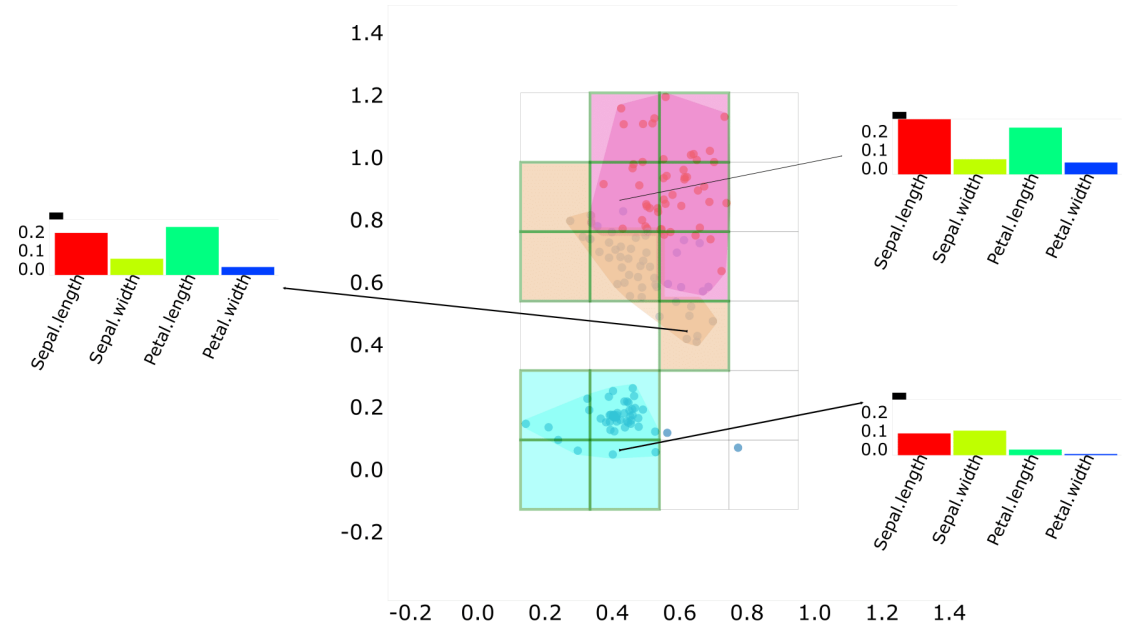

(d)

Fonte: Elaborada pelo autor.

\subsection{Casos de Teste 3}

O conjunto de dados Wine descreve a análise química de vinhos cujas uvas cresceram na mesma região da Itália, mas foram obtidas de três cultivares diferentes. O arquivo contém treze atributos constituintes relevantes observados nos três tipos de vinhos. Como não foi encontrado nenhuma descrição dos atributos deste arquivo, a análise dos dados foi explanatória, e não comprovatória como os exemplos anteriores. A Figura 62 mostra como cada dimensão se comporta em cada classe, determinando quais são os atributos mais específicos para a classificação de cada tipo de vinho. A análise em conjunto com os box-plots de cada dimensão mostra que os atributos malic acid (mali), magnesium ( $m g$ ) e proanthocyanins (proa) contêm um grande número de ruídos, sugerindo que estes atributos podem não representar corretamente cada tipo de vinho. Logo, o usuário pode reavaliar o processo de obtenção desses dados ou realizar uma análise futura sem estas dimensões. Outra possível interpretação obtida pela análise dos box-plots é a identificação de pares de dimensão que caracterizam cada tipo de vinho. Se amostras de vinho apresentam grande variância (maior que 0.5) dos atributos alcohol (alco) e proline (prol), esta amostra pode ser caracterizada pelo primeiro tipo de vinho (grupo superior). Da mesma forma, os demais grupos (meio e inferior) podem ser classificados pela baixa variância destes 
atributos, sendo diferenciados, por exemplo, pela baixa ou alta variância do atributo color (colo), respectivamente.

Figura 62 - Identificação de grupos e análise do conjunto Wine.
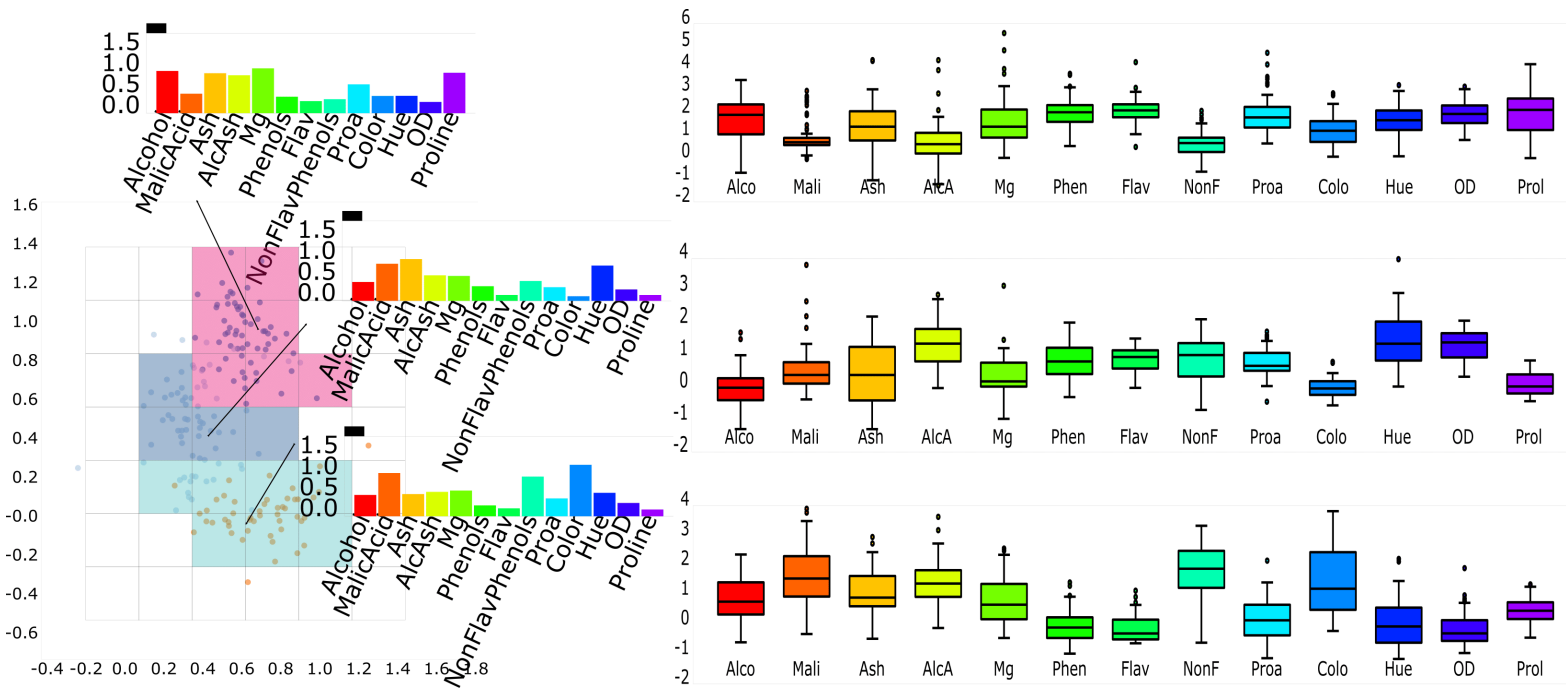

Fonte: Elaborada pelo autor.

A visualização das dimensões mais relevantes (DMR) de cada célula, descrita na Seção 3.3, mostra que a variância de cada atributo está diretamente relacionada com a similaridade da projeção, conforme ilustrado na Figura 63a. O usuário pode explorar, portanto, a relevância de um determinado atributo em toda a projeção, isto é, quais regiões apresentam pontos com maior semelhança em um determinado atributo. Dessa forma, pode-se visualizar como uma dimensão se "comporta" em toda projeção (Figura 63b).

Figura 63 - Análise da relevância dos atributos do conjunto Wine.

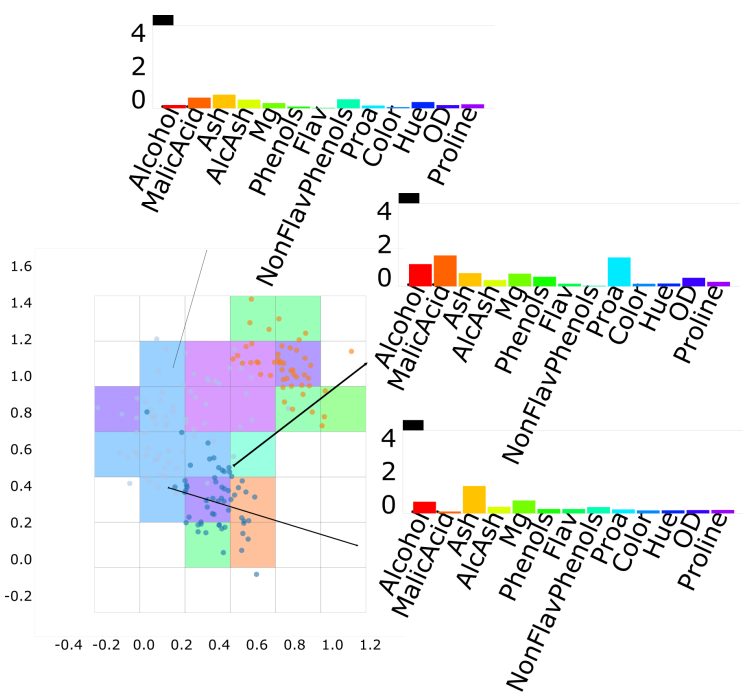

(a) Visualização dos atributos mais relevantes de cada célula.

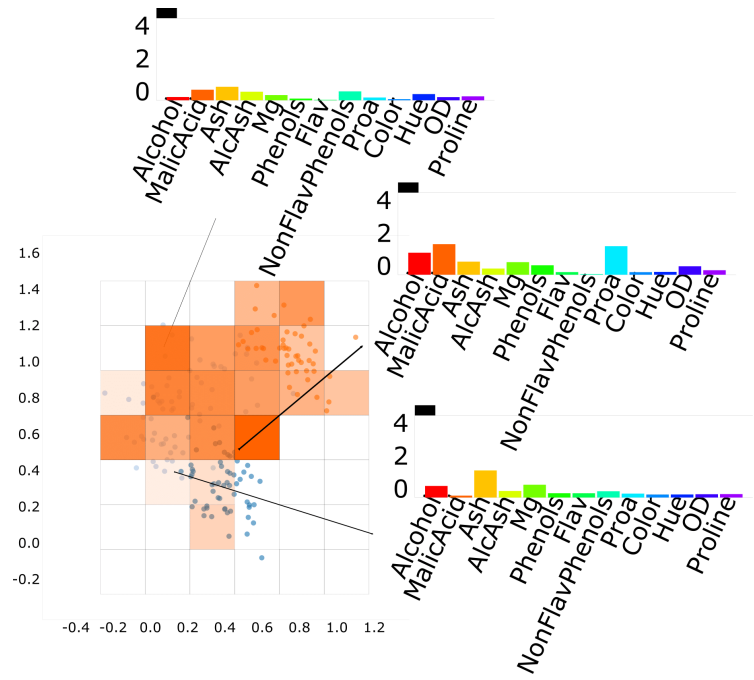

(b) Visualização da relevância do atributo Malic acid em toda a projeção. 


\subsection{Considerações Finais}

As metáforas visuais propostas neste trabalho compõem um arsenal de ferramentas de exploração e análise de projeções multidimensionais. Os experimentos realizados com cada metáfora mostraram-se úteis para o entendimento de diversos fatores da projeção, como a identificação dos principais atributos responsáveis pela similaridade dos pontos na projeção; para a classificação de grupos similares; para a comparação estatísticos entre grupos ou região da projeção; e para detecção e remoção de ruídos, resultantes tanto de erros numéricos da projeção quanto da coleta dos dados.

Além disso, os métodos propostos possibilitam a utilização de diversos artefatos, além da combinação de parâmetros, para a criação de um pipeline de exploração de dados, tornandoos adaptáveis às necessidades do usuário e aos diferentes tipos de dados a serem analisados. Entretanto, por estar implementado para a Web e possuir visualizações vetoriais em SVG, a ferramenta possui limitações para dados que excedem um certo número de instâncias ou dimensões, uma vez que a tarefa de redução de dimensionalidade e fatores de interação podem ser computacionalmente custosos para o navegador.

Também deve-se considerar que a ferramenta pode ser estendida para outras plataformas. Contudo, para casos onde o número de instâncias não excedam um limiar de execução aceitável para o usuário, a possibilidade da análise em tempo real da projeção multidimensional dos dados a partir de qualquer dispositivo conectado a Internet é inovadora, e os resultados mostraram que a ferramenta pode ser usada para uma simples consulta como para uma análise mais profunda dos dados, aumentando o alcance ao público em geral. 


\section{5}

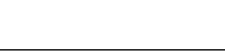

CONCLUSÃO

\subsection{Resultados Obtidos}

Nesta dissertação foram desenvolvidos técnicas e uma ferramenta para análise e exploração de dados multidimensionais na Web, através de metáforas visuais baseadas em projeções multidimensionais e algoritmos de agrupamento. Apesar da projeção multidimensional dos pontos ajudar na visualização de grupos e padrões dos dados, a identificação de por que tais estruturas foram formadas e quais os principais fatores que as diferenciam podem ser úteis para uma análise mais detalhada na busca por relações e no entendimento dos dados. Para tanto, focou-se neste projeto de mestrado em determinar qual o impacto dos atributos sobre os dados, visualizando como as dimensões são distribuídas na projeção e quais as regiões onde os atributos são mais relevantes.

Tal como descrito no Capítulo 1, os objetivos deste projeto consistiam em (O1) estudar e determinar como os atributos dos dados estão relacionados e impactam nas estruturas da projeção; (O2) propor novas metáforas visuais para identificação e ranqueamento de atributos mais importantes em regiões da projeção; (O3) implementar e apresentar métricas de detecção de ruídos e grupos similares; (O4) desenvolver uma aplicação Web para visualização interativa baseada em projeções multidimensionais em navegadores Web; (O5) disponibilizar ferramentas para exploração e análise dos dados. Portanto, como evidenciado ao longo desta dissertação, todos os objetivos propostos foram cumpridos.

A relação entre variância dos atributos e proximidade dos pontos permitiu desenvolver um algoritmo para identificação de regiões com a mesma tendência de distribuição entre dimensões, chamado agrupamento de similaridade de variância (ASV). Essa técnica agrupa regiões cujos pontos apresentam variância similar em todas suas dimensões até um certo limiar de dissimilaridade especificado pelo usuário.

Casos de teste com conjuntos reais de dados mostraram que as metáforas visuais foram 
úteis para análise e compreensão das diferenças entre os grupos formados, além de possibilitarem rápida compreensão de como os pontos são distribuídos e se comportam em cada grupo. Outras ferramentas permitem a identificação de ruídos e de pontos mal projetados na projeção. Foram implementadas outras formas de detecção e seleção de regiões, além de técnicas de agrupamento já existentes, para auxiliar o usuário na exploração dos dados projetados.

\subsection{Trabalhos Futuros}

Algumas motivações para extensão ou trabalhos complementares relacionados ao tema deste projeto são descritas a seguir. Primeiro, todas as metáforas visuais são baseadas em relações de vizinhança do espaço original. Tais operações, no entanto, também poderiam ser feitas levandose em conta os pontos no espaço visual. Segundo, o fluxo de execução da aplicação consiste na análise dos atributos em relação aos pontos projetados. O caminho inverso não foi implementado, de modo que não é possível analisar os pontos em relação a um subconjunto de atributos. Um fator limitante presente neste projeto que poderia ser ajustado consiste na dependência de como as regiões de análise são consideradas. Dependendo de como estas são definidas, as regiões podem não conter ou não representar os pontos/grupos adequadamente, dificultando a análise sobre as mesmas. Neste contexto, uma ferramenta que otimizasse os parâmetros de ajuste de regiões, como tamanho de célula ou o número de vizinhos analisados poderia ser investigada. Por fim, como este projeto foi desenvolvido para a Web utilizando D3, a criação de estruturas visuais vetoriais (SVG) e a análise interativa sobre as mesmas podem tornar inviável a exploração dos dados, caso estes possuem muitas dimensões ou são formados por um número razoável de instâncias (5 a 10 mil), devido à sobrecarga do DOM e à restrita memória dos navegadores.

Trabalhos futuros sobre este projeto também incluem a adição de novas medidas estatísticas para análise de regiões, como obliquidade e curtose, assim como outras maneiras de visualizar a distribuição e relações entre as dimensões na projeção, como metáforas visuais envolvendo a matriz de covariância e/ou os componentes principais de cada região. Outras ferramentas como remoção automática de ruídos e de dimensões não relevantes podem ser úteis para uma análise mais detalhada. 
ALMEIDA, B. S. C.; OPOLINáRIO, L. A. Openedeyes: A web standards-based generic framework for multidimensional information visualization. SBC Journal on 3D Interactive Systems, v. 4, n. 1, 2013. ISSN 2236-3297. Citado 2 vezes nas páginas 48 e 49.

ASIMOV, D. The grand tour: A tool for viewing multidimensional data. SIAM J. Sci. Stat. Comput., Society for Industrial and Applied Mathematics, Philadelphia, PA, USA, v. 6, n. 1, p. 128-143, jan. 1985. ISSN 0196-5204. Disponível em: <http://dx.doi.org/10.1137/0906011>. Citado na página 41.

AUPETIT, M. Visualizing distortions and recovering topology in continuous projection techniques. Neurocomputing, Elsevier, v. 70, n. 7, p. 1304-1330, 2007. Citado na página 27.

AURENHAMMER, F. Voronoi diagrams - a survey of a fundamental geometric data structure. ACM Comput. Surv., ACM, New York, NY, USA, v. 23, n. 3, p. 345-405, set. 1991. ISSN 0360-0300. Disponível em: <http://doi.acm.org/10.1145/116873.116880>. Citado 2 vezes nas páginas 26 e 77.

BARBER, C. B.; DOBKIN, D. P.; HUHDANPAA, H. The quickhull algorithm for convex hulls. ACM Transactions on Mathematical Software, v. 22, n. 4, p. 469-483, 1996. Citado na página 76.

BECKER, R. A.; CLEVELAND, W. S. Brushing scatterplots. Technometrics, American Society for Quality Control and American Statistical Association, Alexandria, Va, USA, v. 29, n. 2, p. 127-142, maio 1987. ISSN 0040-1706. Disponível em: <http://dx.doi.org/10.2307/1269768>. Citado 2 vezes nas páginas 31 e 56.

BERKHIN, P. A survey of clustering data mining techniques. Grouping Multidimensional Data, p. 25-71, 2006. Citado 2 vezes nas páginas 37 e 72.

BOSTOCK, M. Data-Driven Documents. 2013. Disponível em: $<\mathrm{http}: / / \mathrm{d} 3 \mathrm{j} s . o r g />$. Citado na página 45.

BOSTOCK, M.; OGIEVETSKY, V.; HEER, J. D3: Data-driven documents. IEEE Trans. Visualization \& Comp. Graphics (Proc. InfoVis), 2011. Disponível em: <http://vis.stanford.edu/ papers/d3>. Citado 4 vezes nas páginas 32, 33, 45 e 46.

BOX, G. E. P.; JENKINS, G. M. Time Series Analysis: Forecasting and Control. 3rd. ed. Upper Saddle River, NJ, USA: Prentice Hall PTR, 1994. ISBN 0130607746. Citado na página 31.

BROEKSEMA, B.; TELEA, A.; BAUDEL, T. Visual analysis of multi-dimensional categorical data sets. Comp. Graph. Forum, v. 32, n. 8, p. 158-169, 2013. Citado na página 26.

BURGES, C. J. C. A tutorial on support vector machines for pattern recognition. Data Mining and Knowledge Discovery, v. 2, p. 121-167, 1998. Citado na página 57. 
CAO, N.; GOTZ, D.; SUN, J.; QU, H. Dicon: Interactive visual analysis of multidimensional clusters. IEEE Trans. Vis. Comput. Graph., v. 17, n. 12, p. 2581-2590, 2011. Disponível em: $<$ http://dblp.uni-trier.de/db/journals/tvcg/tvcg17.html\#CaoGSQ11>. Citado na página 26.

CARTWRIGHT, J. H. E.; PIRO, O. The dynamics of runge-kutta methods. Int. J. Bifurcation and Chaos, v. 2, p. 427-49, 1992. Citado na página 35.

CHALMERS, M. A linear iteration time layout algorithm for visualising high-dimensional data. In: Proceedings of the 7th Conference on Visualization '96. Los Alamitos, CA, USA: IEEE Computer Society Press, 1996. (VIS '96), p. 127-ff. ISBN 0-89791-864-9. Citado 3 vezes nas páginas 35,36 e 42.

CHANG, D.; NESBITT, K. V.; WILKINS, K. The gestalt principles of similarity and proximity apply to both the haptic and visual grouping of elements. In: Proceedings of the Eight Australasian Conference on User Interface - Volume 64. Darlinghurst, Australia, Australia: Australian Computer Society, Inc., 2007. (AUIC '07), p. 79-86. ISBN 1-920682-46-5. Disponível em: $<$ http://dl.acm.org/citation.cfm?id=1273714.1273727>. Citado na página 26.

CHEN, C.-h.; HARDLE, W.; UNWIN, A. Handbook of Data Visualization. [S.1.]: Springer, 2008. ISBN 978-3-540-33036-3. Citado na página 31.

CHOO, J.; LEE, C.; REDDY, C.; PARK, H. Utopian: User-driven topic modeling based on interactive nonnegative matrix factorization. IEEE Trans. Vis. Comp. Graph., IEEE, v. 19, n. 12, p. 1992-2001, 2013. Citado na página 26.

COX, T. F.; COX, M. Multidimensional Scaling, Second Edition. 2. ed. [S.1.]: Chapman and Hall/CRC, 2000. ISBN 1584880945. Citado 3 vezes nas páginas 37, 41 e 57.

CROCKFORD, D. JavaScript: The Good Parts. [S.1.]: O'Reilly Media, 2008. ISBN 0596517742. Citado 2 vezes nas páginas 43 e 45.

CUFF, J. D.; MATTSON, T. M. Thematic maps: their design and production. [S.1.]: Methuen New York, 1982. ISBN 0416335004, 0416343201. Citado na página 48.

CUNNINGHAM, P.; DELANY, S. J. k-Nearest Neighbour Classifiers. 2007. Citado 3 vezes nas páginas 38, 64 e 78 .

DASGUPTA, A.; KOSARA, R.; GOSINK, L. J. Meta parallel coordinates for visualizing features in large, high-dimensional, time-varying data. In: BARGA, R. S.; PFISTER, H.; ROGERS, D. (Ed.). LDAV. IEEE, 2012. p. 85-89. ISBN 978-1-4673-4732-7. Disponível em: <http://dblp. uni-trier.de/db/conf/ldav/ldav2012.html\#DasguptaKG12>. Citado na página 32.

EADES, P. A. A heuristic for graph drawing. In: Congressus Numerantium. [S.l.: s.n.], 1984. v. 42, p. 149-160. Citado 2 vezes nas páginas 35 e 42.

EISENBERG, J. D. SVG Essentials. 1. ed. [S.1.]: O'Reilly Media, 2002. ISBN 0596002238. Citado 2 vezes nas páginas 43 e 45 .

ESTER, M.; KRIEGEL, H.; S, J.; XU, X. A density-based algorithm for discovering clusters in large spatial databases with noise. In: . [S.1.]: AAAI Press, 1996. p. 226-231. Citado 3 vezes nas páginas 57,72 e 76 .

EVJEN, B.; SHARKEY, K.; THANGARATHINAM, T.; KAY, M.; VERNET, A.; FERGUSON, S. Professional XML. [S.1.]: Wiley, 2007. ISBN 9780470167380. Citado na página 43. 
FADEL, S. G.; FATORE, F. M.; DUARTE, F. S. L. G.; PAULOVICH, F. V. Loch: A neighborhoodbased multidimensional projection technique for high-dimensional sparse spaces. Neurocomputing, v. 150, p. 546-556, 2015. Disponível em: <http://www.sciencedirect.com/science/article/ pii/S0925231214012867>. Citado na página 41.

FUKUNAGA, K. Introduction to Statistical Pattern Recognition (2Nd Ed.). San Diego, CA, USA: Academic Press Professional, Inc., 1990. ISBN 0-12-269851-7. Citado na página 57.

GANSNER, E. R.; HU, Y.; KOBOUROV, S. G. Gmap: Drawing graphs as maps. CoRR, abs/0907.2585, 2009. Disponível em: <http://arxiv.org/abs/0907.2585>. Citado 2 vezes nas páginas 77 e 78 .

GAREY, M. R.; JOHNSON, D. S. Computers and Intractability; A Guide to the Theory of NP-Completeness. New York, NY, USA: W. H. Freeman \& Co., 1990. ISBN 0716710455. Citado na página 71.

GOLDBERG, D. E. Genetic Algorithms in Search, Optimization and Machine Learning. 1st. ed. Boston, MA, USA: Addison-Wesley Longman Publishing Co., Inc., 1989. ISBN 0201157675. Citado na página 71.

GOMEZ-NIETO, E.; San Roman, F.; PAGLIOSA, P.; CASACA, W.; HELOU, E.; OLIVEIRA, M.; NONATO, L. Similarity preserving snippet-based visualization of web search results. IEEE Trans. Vis. Comp. Graph., v. 20, n. 3, p. 457-470, 2014. Citado na página 26.

GOWER, J.; DIJKSTERHUIS, G. Procrustes Problems. [S.1.]: OUP Oxford, 2004. (Oxford Statistical Science Series). ISBN 9780198510581. Citado na página 41.

GRAY, J.; CHAUDHURI, S.; BOSWORTH, A.; LAYMAN, A.; REICHART, D.; VENKATRAO, M.; PELLOW, F.; PIRAHESH, H. Data cube: A relational aggregation operator generalizing group-by, cross-tab, and sub-totals. Data Min. Knowl. Discov., Kluwer Academic Publishers, Hingham, MA, USA, v. 1, n. 1, p. 29-53, jan. 1997. ISSN 1384-5810. Disponível em: <http: //dx.doi.org/10.1023/A:1009726021843>. Citado na página 50.

GUYON, I.; ELISSEEFF, A. An introduction to variable and feature selection. J. Mach. Learn. Res., JMLR.org, v. 3, p. 1157-1182, mar. 2003. ISSN 1532-4435. Disponível em: <http://dl.acm. org/citation.cfm?id=944919.944968>. Citado na página 57.

HALES, W. HTML5 and JavaScript Web Apps. [S.1.]: O'Reilly Media, 2012. ISBN 9781449320515. Citado na página 44.

HALL, M. Core Servlets And Javaserver Pages: Volume I: Core Technologies. [S.1.]: Pearson Education, 2004. ISBN 9788131701638. Citado na página 43.

HARTIGAN, J. A.; WONG, M. A. A K-means clustering algorithm. Applied Statistics, v. 28, p. 100-108, 1979. Citado 2 vezes nas páginas 57 e 72.

HAYKIN, S. Redes Neurais - 2ed. BOOKMAN COMPANHIA ED, 2001. ISBN 9788573077186. Disponível em: <http://books.google.com.br/books?id=lBp0X5qfyjUC>. Citado na página 34.

HEINRICH, J.; WEISKOPF, D. State of the Art of Parallel Coordinates. In: SBERT, M.; SZIRMAY-KALOS, L. (Ed.). Eurographics 2013 - State of the Art Reports. [S.1.]: The Eurographics Association, 2012. ISSN 1017-4656. Citado na página 32. 
HENRY, N.; FEKETE, J.-D.; MCGUFFIN, M. J. Nodetrix: a hybrid visualization of social networks. IEEE Transactions on Visualization and Computer Graphics, IEEE Computer Society, Los Alamitos, CA, USA, v. 13, n. 6, p. 1302-1309, 2007. ISSN 1077-2626. Citado na página 26.

HEULOT, N.; AUPETIT, M.; FEKETE, J. Proxilens: Interactive exploration of high-dimensional data using projections. In: Eurovis Workshop on Visual Analytics using Multidimensional Projections. [S.1.: s.n.], 2013. Citado na página 27.

HODGE, V.; AUSTIN, J. A survey of outlier detection methodologies. Artif. Intell. Rev., Kluwer Academic Publishers, Norwell, MA, USA, v. 22, n. 2, p. 85-126, out. 2004. ISSN 0269-2821. Disponível em: <http://dx.doi.org/10.1023/B:AIRE.0000045502.10941.a9>. Citado na página 27.

HUBER, P. J. Projection pursuit. Ann. Statist., The Institute of Mathematical Statistics, v. 13, n. 2, p. 435-475, 06 1985. Disponível em: <http://dx.doi.org/10.1214/aos/1176349519>. Citado na página 41.

INGRAM, S.; MUNZNER, T.; OLANO, M. Glimmer: Multilevel mds on the gpu. IEEE Trans. Vis. Comp. Graph., IEEE Computer Society, Los Alamitos, CA, USA, v. 15, n. 2, p. 249-261, 2009. ISSN 1077-2626. Citado 2 vezes nas páginas 27 e 41.

INSELBERG, A.; DIMSDALE, B. Parallel coordinates: A tool for visualizing multi-dimensional geometry. In: Proceedings of the 1st Conference on Visualization '90. Los Alamitos, CA, USA: IEEE Computer Society Press, 1990. (VIS '90), p. 361-378. ISBN 0-8186-2083-8. Disponível em: <http://dl.acm.org/citation.cfm?id=949531.949588>. Citado na página 31.

JOIA, P.; COIMBRA, D.; CUMINATO, J. A.; PAULOVICH, F. V.; NONATO, L. G. Local affine multidimensional projection. IEEE Transactions on Visualization and Computer Graphics, IEEE Computer Society, v. 17, p. 2563-2571, 2011. ISSN 1077-2626. Citado 4 vezes nas páginas $25,27,40$ e 42 .

JOIA, P.; PETRONETTO, F.; NONATO, L. Uncovering representative groups in multidimensional projections. Comput. Graph. Forum, 2015. Citado na página 26.

JOLLIFFE, I. Principal Component Analysis. [S.1.]: Springer Verlag, 1986. Citado 2 vezes nas páginas 41 e 57.

KAAZING, C. 2014. Disponível em: <http://www.websocket.org/aboutwebsocket.html>. Citado na página 47.

KANDOGAN, E. Just-in-time annotation of clusters, outliers, and trends in point-based data visualizations. In: IEEE Conf. on Visual Analyt. Science and Tech. [S.1.: s.n.], 2012. p. 73-82. Citado 5 vezes nas páginas 26, 52, 54, 55 e 62 .

LESPINATS, S.; AUPETIT, M. Checkviz: Sanity check and topological clues for linear and nonlinear mappings. Computer Graphics Forum, Blackwell Publishing Ltd, v. 30, n. 1, p. 113-125, 2011. ISSN 1467-8659. Disponível em: <http://dx.doi.org/10.1111/j.1467-8659.2010.01835.x>. Citado na página 27.

LICHMAN, M. UCI Machine Learning Repository. 2013. Disponível em: <http://archive.ics. uci.edu/ml>. Citado na página 86 . 
LINS, L.; KLOSOWSKI, J. T.; SCHEIDEGGER, C. Nanocubes for real-time exploration of spatiotemporal datasets. IEEE Transactions on Visualization and Computer Graphics, IEEE Computer Society, v. 19, n. 12, p. 2456-2465, 2013. ISSN 1077-2626. Citado 3 vezes nas páginas 50,51 e 52.

LIU, Z.; JIANG, B.; HEER, J. immens: Real-time visual querying of big data. Computer Graphics Forum (Proc. EuroVis), v. 32, 2013. Disponível em: <http://vis.stanford.edu/papers/ immens>. Citado 3 vezes nas páginas 48, 49 e 50.

MARTINS, R.; ANDERY, G.; HEBERLE, H.; PAULOVICH, F.; LOPES, A. de A.; PEDRINI, H.; MINGHIM, R. Multidimensional projections for visual analysis of social networks. Journal of Computer Science and Technology, Springer US, v. 27, n. 4, p. 791-810, 2012. ISSN 1000-9000. Disponível em: <http://dx.doi.org/10.1007/s11390-012-1265-5>. Citado na página 68.

MARTINS, R. M.; COIMBRA, D. B.; MINGHIM, R.; TELEA, A. Visual analysis of dimensionality reduction quality for parameterized projections. Computers \& Graphics, Elsevier, v. 41, p. 26-42, 2014. Citado na página 27.

MORRISON, A.; ROSS, G.; CHALMERS, M. A hybrid layout algorithm for sub-quadratic multidimensional scaling. In: IEEE Symposium on Information Visualization. [S.l.]: IEEE, 2002. p. 152-158. Citado 3 vezes nas páginas 35, 36 e 42.

MOTTA, R.; MINGHIM, R.; LOPES, A. de A.; OLIVEIRA, M. C. F. Graph-based measures to assist user assessment of multidimensional projections. Neurocomputing, Elsevier, v. 150, p. 583-598, 2015. Citado na página 27.

MURRAY, S. Interactive Data Visualization for the Web. [S.1.]: O'Reilly Media, 2013. ISBN 9781449340247. Citado na página 45.

PAGLIOSA, P.; PAULOVICH, F. V.; MINGHIM, R.; LEVKOWITZ, H.; NONATO, L. G. Projection inspector: Assessment and synthesis of multidimensional projections. Neurocomputing, Elsevier, v. 150, p. 599-610, 2015. Citado 2 vezes nas páginas 27 e 78.

PARISI, T. WebGL: Up and Running. 1st. ed. [S.1.]: O'Reilly Media, Inc., 2012. ISBN 144932357X, 9781449323578. Citado na página 48.

PAULOVICH, F.; TOLEDO, F.; TELLES, G.; MINGHIM, R.; NONATO, L. Semantic wordification of document collections. Comp. Graph. Forum, v. 31, p. 1145-1153, 2012. Citado na página 26.

PAULOVICH, F. V.; ELER, D. M.; POCO, J.; BOTHA, C. P.; MINGHIM, R.; NONATO, L. G. Piece wise laplacian-based projection for interactive data exploration and organization. Comput. Graph. Forum, v. 30, n. 3, p. 1091-1100, 2011. Citado 5 vezes nas páginas 25, 27, 38, 39 e 42.

PAULOVICH, F. V.; NONATO, L. G.; MINGHIM, R.; LEVKOWITZ, H. Least square projection: A fast high-precision multidimensional projection technique and its application to document mapping. IEEE Transactions on Visualization and Computer Graphics, IEEE Computer Society, v. 14, p. 564-575, 2008. ISSN 1077-2626. Citado 4 vezes nas páginas 25, 37, 38 e 42.

PAULOVICH, F. V.; SILVA, C. T.; NONATO, L. G. Two-phase mapping for projecting massive data sets. IEEE Transactions on Visualization and Computer Graphics, IEEE Educational Activities Department, v. 16, n. 6, p. 1281-1290, 2010. ISSN 1077-2626. Citado 4 vezes nas páginas $25,27,40$ e 42 . 
PEKALSKA, E.; RIDDER, D. de; DUIN, R. P.; KRAAIJVELD, M. A. A new method of generalizing sammon mapping with application to algorithm speed-up. In: Proc. 5th Annual Conference of the Advanced School for Computing and Imaging (ASCI1999). [S.1.: s.n.], 1999. Citado 3 vezes nas páginas 34, 40 e 42.

PISINGER, D. Algorithms for Knapsack Problems. 1995. Citado na página 71.

SALAMA, G. I.; ABDELHALIM, M. B.; ZEID, M. A. Breast cancer diagnosis on three different datasets using multi-classifiers. International Journal of Computer and Information Technology, v. 01, 2012. Disponível em: <http://www.ijcit.com/archives/volume1/issue1/Paper010105. pdf $>$. Citado na página 90.

SAMMON, J. W. A nonlinear mapping for data structure analysis. IEEE Trans. Comput., IEEE Computer Society, Washington, DC, USA, v. 18, n. 5, p. 401-409, maio 1969. ISSN 0018-9340. Citado 2 vezes nas páginas 34 e 42.

SEO, J.; SHNEIDERMAN, B. A rank-by-feature framework for unsupervised multidimensional data exploration using low dimensional projections. In: WARD, M. O.; MUNZNER, T. (Ed.). INFOVIS. IEEE Computer Society, 2004. p. 65-72. ISBN 0-7803-8779-1. Disponível em: $<$ http://dblp.uni-trier.de/db/conf/infovis/infovis2004.html\#SeoS04>. Citado na página 26.

SHNEIDERMAN, B. Tree visualization with tree-maps: A 2-d space-filling approach. ACM Transactions on Graphics, v. 11, p. 92-99, 1991. Citado na página 26.

SISMANIS, Y.; DELIGIANNAKIS, A.; ROUSSOPOULOS, N.; KOTIDIS, Y. Dwarf: Shrinking the petacube. In: Proceedings of the 2002 ACM SIGMOD International Conference on Management of Data. New York, NY, USA: ACM, 2002. (SIGMOD '02), p. 464-475. ISBN 1-58113-497-5. Disponível em: <http://doi.acm.org/10.1145/564691.564745>. Citado na página 50 .

SQUARE, I. Crossfilter. 2014. Disponível em: <http://square.github.io/crossfilter/>. Citado 2 vezes nas páginas 46 e 47.

STEIGER, M.; BERNARD, J.; MITTELSTÄDT, S.; LÜCKE-TIEKE, H.; KEIM, D.; MAY, T.; KOHLHAMMER, J. Visual analysis of time-series similarities for anomaly detection in sensor networks. Comp. Graph. Forum, v. 33, n. 3, p. 401-410, 2014. Citado na página 26.

TEJADA, E.; MINGHIM, R.; NONATO, L. G. On improved projection techniques to support visual exploration of multidimensional data sets. Information Visualization, Palgrave Macmillan, v. 2, n. 4, p. 218-231, dez. 2003. ISSN 1473-8716. Citado 4 vezes nas páginas 35, 36, 40 e 42.

TENENBAUM, J. B.; SILVA, V. de; LANGFORD, J. C. A global geometric framework for nonlinear dimensionality reduction. Science, v. 290, n. 5500, p. 2319, 2000. Citado na página 41.

TURKAY, C.; FILZMOSER, P.; HAUSER, H. Brushing dimensions - a dual visual analysis model for high-dimensional data. IEEE Trans. Vis. Comput. Graph., v. 17, n. 12, p. 2591-2599, 2011. Disponível em: <http://dblp.uni-trier.de/db/journals/tvcg/tvcg17.html\#TurkayFH11>. Citado 3 vezes nas páginas 57,59 e 60 .

W3C. 2014. Disponível em: <http://www.w3.org/Style/CSS/>. Citado na página 42.

2014. Disponível em: <http://www.w3.org/TR/DOM-Level-2-Core/introduction.html>.

Citado 2 vezes nas páginas 43 e 44 . 
2014. Disponível em: <http://www.w3.org/Consortium/>. Citado na página 44.

2014. Disponível em: <http://www.w3.org/Protocols/>. Citado na página 48.

WANG, V.; FRANK, S.; MOSKOVITS, P. The Definitive Guide to HTML5 WebSocket. [S.1.]: Apress, 2013. ISBN 9781430247401. Citado 2 vezes nas páginas 42 e 47.

WARD, M.; GRINSTEIN, G.; KEIM, D. Interactive Data Visualization: Foundations, Techniques, and Applications. Natick, MA, USA: A. K. Peters, Ltd., 2010. ISBN 1568814739, 9781568814735. Citado na página 31.

WARE, C. Information Visualization: Perception for Design. San Francisco, CA, USA: Morgan Kaufmann Publishers Inc., 2004. ISBN 1558608192. Citado na página 64.

WICKHAM, H.; STRYJEWSKI, L. 40 years of boxplots. [S.1.], 2012. Citado na página 68.

WILSON, R. J. Introduction to Graph Theory. New York, NY, USA: John Wiley \& Sons, Inc., 1986. ISBN 0-470-20616-0. Citado na página 76.

WONG, P. C.; BERGERON, R. D. 30 years of multidimensional multivariate visualization. In: Scientific Visualization, Overviews, Methodologies, and Techniques. Washington, DC, USA: IEEE Computer Society, 1997. p. 3-33. ISBN 0-8186-7777-5. Disponível em: <http: //dl.acm.org/citation.cfm?id=647365.725689>. Citado na página 31.

WU, Y.; PROVAN, T.; WEI, F.; LIU, S.; MA, K.-L. Semantic-preserving word clouds by seam carving. Comp. Graph. Forum, v. 30, n. 3, p. 741-750, 2011. Citado na página 26.

XU, R.; WUNSCH II, D. Survey of clustering algorithms. Trans. Neur. Netw., IEEE Press, Piscataway, NJ, USA, v. 16, n. 3, p. 645-678, maio 2005. ISSN 1045-9227. Disponível em: <http://dx.doi.org/10.1109/TNN.2005.845141>. Citado na página 27.

YUAN, X.; REN, D.; WANG, Z.; GUO, C. Dimension Projection Matrix/Tree: Interactive Subspace Visual Exploration and Analysis of High Dimensional Data. Visualization and Computer Graphics, IEEE Transactions on, IEEE, v. 19, n. 12, p. 2625-2633, dez. 2013. ISSN 1077-2626. Disponível em: <http://dx.doi.org/10.1109/tvcg.2013.150>. Citado 4 vezes nas páginas $55,56,57$ e 58 . 